University of Louisville

ThinkIR: The University of Louisville's Institutional Repository

Electronic Theses and Dissertations

$12-2012$

\title{
The role of community college-based transfer programming in transfer student success.
}

Kathren Teresa Partin

University of Louisville

Follow this and additional works at: https://ir.library.louisville.edu/etd

\section{Recommended Citation}

Partin, Kathren Teresa, "The role of community college-based transfer programming in transfer student success." (2012). Electronic Theses and Dissertations. Paper 1097.

https://doi.org/10.18297/etd/1097

This Doctoral Dissertation is brought to you for free and open access by ThinkIR: The University of Louisville's Institutional Repository. It has been accepted for inclusion in Electronic Theses and Dissertations by an authorized administrator of ThinkIR: The University of Louisville's Institutional Repository. This title appears here courtesy of the author, who has retained all other copyrights. For more information, please contact thinkir@louisville.edu. 


\title{
THE ROLE OF COMMUNITY COLLEGE-BASED TRANSFER PROGRAMMING IN TRANSFER STUDENT SUCCESS
}

\author{
By \\ Kathren Teresa Partin \\ B.S., Christopher Newport University, 2004 \\ M.Ed., University of Louisville, 2006

\begin{abstract}
A Dissertation
Submitted to the Faculty of the

College of Education and Human Development

In Partial Fulfillment of the Requirements

For the Degree of
\end{abstract} \\ Doctor of Philosophy \\ Department of Education and Counseling Psychology \\ University of Louisville \\ Louisville, Kentucky
}

December, 2012 
Copyright 2012 by Kathren T. Partin

All rights reserved 
THE ROLE OF COMMUNITY COLLEGE-BASED TRANSFER PROGRAMMING IN

TRANSFER STUDENT SUCCESS

By

Kathren Teresa Partin

B.S., Christopher Newport University, 2004

M.Ed., University of Louisville, 2006

A Dissertation Approved on

November 15, 2012

by the following Dissertation Committee:

Dr. Amy Hirschy, Dissertation Chair

Dr. Michael Cuyjet

Dr. Kathleen Mandlehr

Dr. Brddgette Pregliasco

Dr. Jeff Valentine 


\section{DEDICATION}

This dissertation is dedicated to my grandfather, Col. (ret.) F. Max McCullar. A man of great wit and great wisdom, you have instilled in our family the value of education, the importance of hard work and dedication, and the never-ending joy that comes from the wonderment and love of life and of learning. Always ready to engage in a lively conversation about the state of education in America, or any topic related to my schooling, you have time and again reminded me that the apple does not fall far from the family tree. The end of every phone call is always the same, "I love you Katie, make all A's!" And, Granddaddy, I have! Thank you for all the love, support, and encouragement. This dissertation is also dedicated to my parents. To my mother, Mary Lou Dudley, for pointing out every time the leaves begin to change and for making nature my first classroom. And for being as equally excited about school plays as you were about good grades. To my stepfather, Michael Dudley, for always being reassuring, positive, and ready with a helpful suggestion. And to my father, Frank Peterlin, for making college both an expectation and a privilege. Though you never got to see me graduate, I know you're proud.

And finally, this dissertation is dedicated to my husband, Wesley Partin. When we met in undergrad, I doubt you envisioned me still writing research papers ten years later (without a break!). Thank you for the endless supply of love, support, Boolean text skills, tea, and cookies. I could not have accomplished this without you. If I could hand out honorary degrees, you'd be Dr. Partin, too. (But hey, it's your turn next if you want one!) 


\section{ACKNOWLEDGMENTS}

I would like to thank Dr. Amy Hirschy for her unwavering support and skillful guidance as my dissertation chair and advisor; I always appreciate your thoughtful advice and uncanny ability to calm me down. Thank you to Dr. Jeff Valentine for your patience and enthusiasm as my methodologist. I would also like to thank the other members of my committee, Drs. Michael Cuyjet, Kathleen Mandlehr, and Bridgette Pregliasco for your encouragement, thoughtful feedback, and perfect balance of challenge and support. And an additional thank you to Kathleen for hiring me years ago as your graduate assistant, a role which eventually led to this dissertation. Thank you to the entire team in Institutional Research and Planning - Bob Goldstein and Becky Patterson and your skilled staff - I literally could not have accomplished this without you! Thank you to the other doctoral students who became a family as we helped each other through this process, and to Dr. Glenn Gittings for getting us organized and starting a wonderful mentor tradition in our department. Thank you to Becky Clark and Drs. Cathy Bays, Cheryl Gilchrist, and Nisha Gupta for your positivity, encouragement, and friendship. Thank you to Dr. Nora Scobie for being my third floor cheerleader and dissertation oracle, and to Ron Schildknecht for sharing in my frustration when I ran into roadblocks (as we know, there were many) and cheering with me when I overcame them. Thank you to Greg Carmichael for the final edits of my passive verbs. And finally, a heartfelt thank you to Christy Metzger, for her interminable support and for allowing me the flexibility to achieve this goal and still remain gainfully employed! 


\begin{abstract}
THE ROLE OF COMMUNITY COLLEGE-BASED TRANSFER PROGRAMMING IN TRANSFER STUDENT SUCCESS
\end{abstract}

\author{
Kathren Teresa Partin
}

November 15, 2012

More students now begin their postsecondary education at the two-year college level with the intention of transferring to earn a bachelor's degree, making the transfer function more important. Recent government mandates in Kentucky brought about new programming efforts to aid student transitions between public institutions. This study was designed to determine whether the University of Louisville (ULtra) Transfer Program, designed as a bridge between Jefferson Community and Technical College and the University of Louisville (UofL), played a significant role in community college students' successful academic transition to the four-year institution. Participants of this study were 227 community college students who transferred to UofL between 2006 and 2011.

Results indicated that, even when controlling for relevant background characteristics (age, high school GPA, and ACT score), students who participated in the ULtra program had more credit hours earned and accepted toward their major, suffered less transfer shock after the transition to UofL, earned a slightly higher first and significantly higher second semester GPA, and had a higher persistence rate at UofL. 


\section{TABLE OF CONTENTS}

DEDICATION

ACKNOWLEDGMENTS

iv

ABSTRACT

$\mathrm{V}$

LIST OF TABLES AND FIGURES $\quad$ x

CHAPTER

I. INTRODUCTION 1

$\begin{array}{ll}\text { Problem Statement } & 6\end{array}$

Significance of the Study $\quad 8$

$\begin{array}{ll}\text { Purpose of the Study } & 10\end{array}$

Research Questions and Hypotheses $\quad 10$

$\begin{array}{ll}\text { Background Characteristics } & 10\end{array}$

Prior to Transfer (JCTC) 11

$\begin{array}{ll}\text { Post Transfer (UofL) } & 11\end{array}$

$\begin{array}{ll}\text { Delimitations } & 12\end{array}$

$\begin{array}{ll}\text { Conceptual Model } & 12\end{array}$

Definition of Terms 13

Summary of Chapter I and Overview of Chapters II - V 16

\begin{tabular}{ll} 
II. & REVIEW OF LITERATURE \\
\hline
\end{tabular}

Higher Education in Kentucky: General Overview 18

UofL and JCTC Transfer Partnership $\quad 19$ 
Pathways to Success

The ULtra Transfer Program

Theoretical Framework $\quad 23$

Constructive-Developmental Theory 23

Student Involvement Theory $\quad 32$

Summary $\quad 35$

Literature Review 37

Higher Education: A Statistical Overview 37

The Community College $\quad 40$

Foundations $\quad 41$

Major Community College Philosophies: $\quad 42$ A Brief Overview

General Population $\quad 43$

Major Populations $\quad 45$

$\begin{array}{ll}\text { Transfer Population } & 47\end{array}$

Does the Community College Help or Hinder Student $\quad 48$ Success?

The Transfer Function $\quad 51$

Transfer Problem \#1: Timing 51

Transfer Problem \#2: Credits 53

Transfer Problem \#3: Transfer Shock 53

Building Relationships between Community Colleges $\quad 55$ and Universities

$\begin{array}{ll}\text { Summary } & 56\end{array}$

III. METHODOLOGY $\quad 58$ 
$\begin{array}{ll}\text { Introduction } & 58\end{array}$

$\begin{array}{ll}\text { Research Design } & 58\end{array}$

Population and Sample $\quad 59$

$\begin{array}{ll}\text { Variables } & 59\end{array}$

$\begin{array}{ll}\text { Setting } & 62\end{array}$

University of Louisville $\quad 62$

Jefferson Community and Technical College 63

Data Sources and Collection Procedures $\quad 64$

Research Questions and Analyses $\quad 65$

$\begin{array}{ll}\text { Background Characteristics } & 66\end{array}$

Prior to Transfer (JCTC) 67

$\begin{array}{ll}\text { Post Transfer (UofL) } & 69\end{array}$

$\begin{array}{ll}\text { Limitations } & 71\end{array}$

IV. RESULTS OF THE STUDY $\quad 75$

$\begin{array}{ll}\text { Introduction } & 75\end{array}$

$\begin{array}{ll}\text { Sample Demographics } & 75\end{array}$

$\begin{array}{ll}\text { Results } & 77\end{array}$

$\begin{array}{ll}\text { Background Characteristics } & 77\end{array}$

$\begin{array}{ll}\text { Research Question } 1 & 77\end{array}$

$\begin{array}{ll}\text { Prior to Transfer (JCTC) } & 80\end{array}$

$\begin{array}{ll}\text { Research Question } 2 & 80\end{array}$

Research Question $3 \quad 84$

$\begin{array}{ll}\text { Post Transfer (UofL) } & 85\end{array}$ 
Research Question $4 \quad 85$

Research Question 5

$\begin{array}{ll}\text { Summary } & 90\end{array}$

V. SUMMARY AND CONCLUSIONS 92

$\begin{array}{ll}\text { Discussion } & 94\end{array}$

Recommendations for Policy and Practice 100

Recommendations for Future Research 106

$\begin{array}{ll}\text { Conclusion } & 109\end{array}$

$\begin{array}{lr}\text { REFERENCES } & 112\end{array}$

$\begin{array}{ll}\text { CURRICULUM VITAE } & 129\end{array}$ 


\section{LIST OF TABLES AND FIGURES}

\section{TABLES}

1. Background, Independent, and Dependent Variables 62

2. Descriptive Statistics for the Sample: Age, Gender, Race/Ethnicity, and SES 76

3. Descriptive Statistics for Pre-college Achievement (High School GPA and 77 ACT Score)

4. Cross-tabulations for Non-ULtra and ULtra: Gender, Race/Ethnicity, and SES 78

5. Cross-tabulations for Non-ULtra and ULtra: Age 78

6. Cross-tabulation for Pre-college Achievement: High School GPA 79

7. Cross-tabulation for Pre-college Achievement: ACT Score 80

8. MANCOVA Estimates: JCTC Credits Earned, Credit Ratio, and Credits 82 Toward Major

9. Cross-tabulations for the Groups: JCTC Credits Attempted 82

10. Cross-tabulations for the Groups: JCTC Credits Earned 83

11. Cross-tabulations for the Groups: JCTC Credits Accepted toward Major 84

12. Descriptive Statistics for the Groups: JCTC GPA, UofL $1^{\text {st }}$ Semester and 86 $2^{\text {nd }}$ Semester GPAs

13. Cross-tabulation: First to Second Semester Persistence Rates 87

14. Logistic Regression Results: First to Second Semester Persistence Rates 87

15. Cross-tabulation: Overall Persistence Rates 88

16. Logistic Regression Results: Overall Persistence Rates 88

17. Cross-tabulation: Expanded First to Second Semester Persistence Rates 89 
18. Cross-tabulation: Expanded Overall Persistence Rates

19. Overview of Results

FIGURES

1. Conceptual Model 13

2. "A Figure to Figure" 25

3. Interpretation of Kegan's Bridge Metaphor Integrated with Dewey's 30 (1916) Ideas of Active Learning

4. Estimated Marginal Means of GPA between Non-ULtra and ULtra Students 86 


\section{CHAPTER I}

\section{INTRODUCTION}

It can be argued that the system of higher education in American is more complex now than at any other point in history. With the nation in the midst of a financial crisis, second only to the Great Depression (Hudzik, 2010), economic demands on the government (Duncan, 2011), students, and institutions necessitate increasingly difficult and sometimes costly decisions (Anderson, Alfonso, \& Sun, 2006). In large part due to both the bleak economic climate and government encouragement, students now choose to attend college in record numbers in hopes of greater financial security and success (Brand \& Xie, 2010; Duncan, 2011; Mincer, 1997; Sandy, Gonzalez, \& Hilmer, 2006). Recent data from the National Center for Education Statistics (NCES) indicate that in 2010, 68\% of high school graduates enrolled in a two- or four-year college the fall immediately following graduation (Aud et al., 2012). NCES reports that between 2000 and 2010, enrollment at degree-granting postsecondary institutions increased by $37 \%$ (13.2 to 18.1 million), and enrollment is projected to reach 20.6 million by 2021 (Aud et al., 2012). Of those 18.1 million students, approximately 7.7 million are enrolled in public degreegranting two-year community colleges, with an additional 1.1 million projected by 2021 (Aud et al., 2012). Almost half of these students plan to transfer at some point to earn a four-year degree (Dervarics, 2007; Fredrickson, 1998). Given the large number of students who intend to transfer from the community to the four-year college, there is 
increasing interest from policymakers, researchers, and administrators in the progress and achievement of these students (Kozeracki, 2001; O'Banion, 2010).

Research indicates that postsecondary education is one of the best ways to overcome lower social and economic conditions (U.S. Department of Education, 2006; Wang, 2009). The community college serves as an equal access "front door" to higher education, providing opportunity to students who might not otherwise attend college (Alfonso, 2006; Clark, 1960; Dougherty \& Kienzl, 2006; Kinnick \& Kempner, 1988; Laanan, 2001; Laanan, 2007; Leigh \& Gill, 2004; Rouse, 1995). Over the past century, the multiple missions of the community college have grown and changed in response to the communities' needs (Amey, 2010; Bueschel, 2009; O'Banion, 2010). The most recent shift is connected to the nation's increasing awareness that the majority of new jobs created in the $21^{\text {st }}$ century will require some sort of postsecondary degree (Cuseo, 2001; Dougherty \& Townsend, 2006; Duggan \& Pickering, 2008; Duncan, 2011; U.S. Department of Education, 2006).

The growing awareness of an impending shift in job skills prompted a presidential goal for the United States to hold the world's largest share of college-educated adults by the year 2020 (Arguijo \& Howard, 2010; Hudzik, 2010; Duncan, 2011) and to remain globally competitive (O’Banion, 2010). While college enrollment continues to rise, college completion is not increasing at the same rate (U.S. Department of Education, 2006). Unfortunately, the U.S. stands in $14^{\text {th }}$ place in higher education attainment for 25 34 year-olds among the 37 Organisation for Economic Cooperation (OECD) and G20 countries (OECD, 2012). With more young people attempting to earn a postsecondary degree, the ability of that community college "front door" to ultimately lead to a 
bachelor's degree has become even more essential. Starting at the community college level now has become a bona fide entry point into higher education for over $42 \%$ of the college student population (Aud et al., 2012; Hudzik, 2010; U.S. Department of Education, 2006).

Unfortunately research indicates that, even after controlling for differences (e.g. socioeconomic status, gender, race/ethnicity, initial degree aspirations, academic ability, etc.), students who begin at a two-year college are significantly less likely to persist and earn a bachelor's degree than students who begin at a four-year institution (Dougherty \& Townsend, 2006; Kinnick \& Kempner, 1988; Pascarella \& Terenzini, 1991; Prager, 1993; Zamani, 2001). Research suggests that even when compared on equivalent characteristics, community college students will receive $11 \%$ to $20 \%$ fewer baccalaureate degrees than students who begin at four-year colleges (Dougherty, 1992; Townsend, 2007). Dougherty (1992) indicates that it is not simply the student, but also the nature of the community college that has a negative effect on baccalaureate attainment, suggesting further that the biggest institutional factors hindering retention are the school's inability to integrate students adequately into the academic and social aspects of the two-year college. There are the ideals of what community college students should be able to gain from their educational experience, and there are the realities of what this type of institution currently provides. Where these two views diverge is where the real work begins of creating mechanisms to help students reach their goals no matter where they start their journey.

Students who intend to earn a bachelor's degree by beginning at a two-year and transferring to a four-year institution (known as a vertical transfer) (Hood, Hunt, \& 
Haeffele, 2009), are a nebulous group. These students have aspirations beyond those of their community college peers (Lee \& Frank, 1990) but have chosen a less reliable path than their native four-year counterparts. Even though data show that students who successfully transfer from the two- to four-year institution and earn their bachelor's degree achieve comparable economic success as those who begin at the four-year (Pascarella \& Terenzini, 1991), the transition from the community college to the fouryear institution can be a difficult one (Cuseo, 2001; Duggan \& Pickering, 2008; Hood et al., 2009).

Postsecondary institutions, both two- and four-year, have a vested interest in students successfully transferring from the community college to a senior institution and earning a baccalaureate degree. NCES data from 2012 show that for the 2009-10 academic year, over 1.65 million students graduated from four-year institutions in the United States (Aud et al., 2012). Current research shows that approximately $60 \%$ of college students will attend more than one institution (both two- and four-year) over the course of their career (Goldrick-Rab \& Pfeffer, 2009; Hood et al., 2009). According to 2008 NCES data, $18 \%$ of students enrolling at a four-year institution for the 2003-04 school year were transfers (Berkner \& Choy, 2008). In higher education today, community college transfer students are an important resource for four-year institutions (Kentucky Council on Postsecondary Education [KY CPE], 2010, "Transfer"). Therefore, in these times of increased pressures on accountability, leaders at four-year institutions should facilitate the successful transfer to and retention of students at their schools in order to increase completion rates (Wang, 2009). 
Beyond that, four-year institutions are interested in community college transfer students because they often meet some very specific needs of the school: First, since the majority of transfer students (about two-thirds) typically stay at the two-year college for at least two semesters, they tend to bring with them enough credit hours to start as sophomores or higher in their new institution (Cheslock, 2003). This is useful to the receiving institution because second year students "consume less of those resources disproportionately used up by freshmen (such as student housing) and more of those resources disproportionately used by upperclassmen (such as upper-level courses)" (Cheslock, 2003, p. 57). Institutions with high attrition rates also find students transferring in at the sophomore level or higher useful to maintain optimal enrollment. Community college students are equally appealing to four-year schools that hope to increase the diversity of their campus, with institutions trying to attract high achieving minority students to transfer and help round out their numbers (Cheslock, 2003). Despite both community colleges and four-year institutions wanting and needing students to transfer, the process is still remarkably arduous (Laanan, 1996; Leigh \& Gill, 2004).

Given the uphill battle that students face in the transfer process, it is imperative that institutions work to find ways to help ease the transition (Prager, 1993). According to Wang (2009), the evident drawbacks associated with beginning at a community college represent "an obligation among higher education researchers to look within the community college transfer student group in identifying factors that affect these students' educational attainment" (p. 571). One of these factors that helps students be successful during and after transfer is taking the appropriate preparatory coursework—work that will be accepted by the receiving institution—and work that matches the students' 
academic abilities and needs. Over the past few decades, research has shown that some progress has been made in the way of articulation agreements and other programmatic initiatives to help transfer students succeed (Cameron, 2005; Ignash \& Townsend, 2000; Kisker, 2007; Laanan, 1996). Still, more research needs to be conducted to see if these initiatives have a positive impact on the transfer student population they were designed to assist. If students choose to participate in transfer programming and services, can they expect to have a better transition and persist at the four-year institution?

\section{Problem Statement}

As more students begin their postsecondary education at the two-year college level, fully intending to earn a bachelor's degree, the transfer function becomes more important (Dougherty \& Kienzl, 2006). In order for students to transfer successfully, however, they must first be retained at the community college and be prepared both academically and socially for the transition to the four-year institution (Dougherty, 1992). Students who start at the community college are at a disadvantage when compared to their four-year counterparts (Alfonso, 2006). Only about half of students who intend to transfer to the four-year institution do so successfully, a percentage that is far below what government officials and higher education administrators would like (Bradburn \& Hurst, 2001). This phenomenon is known as the baccalaureate gap (National Center for Academic Achievement and Transfer, 1991). For the community college students who do successfully transfer to the four-year institution, the question is whether or not they are adequately prepared to excel in their new environment. Students, parents, and community members believe that starting at the two-year college is the most economical way to earn a bachelor's degree, and that may be true. However, money saved does not always equal 
a better deal. For some students, starting at the community college is their only option (Pascarella \& Terenzini, 1991), but if their goal is a bachelor's degree, it might not be the surest bet.

Unfortunately, the reality that these students may very likely never reach their goals is masked in part by government and institutional bureaucracy, but also inadvertently through the best intentions of educators who want to help (Dougherty \& Townsend, 2006). Government officials are continually challenged to balance the needs of their diverse constituency as well as their budgets. Evidence from the research suggests that these officials see community college as a cheaper and more efficient means of educating the people in their communities, but fail to see the negative consequences (Anderson, Sun, \& Alfonso, 2006; Dougherty \& Kienzl, 2006). For their part, institutional leaders have played a role in the educational bureaucracy since the creation of the community college (Jurgens, 2010).

The barriers to success are numerous, and higher education professionals are faced with the daunting task of helping these students persevere against difficult odds. For instance, in Kentucky educational attainment is extremely low, with only about $12 \%$ of resident adults aged 25 or older having earned a bachelor's degree as of 2006 (Snyder, Dillow, \& Hoffman, 2009). Likewise, barriers such as wide-spread financial shortfalls necessitate that colleges and universities do more with less, such as assisting community college students in their desire to transfer. For students who have taken the next step and are accepted at the four-year institution, the skills and experiences they bring with them from the community college are vitally important. This study looks at community college students who are now beyond that first step in order to see if the preparation they 
received through transfer programming helped create the necessary conditions for academic success and persistence at the four-year university. This dissertation focuses on one such transfer program in Kentucky: the University of Louisville Transfer (ULtra) Program.

\section{Significance of the Study}

The demands on higher education to produce productive, college educated citizens are growing in the $21^{\text {st }}$ century, while the resources to meet those demands are not (Arguijo \& Howard, 2010). Education is tantamount to social and economic mobility (Becker, 1960; Brand \& Xie, 2010; Mincer, 1997) and as such, more students are entering higher education. In this equation, the community college and the transfer function play an increasingly important role. The issue is that the transfer process is often so difficult that it in itself becomes a barrier to student success (Duggan \& Pickering, 2008). Kinnick and Kempner (1988) suggested that in order to increase community college student baccalaureate attainment, the plan must be to "initiate, in as deliberate and as vigorously a manner as possible, strategies designed to strengthen the community college transfer role" (p. 315). They cite findings that indicate that student involvement, clear direction, appropriate academic preparation, and intentional articulation between institutions are integral factors to retention and degree completion (Kinnick \& Kempner, 1988). In Kentucky, where educational attainment has been particularly low, initiatives created to address the issue of transfer student success, such as the Kentucky Postsecondary Education Improvement Act of 1997, which will be discussed briefly in chapter two, are essential. 
The community college transfer population in Kentucky is large enough that it warrants scholarly attention. For the 2008-09 year, 7,179 students transferred from within the Kentucky Community and Technical College System (KCTCS) to another institution (KY CPE, 2010, "Transfer"). Of those students, about 49\% transferred to a public fouryear university in Kentucky, $13 \%$ to an independent college or university within the state, and $38 \%$ to an out-of-state four-year institution. KCTC transfer students made up about $11 \%$ of the incoming student population at public Kentucky universities for 2007-08 (KY CPE, 2010, "Transfer"). Of the 646 first-time transfer students from Jefferson Community and Technical College (JCTC) in fall 2006/spring 2007, 358 (about 55\%) transferred to the University of Louisville (UofL) (KY CPE, 2010, "Diversity \& Demographics"). Likewise, of the 520 students who transferred from KCTCS to UofL, JCTC transfers made up approximately 69\% (KY CPE, 2010, "Diversity \& Demographics").

The new state initiatives for Kentucky, which will be discussed in the next chapter, have produced a shift in how the state community colleges and four-year institutions facilitate the transfer process. The creation of the ULtra Transfer Program as a partnership between JCTC and UofL is a prime example of the new collaborative approach being undertaken. While a small number of studies have been published indicating that similarly structured programs show promising results (Munkittrick, 2009; Whorton, 2009), the ULtra program has not yet been formally assessed and warrants its own quantitative review. Furthermore, with educational funding continuing to dwindle in Kentucky, it is imperative that the fiscal, temporal, and human resources dedicated to this type of program be well utilized and meet their intended goals. In other words, it is 
important to know if the program created to help support transfer students' successful transitions is effective. Therefore, this study was designed to ascertain whether or not the ULtra Transfer Program significantly influenced transfer students' academic success and persistence.

\section{Purpose of the Study}

The purpose of this dissertation research study was to determine whether the ULtra Transfer Program plays a significant role in JCTC students' successful academic transitions to UofL, as defined and indicated by students a) earning more credit hours that are accepted toward their major, b) suffering less transfer shock after the transition to UofL and earning a higher first and second semester GPA, and c) having a higher persistence rate at UofL.

\section{Research Questions and Hypotheses}

The current study examined the relationship between key variables, both demographic and academic, as they relate to transfer student success. Five research questions and their corresponding directional hypotheses were addressed in this study. Details about the methodology employed to test these hypotheses are discussed in chapter three.

\section{Background Characteristics}

1. Do students who utilize the ULtra Transfer Program differ in background characteristics (age, race/ethnicity, gender, SES, high school GPA, ACT score) from Non-ULtra transfer students? 
$\mathrm{H}_{1}$ : The background characteristics of transfer students who utilized the

ULtra Transfer Program do not differ from the transfer students who did not participate in ULtra (Non-ULtra).

\section{Prior to Transfer (JCTC)}

2. Do students who utilize the ULtra Transfer Program complete more, and more appropriate, preparatory work at JCTC prior to transfer?

a. Do students earn a higher number of credit hours?

b. Do students have a higher ratio of credit hours attempted to credit hours earned?

c. Do students have a higher number of credit hours accepted toward their major?

$\mathrm{H}_{2}$ : Students with the ULtra Transfer Program have more appropriate preparatory work (work that will be accepted toward their major by the receiving institution) successfully completed prior to transfer.

3. Do students who utilize the ULtra Transfer Program have a higher GPA at the time of transfer?

$\mathrm{H}_{3}$ : Students with the ULtra Transfer Program have higher JCTC GPAs at the time of transfer when compared to Non-ULtra transfer students.

\section{Post Transfer (UofL)}

4. Do students who utilize the ULtra Transfer Program suffer less transfer shock in their first year at the four-year institution?

a. Do students experience a smaller decline in GPA in the first semester? 
b. Do students experience a greater rebound in GPA in the second semester?

$\mathrm{H}_{4}$ : Students with the ULtra Transfer Program experience less transfer shock in their first year at UofL, relative to Non-ULtra transfer students.

5. Do students who utilize the ULtra Transfer Program have a higher persistence rate?

a. Do students have a higher first to second semester persistence rate?

b. Do students have a higher overall persistence rate?

$\mathrm{H}_{5}$ : Students in the ULtra Transfer Program have higher persistence rates relative to Non-ULtra transfer students.

\section{Delimitations}

This dissertation research only encompasses students who have transferred from Jefferson Community and Technical College, a public two-year associate degree-granting institution, to the University of Louisville, a large public research comprehensive institution serving approximately 22,300 students in the state of Kentucky. The population of transfer students is also limited to those who have only attended JCTC before their transfer to UofL and for whom there is enough complete data within the student record system to facilitate the statistical model. ULtra students will be limited to those who participated in the program between 2006 and 2011.

\section{Conceptual Model}

This study aims to determine whether or not the ULtra Transfer Program, available to students who intend to transition from JCTC to UofL, significantly impacts 
student academic success and persistence. Figure 1 shows the conceptual model that guides this study.

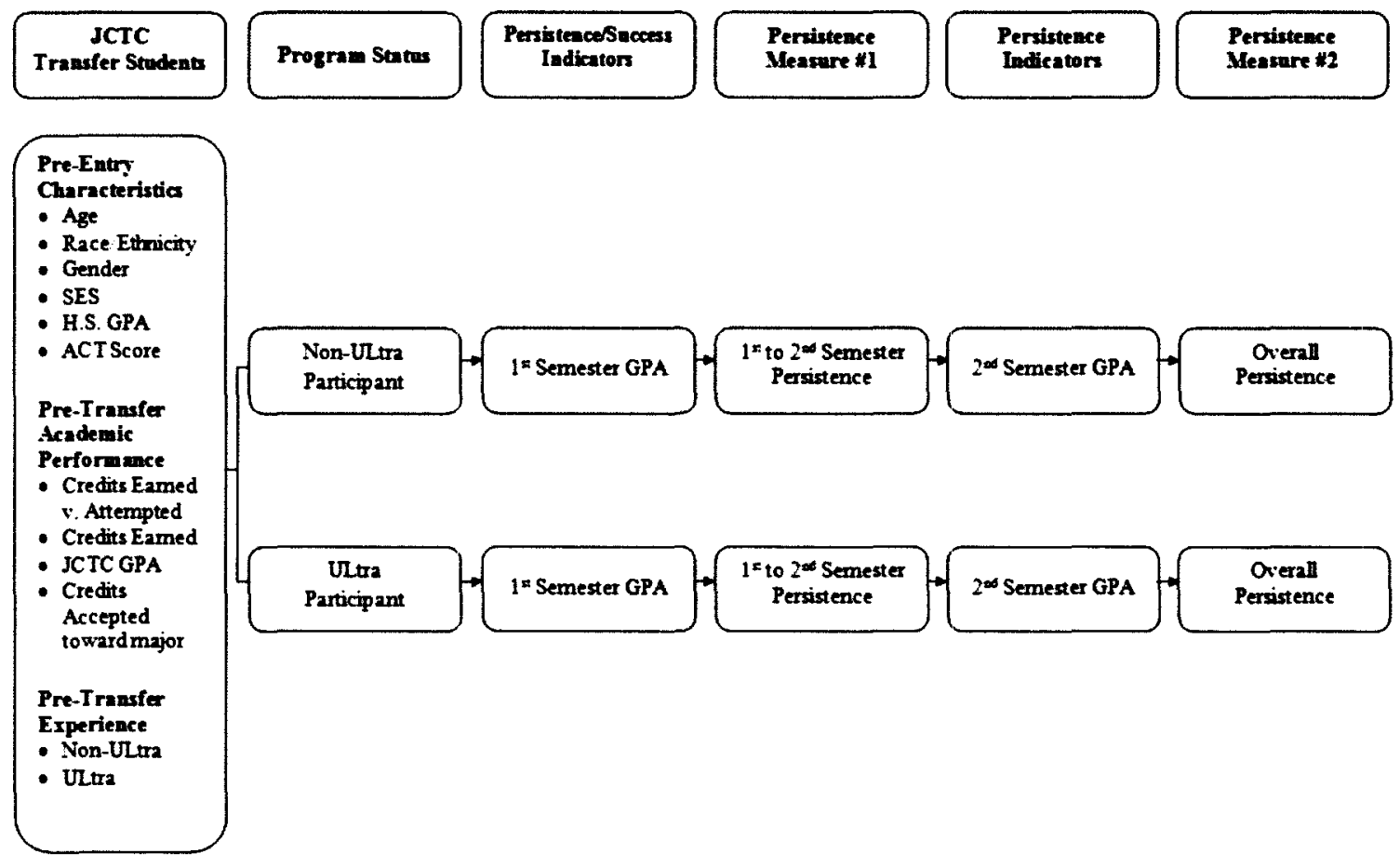

Figure 1. Conceptual Model

\section{Definition of Terms}

The following definitions apply to this study:

1. Articulation: "Refers to the movement of students - or, more precisely, the students' academic credits - from one point to another. The concept includes admission, exclusion, readmission, advising, counseling, planning, and course and credit evaluation" (Cohen \& Brawer, 2003, p. 212).

2. Baccalaureate gap: The discrepancy between the number (or percent) of community college students who aspire to earn a baccalaureate degree and those who actually do (National Center for Academic Achievement and Transfer, 1991). 
3. Cohort: "A specific group of students established for tracking purposes" (IPEDS Glossary, n.d.).

4. Community college: "Any institution regionally accredited to award the associate in arts or the associate in science as its highest degree" (Cohen \& Brawer, 2008, p. 5). The terms community college, two-year college, two-year institution, junior college and subbaccalaureate level are used interchangeably throughout this dissertation.

5. Cooling out: The effect that community colleges have on potential transfer students who are underperforming to eventually change tracks and work towards a terminal degree (Clark, 1960).

6. Democratization: The opportunity community colleges provide for higher education for those students who might not have otherwise attended college either because of financial constraints or because they were not yet ready to enroll at a four-year institution (Rouse, 1995).

7. Diversion effect: "...local community colleges may ... draw away students who might otherwise have attended a four-year college" (Rouse, 1995, p. 218).

8. First-time transfer: "A student is counted as a first-time transfer during their first semester of enrollment after transferring to a new institution" (KY CPE, n.d., "Transfer", para. 3).

9. General Education Certified: Students who are able to transfer with this certification have completed at least 48 semester hours of general education, which include the 33-hour "Core Component" and all other required general education courses (KY CPE, 2004). 
10. Native students: Students who begin their postsecondary education and remain at the four-year institution (Townsend \& Wilson, 2006).

11. Persistence: "Continued enrollment of students as they work toward completing a credential" (KY CPE, 2011, "Retention \& Graduation Rates", para. 4).

12. Receiving institution: The institution to which a transfer student transitions (Ignash \& Townsend, 2000).

13. Retention rate: "A measure of the rate at which students persist in their educational program at an institution, expressed as a percentage. For four-year institutions this is the percentage of first-time bachelor's (or equivalent) degreeseeking undergraduates from the previous fall who are again enrolled in the current fall. For all other institutions this is the percentage of first-time degree/certificate-seeking students from the previous fall who either re-enrolled or successfully completed their program by the current fall" (IPEDS Glossary, n.d.).

14. Student success: Defined in this study by a) more credit hours earned and accepted toward a major, b) suffering less transfer shock after the transition to UofL and earning a higher first and second semester GPA, and c) having a higher persistence rate at UofL.

15. Transfer: "An intention expressed by some students who take community college classes and a behavior manifested by those who eventually matriculate at a fouryear college or university" (Cohen \& Brawer, 1987, p. 89). 
16. Transfer credit hours: The total number of credit hours taken at one institution that are then accepted for transfer at the second institution (KY CPE, 2010, “Transfer").

17. Transfer shock/ Transfer dip: The drop in academic performance generally experienced by students in the first semester after transfer from a two-year to a four-year institution, usually identified by a grade point drop of .5 (Hills, 1965; Kintzer \& Wattenbarger, 1985).

\section{Summary of Chapter I and Overview of Chapters II-V}

Higher education has become increasingly important in today's society as economic and social demands necessitate schooling past a high school diploma. Many students choose to start their college career at the community college level with the intention of transferring to a four-year institution to earn their bachelor's degree. At the same time, these transfer students are becoming a population critical to colleges and universities in their efforts to increase graduation rates as well as the state and federal funding, which is vital to an institution's survival in tough economic times.

Administrators at both types of institutions need to work together to create programming and services that will help transfer students be successful before, during, and after transfer. Creating such initiatives in the current economic climate presents a difficult task. Given the importance of this particular group of students and the limited funding available to supply resources to university initiatives, it is essential to know if a program such as ULtra benefits students.

The current chapter has provided the context for this dissertation, introducing the issue of community college transfer student success and its importance in higher 
education. Chapter II includes a current look at higher education in Kentucky and a review of the relevant literature on community colleges and transfer students. Chapter III details the methodology employed for this study, along with more detailed information on the population, research setting, design, and limitations. Chapter IV provides the results of the study and a discussion of the findings, and Chapter V presents the conclusions and suggestions for future research. 


\section{CHAPTER II}

\section{REVIEW OF LITERATURE}

This dissertation examined the possible impact that transfer support programs have on transfer students' success. Specifically, this dissertation focused on the ULtra Transfer Program model and attempted to determine if there was a significant correlation between transfer student involvement in the program and their successful transfer to and persistence at a four-year institution. This chapter is divided into four sections: (1) the introduction, (2) a brief look at higher education in Kentucky, (3) the theoretical framework for the study, and (4) the review of literature. The literature review consists of the following relevant research: (1) higher education, (2) the community college, (3) student success, and (4) community college and university relationships. The chapter will conclude with a summary of the research.

\section{Higher Education in Kentucky: General Overview}

Education in Kentucky has not always been a top priority, and from primary through postsecondary education, rankings for the state have not been favorable (Howarth, 2003). Kentucky's 2.8 million-plus residents age 25 and older were below the 2006 national averages for high school (including GED) (about 80\% vs. 84\%), associate (6.5\% vs. $7.4 \%$ ), and bachelor's (about $12 \%$ vs. $17 \%$ ) degree attainment (KY CPE, 2009, "Educational Attainment"). The current national data indicate that Kentucky (19.1\%) is ranked $48^{\text {th }}$ in education ahead of only three states: Mississippi (about 19\%), Arkansas (19\%), and West Virginia (17\%) (Snyder \& Dillow, 2011). 
In response to federal mandates (Duncan, 2011), the economic downturn, and low achievement rates, educational efforts in Kentucky have increased steadily with the assistance of new state government policies. The General Assembly enacted the Kentucky Postsecondary Education Improvement Act of 1997, commonly known as House Bill 1 (Howarth, 2003). House Bill 1 established the goals and objectives for the Kentucky Council on Postsecondary Education (KY CPE), which was charged with coordinating "change and improvement" within the system of higher education for the state (KY CPE, 2011, “About Us,” para. 1). House Bill 1 specified significant changes to the system of higher education in Kentucky, required to be achieved by the year 2020 (Kentucky Postsecondary Education Improvement Act, 1997). To create the "seamless, integrated system of postsecondary education" that was mandated (KY Postsecondary Education Improvement Act, 1997, p. 2), work needed to be done to better facilitate transitions and partnerships among public colleges and universities in the state.

With House Bill 1, all public institutions in Kentucky needed to begin formulating and implementing their own strategic plans to meet the goals of 2020 and the Transfer Policy set forth by the KY CPE. For the University of Louisville (UofL) and Jefferson Community and Technical College (JCTC), that meant working on a new partnership.

\section{UofL and JCTC Transfer Partnership}

\section{Pathways to Success}

One of the first initiatives cosponsored by UofL and JCTC was Pathways to Success (Pathways), the precursor to what is now the UofL Transfer Program, ULtra. A major function of Pathways was to encourage students who were denied admission to UofL to enroll at JCTC and earn at least 12 college-level credit hours (beyond any 
developmental coursework required), and then transfer to the university (T. O.

McWhorter \& P. P. Sheth, personal communication, October 1, 2010). A UofL academic advisor was located on the JCTC downtown campus and was the primary contact for these students. Pathways students participated in an orientation and were required to attend a "successful transition" workshop and an academic or cultural event, participate in learning resource hours (similar to study hall), and meet with an academic advisor regularly. These students were also required to complete the JCTC GE 101 "Strategies for Academic Success" course, all developmental coursework identified on the COMPASS placement test, and a minimum of 12 hours of transferrable credit. Pathways students were granted many of the same privileges that native UofL students enjoyed, such as housing, student ID, and access to join some clubs and organizations at UofL, among others. Once students had met the requirements for the program, they were admitted to UofL and could transfer to the university. Data reported by Howarth (2003) indicate that by fall 2003, 100 students had transferred to UofL or another four-year institution. One of the main problems with this model was that only developmental students at UofL and denied students at JCTC were allowed to participate, while all other students wishing to transfer from the two-year to the four-year institution were left to fend for themselves (T. O. McWhorter \& P. P. Sheth, personal communication, October $1,2010)$.

With KY CPE's mandates for vast educational improvements by 2020 firmly taking shape, even more changes were needed to continue the forward momentum. KCTCS was now required to facilitate more directly the transition of community college students to the four-year public institutions in the state. No longer could UofL and JCTC 
only focus their joint efforts on the academically underprepared students; they needed to create an initiative that would also help any student who wanted to transfer from the twoto the four-year institution (T. O. McWhorter \& P. P. Sheth, personal communication, October 1, 2010). Thus, the concept for ULtra was born.

\section{The ULtra Transfer Program}

With a new idea came new leadership. A director for the ULtra program was hired and tasked with taking the "successful parts" of the Pathways program to create the new structure that would meet the needs of the more general JCTC/UofL transfer student population (K. T. Mandlehr, personal communication, November 3, 2010). The main impetuses were to help transfer students earn community college credit that would be accepted at the university, to assist in their transfer, and to successfully retain those students at UofL. The two most important components for this to work were a) proper advising for the general education coursework that would transfer (which students in the Pathways program were already receiving) and b) a compendium of this coursework, easy for students and advisors to follow. The director of ULtra worked with JCTC to create University of Louisville Academic Program Plans (APPs) to provide information about the most appropriate classes to take at the community college related to the majors offered at UofL. The APPs allow students to earn their first 60 credit hours at JCTC and transfer them to UofL, entering the university with junior (upper division) status without any additional coursework (JCTC, n.d., "Academic Program Plans", para. 1). Along with the APPs came other programmatic changes considered necessary for the growth of the program and its students. 
New features were introduced to the ULtra program, while other components from Pathways fell away. Namely, the more formal/required parts of the Pathways program (mandatory attendance at events, the required GE 101 course, participation in workshops, instructional support, etc.) were eliminated. These changes were made, in part, because of design (the program was no longer just for developmental students who would most benefit from these additional services) and in part because of sheer numbers. With the doors of ULtra now open to all students wishing to transfer from JCTC to UofL, the still small staff (now a director and two full-time advisors), would not be able to handle the work load of so many required programs. Another reason for the change in design was based on research of best practices in the field (Amey, 2010; Flaga, 2006; Laanan, 2007; Townsend \& Wilson, 2006).

Several new initiatives were created by ULtra, including one of the most important additions: the ULtra Orientation. A replacement for the traditional JCTC Orientation, this program is intended for students who know they want to transfer to UofL. Research shows that students perceive orientation programs to be useful to their college adjustment (Mayhew, Vanderlinden, \& Kim, 2010; Perrine \& Spain, 2009), and this transfer-specific orientation allows students to begin their college careers already on the path to successful transfer. ULtra also created Intro to ULtra informational sessions hosted throughout the school year and designed for students who did not attend orientation and who have fewer than 24 college-level credit hours. ULtra now also includes a class visit program, special transfer campus tours, Transfer Days (transitional workshops), and the Leaders Exploring Advanced Degrees (L.E.A.D) program - a series of visits "designed to expose students to the realities of admission to graduate and 
professional programs at the University of Louisville" (ULtra, 2011, "L.E.A.D.”, para. 2) (ULtra, 2011). These new programs created by ULtra are designed to meet student needs and based on research in the field (Davies \& Dickmann, 1998; Eggleston \& Laanan, 2001; Laanan, 1996).

\section{Theoretical Framework}

The theoretical framework for this study was grounded in both constructivedevelopmental theory (Kegan, 1982; 1994) and Astin's (1984/1999) theory of student involvement. These theories were chosen to help frame the current study due to their ability to connect both the thinking and actions on the part of the student with the philosophy and actions on the part of the institution(s) and characterize a particular outcome. First, Kegan's constructive-developmental framework and the subsequent "bridge metaphor" are discussed to set the stage for how students develop and how they might actively engage with transition programming. Then, Astin's theory of student involvement is reviewed to integrate how students' active involvement with such programming can lead to success at the four-year institution.

\section{Constructive-Developmental Theory}

Kegan $(1982 ; 1994)$ provides a constructive-developmental framework to explain what he calls the human process of "meaning-making" (p. 28). This theory addresses how humans make meaning of themselves, other people, and all of their personal experiences throughout their lifetime. A constructive-developmental contention is that humans actively build their own sense of reality in an effort to organize and understand their experiences. Kegan (1982) uses the most basic human context, a newborn baby, to explain that meaning making is equally a physical, social, and survival activity. Meaning- 
making is physical from the very beginning of life in the way that an infant is able to grasp at and see his or her mother, actions which grow into recognition of the other person. Kegan (1982) posits that what is first experienced "physically and concretely" may later be experienced "metaphysically and abstractly" (p. 18). Meaning-making is social because the process requires more than one person; meaning is made in context. Finally, our survival as physical and social beings depends on the ability to understand our experiences, helping us to grow and form essential relationships.

In Kegan's (1982;1994) estimation, events do not inherently have one meaning upon which all humans are able to understand and agree, but rather meaning is formed between an event and a person's individual reaction to it. To more readily explain this concept of constructing one's own reality, Kegan (1982) pulls from the Gestalt perception psychology, a school of thought that "stresses perception of completeness and wholeness" (Gladding, 2004, p. 204). The central axiom of Gestalt psychology is that the study of various parts will never lead to an understanding of a whole, given that the whole is expressed by the parts plus the interactions and interconnections of the parts; a person's reaction to an experience informs the experience (Fadiman \& Frager, 2002). Gestalt psychologists often maintained that, in perception, the whole is greater than the sum of its parts (Myers, 2001). To provide an example, Gestalt psychology sometimes employed a picture such as figure 2 , which might elicit two equally relevant perceptions; a person may look at the figure and see a "youngish" woman with her head turned away to the left, or perhaps instead, see an "oldish" woman with a large nose looking down. With this drawing, Kegan (1982) contends that people are not necessarily 


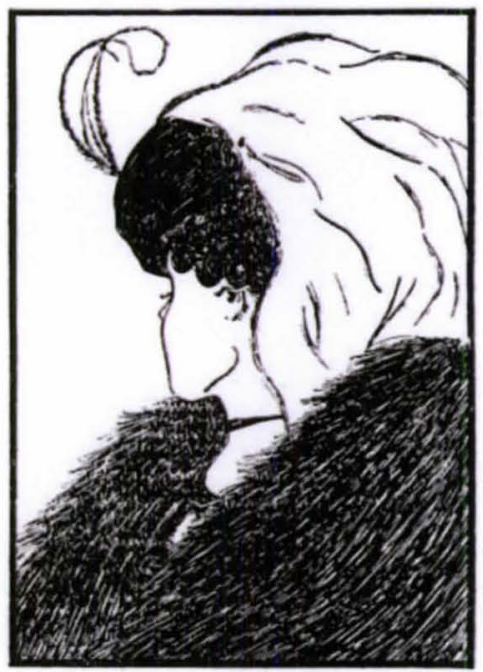

Figure 2. "A Figure to Figure" Originally drawn by W. E. Hill and published in Puck, (1905). First used for psychological purposes by Boring (1930). Reprinted by Kegan (1982, p. 9).

seeing the same image in different ways, but perhaps that they are seeing different images in different ways. After all, Kegan (1982) contends, the picture we see is not really on the page at all - the page merely contains a splash of light, dark, and blank spaces, and some lines - it is in the metaphysical "space between" (p. 11) (vis-à-vis the page and the meaning maker) that the image is created.

Kegan (1982) suggests that meaning making is a lifelong process, which allows a person to grow and change as he or she is able to incorporate new meaning into his or her own reality. Kegan (1994) offers six forms of meaning that are qualitatively different, and numbers these "orders of consciousness" (p. 10) from 0 to 5. A person's meaningmaking will change, affecting his or her view of self, relations to other people, and understanding of any given experience as he or she progresses through the orders (Ignelzi, 2000). It is the transition between these orders in which Kegan is most interested. Love and Guthrie (1999) point out that there are five important assumptions that underlie Kegan's theory: First, the orders of consciousness do not just refer to how a 
person thinks, but more broadly, to how a person constructs experience; this includes "thinking, feeling, and relating to others" (p. 67). Second, in developing his orders of consciousness, Kegan focuses on the organization of how a person thinks, feels, and relates to others instead of the actual content (Love \& Guthrie, 1999). Third, in each order of consciousness there is a different subject-object relationship. Kegan (1982) explains that the subject is "self" and the object is "other" or anything that is separate from the self. As further explanation, Kegan (1982) states that "evolutionary activity involves the very creating of the object (a process of differentiation) as well as our relating to it (a process of integration)" (p. 77). The fourth assumption is that all six orders are related to one another; they do not replace each other, but rather each order incorporates the one prior. In this way, the higher order becomes more complex (Love \& Guthrie, 1999). Finally, "what is taken as subject and object is not fixed; what was subject at one order becomes object at the next order. Therefore, there is a developing ability to relate to or see that in which we were formerly enmeshed" (Love \& Guthrie, 1999, p. 67).

It is important to note that meaning-making is not a reflection of intellectual ability, but rather the evolution of a person's thinking over time. One order does not prove greater intellectual potential, but instead contextualizes a person's thinking (Ignelzi, 2000). The vast majority of humans proceed through the initial orders of consciousness, incorporative (order 0) and impulsive (order 1), by the age of seven (Kegan, 1982). Briefly, the incorporative order takes place between 6 months and 2 years, and is closely tied to the mother-child relationship (physical contact, trust, bonding, etc.) (Kegan, 1982). Order 1, impulsive, centers on egocentrism as children 
(ages 5 to 7) view the world from a fantasy-filled position, the objects and meaning changing as the child's perception of them changes (Love \& Guthrie, 1999). Most adolescents between the ages of 12 and 16 also make their way through the next order, imperial (order 2), which focuses on "durable categories" that are consistent and separate from the individual. Children in this order are now able to group things (people, objects) by their similarities and differences (Kegan, 1982; Love \& Guthrie, 1999). There is a chance that some beginning college students still will be making the transition between this order and the next, interpersonal (order 3), on which it is much more difficult to place an age norm (Kegan, 1982, Love \& Guthrie, 1999; Ignelzi, 2000). So, between the ages of 12 and early adulthood (where a majority of transfer students will fall), adolescents will make the "gradual transformation of mind" (p. 69) from the imperial $\left(2^{\text {nd }}\right)$ to the interpersonal $\left(3^{\text {rd }}\right)$ order (Love \& Guthrie, 1999). In this transition, a person will have to stretch to begin to think abstractly and see him- or herself as part of a community in a "culture of mutuality" (Kegan, 1982, p. 119). Student affairs practitioners and faculty can assist students who are beginning this transition by helping them identify the "rules of the game" in an effort to help them meet the expectations of their college community (Love \& Guthrie, 1999, p. 70).

Order 3, interpersonal meaning-makers "co-construct their sense of meaning with other persons and sources (books, ideas) in their environment" (Ignelzi, 2000, p. 7). In this order, a person does not see him- or herself as separate from others (co-creators). A person in order 3 has the ability to coordinate the points of view of those around them and can construct a shared vision or reality but is unable to fully reflect on that reality or recognize how it affects their own thinking (Ignelzi, 2000). According to Kegan (1994), 
at this point in time a person begins to think abstractly and "identify a complex internal psychological life" (p. 75). A person in this order gradually gains the ability to have greater concern for their relationships with others than for themselves, considering their personal interests secondary to the loyalty of friendship (Kegan, 1994). The transition from the third order to the fourth order (institutional) may begin at approximately the same time a student enters college and continue throughout adulthood (with some never making it fully into the fourth order at all). The transition to the fourth order occurs when one attains "self-authorship," which is the ability to "write" one's own life (Love \& Guthrie, 1999, p. 71). Much, if not all of the teaching in college comes from professors and others who are most likely fourth order meaning-makers. Students, especially young ones, may not have reached the fourth order by the time they enter college (Ignelzi, 2000) and tend to find themselves "in over their heads" (Kegan, 1994, p. 41). Kegan (1994) summarizes the demands placed on students' minds, describing them as the "hidden curriculum" (p. 287). He states that students are expected to employ critical thinking, to be active readers and self-directed learners; they are asked to view themselves as cocreators of the culture as opposed to merely being shaped by the culture; and faculty expect that when students write, it will be to themselves, bringing the instructor into the reflection, instead of writing for and/or to the teacher.

In order for students to eventually achieve these curricular goals, they must begin from a place of comfort and be stretched to the next order with care and diligence. In an effort to help students in this process, educators must begin where the students begin (Kegan, 1994). To accomplish this task, Kegan (1994) reminds us that it is not sufficient to simply know that our students understand, but that we must know how they 
understand. Kegan (1994) expands on past theorists' imagery (notably Kierkegaard, 1959 and Perry, 1967) and uses the metaphor of building a bridge. On one side of the bridge lies what the student understands and how he or she understands it. On the other side, there are the educator's goals for what and how a student should understand (Blimling, Whitt, \& Associates, 1999). Kegan (1994) explains Perry's idea further, stating: Perry understood that if developmental education is a matter of collaboratively building a 'consciousness bridge', then the bridge builder must have an equal respect for both ends, creating a firm foundation on both sides of the chasm students will traverse. Firmly anchoring the bridge on one end by welcoming rather than disdaining 'the way they understand', as Kierkegaard put it, Perry then invited his students to join him in constructing what they would only gradually come to see was a bridge they could choose to walk out on. (pp. 278-279) For use in higher education, Blimling, et al. (1999) coupled Kegan's (1994) bridge metaphor with the work of others and defined three principles for "bridge building" (p. 26). The first principle is to situate learning in students' experience by listening to students' language, feelings, and knowledge to establish a base from which to approach subject matter. This "anchors" learning on the students' side of the bridge. This is an important first step because students thrive when their prior knowledge is respected and their favored styles of learning are acknowledged (Kuh et al., 2005). Second, it is necessary to validate students as knowers by validating students' ability to think, even if not necessarily validating their ideas. Finally, mutually constructing meaning is the joint effort by educator and learner to develop new perspectives and ways of thinking and to apply these new perspectives and structures to everyday life. Dewey (1916) suggested 
that students' learning must be active in order for them to make connections between their actions and the resulting consequences. In this way, students work through problems by relying on their own experiences and other available data to generate possible explanations. Components of active learning based on these assumptions are experience, reflection, integration, and application. For a visual representation of Kegan's (1994) bridge metaphor coupled with Dewey's (1916) components of active learning, see Figure 3.

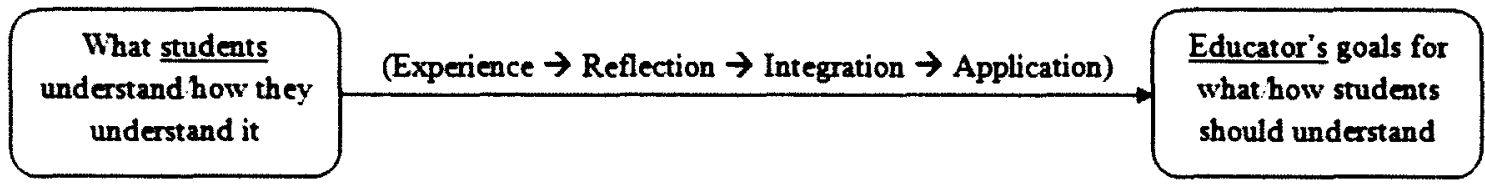

Figure 3. Interpretation of Kegan's Bridge Metaphor integrated with Dewey's (1916) Ideas of Active Learning (as cited in Blimling, et al., 1999).

Kegan's $(1982 ; 1994)$ constructive-developmental approach has been successfully utilized with community college students (Gabb, Tinberg, \& Weisberger, 2011; Tinberg \& Weisberger, 1998), and his theory, joined with the bridge metaphor and notion of active learning (Blimling, et al., 1999; Dewey, 1916), is important to this study and the concept of the ULtra Transfer Program for two primary reasons: First, in the traditional use of the theory, it is important for college faculty and staff at both the two- and fouryear institutions to recognize that students will enter at varying levels (or orders) of development. For these students to succeed, their ways of knowing and making meaning should be recognized and respected. Likewise, students' learning should be situated in their current understanding. For ULtra, this means that the design of the program and the ways in which the academic advisors interact with program participants should presumably be in line with this philosophy in order for maximal growth and development to occur. Given that most college students will enter school in the transition between 
orders 2 and 3 or 3 and 4 (Love \& Guthrie, 1999), advisors should take care to create advising sessions and learning experiences that produce a comfortable environment for the student. Advisors should also work with students to mutually construct meaning as well as facilitate the necessary stretching that must occur for students to continue to grow. Kegan (1994) distilled his thinking down to the clear reality that in order for an environment to promote the growth of its members they must always experience an expert combination of challenge and support (Sanford, 1966). In referring to Kegan's philosophy, Baxter Magolda (2002) stated that "successful journeys, even short ones, require good company" (p. 2). It is in this spirit of good company and of challenge and support that the ULtra program must strive to aid students in their transitions. Ultimately, faculty and staff should strive to help students move through the orders, with the eventual goal of reaching order 5, interindividual. However, reaching the last order is fairly rare and never occurs before a person reaches their forties, and it centers on relationships and interdependence (Kegan, 1994).

Second, and perhaps a bit more abstractly, this bridge metaphor can be expanded as a way to conceive of the entire transfer program process; after all, what is a transition program if not a bridge from the community college to the four-year institution?

Community college students' ways of making meaning are context specific, with the notion of transferring and earning a bachelor's degree more abstract than they may be ready to grasp fully. Helping these students navigate the path from where they begin to where they (and the college) would like them to be could utilize the same process that Kegan discusses (bridge building), which aids in students' overall growth. To begin, it is important to meet the students where they are both mentally (the order and transition in 
which they reside) and physically (the community college). An educator needs to first understand how the student comprehends the world (his or her education, outside commitments, etc.). Then, knowing the preferred end goal (transfer and ultimately graduation), it is up to educators (faculty and staff) to help students make the active journey from one place to another through their experience, reflection, integration, and application.

\section{Student Involvement Theory}

Schuh, Upcraft, and associates (2001) point out that there are many problems with the way studies attempt to quantify student academic success. Given the multitude of demographic, background, and academic characteristics students bring with them to college, as well as the educational experiences they have during their time in college, it is difficult to account for all of the relevant variables. To put it bluntly, "what is wrong with these studies is that, at best, they do not tell the whole story; at worst, they tell the wrong story" (Schuh, et al., 2001, p. 250). What experts in higher education assessment and theory agree on is that Astin's student development theory (1984/1999), which has become an important element in his input-environment-outcome (IEO) model (1991; 1993), does a relatively good job of organizing both pre-college and educational variables that work to affect student outcomes of success (Pascarella \& Terenzini, 1991; Schuh, et al., 2001) and has been used in the study of community college students (Wilmer, 2009). Astin (1984/1999) referred to student involvement as "the amount of physical and psychological energy that the student devotes to the academic experience" (p. 518). For example, he explains how students categorized as highly involved dedicate considerable physical and psychological energy to activities such as studying, interacting with 
professors and students, and participating in student activities. Students categorized as uninvolved do not commit their energy to these types of educational endeavors. Astin intentionally discusses student involvement in terms of behavior because he feels that, apart from what a student thinks or feels, it is what he or she does that defines involvement.

In his original framing of the theory, Astin (1984/1999) offered five basic postulates:

1. Involvement refers to the investment of physical and psychological energy in various objects. These objects may be highly generalized (the student experience) or highly specific (preparing for a chemistry examination).

2. Regardless of its object, involvement occurs along a continuum; that is, different students manifest different degrees of involvement in a given object, and the same student manifests different degrees of involvement in different objects at different times.

3. Involvement has both quantitative and qualitative features. The extent of a student's involvement in academic work, for instance, can be measured quantitatively (how many hours the student spends studying) and qualitatively (whether the student reviews and comprehends reading assignments or simply stares at the textbook and daydreams).

4. The amount of student learning and personal development associated with any educational program is directly proportional to the quality and quantity of student involvement in that program. 
5. The effectiveness of any educational policy or practice is directly related to the capacity of that policy or practice to increase student involvement. (p. 519)

Astin further states that this theory of involvement stresses that students are active participants in their own learning. Astin also notes that the most valuable capital an institution possesses might be students' time; a student's ability to reach various developmental goals is directly related to the amount of time and energy he or she dedicates to the activities that are created to help achieve those goals.

The theory that students must be actively involved in their own learning and commit their time and effort to the programs and activities that will aid in their success fits nicely with the design and function of the ULtra Transfer Program as it was discussed previously. Utilizing Astin's five postulates, we first recognize that students self-select to participate in this transition program designed to aid in their successful transfer to the University of Louisville. Students commit their time and energy and actively engage with ULtra to increase their chances of reaching their goal to earn a bachelor's degree. Participation in ULtra could have an interesting effect on what Astin (1984/1999) refers to as the "zero-sum game" (p. 523), "in which the time and energy that the student invests in family, friends, job, and other outside activities represent a reduction in the time and energy the student has to devote to educational development" (p. 523). Given that community college students are more likely to attend school part time, work, and have other outside commitments (Choy, 2002; Duggan \& Pickering, 2008; Wang, 2009), participation in the ULtra program, which is in part designed to help them make the best use of their educational time (mainly by ensuring the classes they take are the most beneficial in terms of transferability), could in the long run of their educational career 
save them a substantial amount of time. Saving students time, which also saves them money, may help lead to higher persistence (Townsend, 2008; U.S. Department of Education, 2006).

Secondly, Astin (1984/1999) notes that "involvement occurs along a continuum" (p. 519). Students choose to participate in ULtra programming to varying degrees; some attend events and activities regularly, while others may only seek the advice of an advisor periodically when scheduling classes. The degree to which they participate may change over time depending on their needs or other commitments. Thirdly, Astin recognized that involvement has both quantitative and qualitative components, which can be analyzed to ascertain how much time and effort are put into an activity (like ULtra). As an extension of this idea, Astin notes in his fourth postulate that the amount of learning and development achieved by a student is directly related to the quantity and quality of their efforts. For students in ULtra this means that, in theory, attending and fully engaging in events, activities, and advising sessions should lead to more learning and development. Finally, "the effectiveness of any educational policy or practice is directly related to the capacity of that policy of practice to increase student involvement" (Astin, 1984/1999, p. 510). This study is designed to help determine if ULtra is an effective educational program, which increases student involvement and, by extension, student success.

\section{Summary}

Kegan's bridge metaphor (Kegan, 1982; 1994; Blimling, et al., 1999) helps to explain the importance of understanding where students reside developmentally, given where they reside educationally, so that educators are able to meet them where they are. The metaphor is a reminder to faculty and staff involved with community college 
students that the desired result (in this case, successful transfer to, and persistence at, a four-year institution) is achieved by being "good company" to the students and providing an appropriate balance of challenge and support. To be good company, one must situate the learning in the students' experiences, validate them as knowers, and then work to mutually construct meaning. In so doing, practitioners will help build the bridge to transfer student success.

Astin (1984/1999) provides a compelling framework in his theory of student involvement. Students who are actively engaged with their environment and in academic activities are more likely to be successful. In working with transfer students, it is helpful to remember that the quantity and quality of time and effort that a student is willing to invest in a program is directly related to his or her learning and achievement of desired outcomes. It stands to reason that students who seek out and utilize the ULtra program invest more time and effort in their education and are therefore more likely to be successful. The more opportunities the transfer program provides for students to become actively involved with their learning and goal setting, the better.

The initiatives generated by the ULtra program discussed earlier in the chapter seem to fit within the theoretical framework presented here. ULtra provides students with the opportunity to become more involved both academically and socially at JCTC and UofL. Through programming, students have the ability to connect to campus and their goals at UofL, presumably making them more likely to achieve their goal of earning a bachelor's degree. The Leaders Exploring Advanced Degrees (L.E.A.D.) program even goes one step further in its reach, attempting to inspire students beyond the bachelor's degree. All ULtra students are encouraged to sign up for afternoon trips to visit with 
faculty from the university's dental, medical, law school, etc. to get a closer look. The program was designed to provide students "an opportunity to find out how to prepare themselves academically to be competitive applicants to such post-baccalaureate programs. This program continues to be in demand and is assessed by participants to have an impact on their academic habits and actions" (A. K. Tonnemacher, personal communication, March 29, 2011). The L.E.A.D. program is one example of how these important features of ULtra, along with the structured academic advising and Academic Program Plans (APPs), should make a difference when comparing ULtra students to students who do not participate in transfer programming.

\section{Literature Review}

The literature is rich with research on higher education and the myriad ways students navigate through the system. The community college is the path most relevant to this study and will be thoroughly addressed in this review. Issues hindering student transfer will be discussed to help identify how community colleges and four-year institutions can, and are, working together to help students in their college career.

\section{Higher Education: A Statistical Overview}

NCES data reveal that in 2010, overall, more high school graduates enrolled immediately in a four-year than a two-year institution (41\% vs. 27\%) (Aud et al., 2012). Interestingly, the immediate enrollment at four-year institutions is lower for male (34\%) than female (49\%) high school completers, but the enrollment at two-year institutions immediately following high school is not significantly different for either gender $(29 \%$ vs. $25 \%$ respectively) (Aud et al., 2012). With the increase in enrollment in degreegranting institutions, it stands to reason that the number of degrees earned also has 
increased (Aud et al., 2012). For 2009-10, the number of degrees earned rose to 3.35 million across all degree types. Specifically, associate's degrees increased by $50 \%$ to 849,452 degrees, while bachelor's degrees increased by $33 \%$ for a total of 1.65 million (Aud et al., 2012). More and more, students attempt to earn a college degree because they believe it will help them get a better job and increase their income (Pascarella \& Terenzini, 1991; Sandy et al., 2006).

An undergraduate college degree has become critical for social and economic success, so much so that Pascarella and Terenzini (1991) have referred to the bachelor's degree as "a passport to the American middle class" (p. 369). According to data from NCES, students' perceptions that a college education will help them make a better living are accurate; data from 2008 indicate that overall, 65\% of young adults (ages 25-34) were employed full time for a full year (Aud et al., 2010). Seventy-two percent of young adults with a bachelor's degree or higher were employed full time for a full year, compared to $62 \%$ of young adults with a high school diploma or equivalent certificate (Aud et al., 2010).

Even across gender and race/ethnicity, young adults with a bachelor's degree had higher median incomes than their counterparts with less education, earning $\$ 46,000$ on average compared to $\$ 36,000$ for those with an associate's degree and $\$ 30,000$ for those with only a high school diploma or equivalent (Aud et al., 2010). Not surprisingly, the general demographic trends are still supported with regard to median income for young adults, with males holding a bachelor's earning on average $\$ 11,000$ more than females $(\$ 53,000$ vs. $\$ 42,000)$, and White young adults $(\$ 47,000)$ with a bachelor's degree earning more than Black $(\$ 40,000)$ or Hispanic $(\$ 42,000)$ young adults (Aud et al., 
2010). Earning a bachelor's degree provides a clear financial advantage, but just getting started on the right path can be difficult. For some students, beginning at the community college is their only option; others choose to begin at this level.

Even though the opportunity for increased future earnings rises with level of education, the current economic climate has forced federal and state governments to increase tuition and fees at unprecedented rates, requiring students to make difficult financial decisions about their college careers (Bueschel, 2009; Sandy et al., 2006; U.S. Department of Education, 2006). Anderson, Alfonso, and Sun (2006) argue that the increasing fiscal demands on state government officials have necessitated that monies be funneled away from higher education and into other public mandates such as Medicare, Medicaid, OSHA, ADA, etc. This suggests that state representatives see community colleges and articulation or transfer agreements as cost-saving techniques for higher education (Anderson et al., 2006). With less funding going to higher education, institutions of all types and sizes are forced to make up the financial difference on their own.

The continuing rise in cost for higher education is a factor that cannot be ignored in the discussion of college choice. Information gathered by NCES shows that price for undergraduate tuition, room, and board rose $32 \%$ over the last ten years (Snyder \& Dillow, 2010) and is expected to double by 2015 (Anderson, Alfonso, \& Sun, 2006). If this occurs, it is projected that approximately half of the student population will not be able to afford college. For four-year public institutions, the average cost (in current dollars) of tuition, room, and board is $\$ 14,256.00$. The average cost for two-year institutions is just over half that amount at $\$ 7,567.00$ (Snyder \& Dillow, 2010). Students 
not only choose two-year colleges because of affordability, but also because of their location and open enrollment admission policies (Anderson, Sun, \& Alfonso, 2006). Family income plays an important role in when, if, and where a student enrolls in college. NCES data for the 2008 school-year indicate that immediate college enrollment for students from low-income families trailed that of high-income families by $25 \%$ (57\% vs. $82 \%$ respectively), while the gap between middle-class students and high-income students was 17\% (Aud et al., 2010). Lower income students are also more likely to begin at the community college (Duggan \& Pickering, 2008) and are more likely to attend parttime (Goldrick-Rab \& Pfeffer, 2009). For the past 40 years, part-time enrollment has accounted for over half of all enrollment at community colleges, which is typically double that of public and private four-year intuitions (Provasnik \& Planty, 2008). Parttime enrollment is not as conducive to transfer. Research indicates that taking at least 12 credit hours (full-time) increases the probability by up to $15 \%$ that a student will transfer (Doyle, 2009).

\section{The Community College}

Many students who otherwise may have chosen to start at the four-year college now make the decision to take some or all of the first two years' worth of college coursework at a community college, with plans to transfer to the four-year at some point (Dougherty \& Townsend, 2006). Given that over $40 \%$ of college students are enrolled in community colleges (Provasnik \& Planty, 2008; U.S. Department of Education, 2006), understanding the history of community colleges and how they affect students is critical to the success of future programs and initiatives. 
Foundations. Public two-year institutions were first proposed in the mid-1800s as a way to minimize the demand on universities to offer general education courses to high school graduates (Jurgens, 2010). The Morrill Act of 1890 was created to open public higher education to all students, including women and minorities. The Act required states to show proof that race was not a criterion for admissions, or that separate land grants were designated for minorities (Jurgens, 2010). Absent in actual practice in the United States until the beginning of the twentieth century, the first official community college on record was Joliet Junior College, founded in 1901 (American Association of Community Colleges [AACC], 2006, "Community Colleges Past to Present"; Dougherty, 1987).

With community colleges originally designed as an extension of high school and focusing on general studies, officials from several prominent universities advocated to modify the higher education system. Officials wanted something more akin to the European model, which allowed universities to focus on true scholarship, leaving the vocational and technical training to the junior college (Jurgens, 2010). In hopes of reducing the unemployment that was plaguing the county, the Great Depression brought to community colleges a new mission centered on job training. The end of World War II coupled with the enactment of the G.I. Bill in 1944 created the need for more local options in higher education. The historic Truman Commission Report in 1947, also known as the "Higher Education for an American Democracy" report, paved the way for two-year institutions to become "genuine academic institutions" (Jurgens, 2010, p. 254). In 1958 the Joint Committee on Junior and Senior Colleges was formed and research began on transfer credits and articulation to help rectify problems community college students had when attempting to transfer to the four-year institution (Jurgens, 2010). 
By the 1960s there was a network of 457 public community colleges, and by 1974 that number was quickly approaching 900 (Jurgens, 2010). The number of community colleges across the nation reached its peak in 1997 with 1,092 institutions, then dropped to 1,024 by 2008 (Provasnik \& Planty, 2008; Snyder \& Dillow, 2010). Even with the slight decline in the number of two-year institutions, the number of students they serve has continued to rise, accounting for approximately $43 \%$ of the postsecondary population in 2008 (Provasnik \& Planty, 2008). Today, community colleges can be found throughout the country in a variety of community types, with NCES data showing $29 \%$ in cities, $29 \%$ in rural areas, $24 \%$ in towns, and $18 \%$ in suburban areas (Laanan, 2001; Provasnik \& Planty, 2008). Even though the two-year college system has staked its claim in the realm of higher education, there is still much debate as to what role these institutions actually serve.

Major community college philosophies: A brief overview. There are four major historical-conceptual frameworks often used to view the origins and true purpose of community colleges, which Anderson, Alfonso, and Sun (2006) categorized to provide a clear overview. Functionalists typically argue that community colleges both serve to provide vocational and technical skills to those seeking terminal degrees, as well as to provide an avenue to transfer for qualified students hoping to earn a bachelor's degree (Anderson et al., 2006). Neo-Marxists, on the other hand, are critics of the community college system. This group attests that these institutions only serve to cool out (Clark, 1960) the educational aspirations of minority (female, ethnic/racial minority, workingclass, etc.) students, where they will ultimately end up tracked into vocational and technical programs (Anderson et al., 2006). 
Institutionalists view the community college as a necessary repository for the growing numbers of students who began seeking postsecondary degrees in the second half of the $20^{\text {th }}$ century (Anderson et al., 2006). Administrators at state universities began to worry that their degrees would depreciate once too many students entered into the system. Community colleges were seen as a "catch all" for students who could complete terminal degrees at the two-year college. Finally, there are the Statists. This contingent posits that "the contradictory nature of community colleges is attributed to the multiple goals and the different influences and forces, both ideological and economic, that constrain and shape the evolution of these institutions" (Anderson et al., 2006, p. 426). The argument continues by stating that state and local officials juggle both the needs of community businesses for skilled laborers and the appeals from their constituents for higher education opportunities against their own desires to remain in power. These officials ultimately land on community college education as the best resource for their electorate (Anderson et al., 2006). Unfortunately, that electorate (and potential student body) is as diverse as the philosophies that define the community college system.

General population. As previously mentioned, community colleges were, in part, designed to provide access to students who would be otherwise excluded from higher education (Jurgens, 2010; Laanan, 2001; Lee \& Frank, 1990). The term democratization is used to describe this function of the community college (Melguizo \& Dowd, 2009; Rouse, 1995). These students are typically ethnic minorities (40\%), first generation (42\%), and/or those who are otherwise ill-prepared for college-level work (AACC, 2009, "Fast Facts"; Bragg, Kim, \& Barnett, 2006; Laanan, 1996). Approximately 50\% of minority students will begin their college career at a community college; a notable 
percentage given that minority students make up less than $25 \%$ of all students enrolled in higher education in the United States (Cuseo, 2001). The average age of a community college student is 28 , with $46 \%$ of the student population 21 years old or younger. Like their four-year counterparts, community colleges enroll more women $(56 \%)$ than men (44\%). Approximately $40 \%$ of the first-time freshmen are enrolled at a two-year institution (AACC, 2009, "Fast Facts").

The community college system has been dubbed an "anti-academic student culture" (Dougherty, 1992, p. 195) by its opponents. This label refers to both the students who attend these institutions, as well as the faculty. According to Dougherty (1992), a large portion of community college goers, primarily the working-class and minority students, are seen as being ambivalent about their education. Fears of failure and rejection by their family and friends inhibit students from becoming actively engaged in their own learning. Then there are the professors who, "noting the unselective character of their institutions... tend to have low expectations of their students, perceiving them as largely lacking academic ability and motivation" (Dougherty, 1992, p. 195). Because of this difficulty, some professors are inclined to focus on teaching only a few students while the rest fall by the wayside (Clark, 1960; Dougherty, 1992). This lack of attention and support only deepens the divide between the educational quality of two- and fouryear schools (Sandy et al., 2005). Students educated within this system continue to fall behind their four-year counterparts (Carlan \& Byxbe, 2000), begging the question of whether the community college provides a "gradual transition to the rigors of college life" (Hills, 1965, p. 201) or decreases chances of baccalaureate degree attainment, as most researchers suggest (Anderson, Alfonso, \& Sun, 2006; Astin, 1984/1999; Cuseo, 
2001; Hood et al., 2009; Pascarella \& Terenzini, 1991; Rouse, 1995; Townsend \& Wilson, 2006).

Major populations. The multiple missions of two-year institutions have come about due to both large scale demands and the sundry populations these schools strive to educate (Dougherty \& Townsend, 2006; Melguizo, Hagedorn, \& Cypers, 2008). While community colleges offer continuing education, developmental education, and community service components, two of the principal groups currently served are potential transfer students and vocational and technical students (also known as career and technical education [CTE] students) (Cohen \& Brawer, 2008; Dougherty \& Townsend, 2006; Levesque et al., 2008). It is worthwhile to note that there are important behaviors and characteristics of these two groups that can cause them to overlap (Cohen \& Brawer, 2008; Fredrickson, 1998). A 2001 NCES report examined the varying definitions of "transfer", determining that at the community college level, eight are commonly used throughout the research (for a complete list of definitions, see Bradburn \& Hurst, 2001). The definition for the current study is simplified by the fact that only students who have successfully transferred to the four-year institution will be analyzed. However, the paths students take through the community college to eventually transfer are varied (Bradburn \& Hurst, 2001; Cohen \& Brawer, 2008).

The CTE track at a community college is designed to teach specific skill sets and knowledge related to a particular occupation or career, typically involving the application of information and less theory-based learning (Levesque et al., 2008). The academic track (most suitable for transfer of credits to a baccalaureate program) is more theoretical in nature and designed to teach students the skills and knowledge that embody a particular 
subject area (Cohen \& Brawer, 2008; Levesque et al., 2008). For ease of comparison, only associate's degree-seeking students in either CTE or an academic track will be compared on relevant characteristics in this section. When compared to CTE students, students in the academic track are more likely to be male (41\% vs. $38 \%)$, Hispanic (15\% vs. $13 \%$ ), younger than 25 (75\% vs. $63 \%$ ), single ( $80 \%$ vs. $69 \%$ ), financially dependent ( $51 \%$ vs. $35 \%$ ), work part time ( $44 \%$ vs. $38 \%$ ), and attend school part time, for part of the year (30\% vs. $28 \%)$. Academic track students are also more likely to have a parent(s) who hold(s) at least a bachelor's degree (35\% vs. $29 \%$ ), and have between a 2.0 and 3.49 GPA (63\% vs. $60 \%$ ), while they are less likely to receive financial aid (41\% vs. $49 \%$ ) (Levesque et al., 2008).

Though there are some differences in the demographics of these two student populations, their membership into one group or the other is not as clear as once thought (Fredrickson, 1998). Studies on CTE students have shown that, in some cases, up to $25 \%$ intend to transfer at some point (Cohen \& Brawer, 2008). Other studies indicate that between $5 \%$ and $30 \%$ of CTE students transfer to a baccalaureate program, regardless of their initial intentions (Cohen \& Brawer, 2008). NCES data reveal that approximately $40 \%$ of CTE students will leave higher education without any kind of credential (Levesque et al., 2008). Given that students may change their trajectory at any point during their schooling, it is difficult (if not impossible) to place a definitive label on a student until her or she drops out, transfers, or graduates (Best \& Gehring, 1993). Chapter three's limitation section will discuss CTE students as they relate to ULtra and the current study. What these groups of students do have in common is that their educational goals 
have brought them to the community college, which consists of a different population than four-year institutions.

Transfer Population. While some research estimates that up to half of community college students either do not aspire to or do not make it to transfer (Bradburn \& Hurst, 2001), some students successfully navigate the two-year college system and at least make it to the four-year college or university. So, who are these students? Researchers have found that transfer students are often members of a higher social class (Lee \& Frank, 1990; Melguizo et al., 2008), less likely to be female (Lee \& Frank, 1900) or from an ethnic/racial minority, and more likely to have a socioeconomic status (SES) that closely matches that of native four-year students (Lee \& Frank, 1990; Melguizo et al., 2008). Parental education is a commonly used demographic variable to aid in the prediction of college student success, as it can serve as a proxy for SES (Campbell, 2009; Chen, Martin, \& Matthews, 2006; Crisp \& Nora, 2010; Lewis \& Oppenheimer, 2000) and is highly correlated with students' immediate entry into higher education (Aud et al., 2010). NCES data reveal that, since 1992 (the first year data was collected), high school graduates whose parent(s) held at least a bachelor's degree were more likely to enroll in college immediately following high school compared to students whose parents' highest level of education was high school or less ( $82 \%$ vs. 54\%) (Aud et al., 2010). Astin (2005) found that completing the baccalaureate degree in four years was positively and significantly related to father's education level. Correlated with parental education level, Pell Grant eligibility is based on a student's estimated family contribution (EFC) to financially support their education (Chen \& DesJardins, 2008; Lips, 2011; Mahan, 2011) and can also be used as a proxy for SES. 
Based on the Kentucky Transfer Feedback Report for KCTCS students in 200708 , students transferring to a four-year public school were generally White (87.4\%), female (61.2\%), traditionally-aged (24 and younger) $(57.7 \%)$, and enrolled full time at the four-year institution (73.4\%) (KY CPE, 2010, "Transfer"). According to Lee and Frank (1990), transfer students were also more academically-oriented in high school, were twice as likely to have been on the academic track, and scored significantly above their community college peers in twelfth-grade achievement. Overall, transfer students more closely resembled four-year starters than they did other community college students. In fact, research shows that transfers earned significantly higher grades in the first two years than native students (Glass \& Harrington, 2002), yet their transition is inevitably rocky (Laanan, 1996; Leigh \& Gill, 2004). A looming question is whether or not the education and/or services students receive at the community college adequately prepare them for the next step in their college career.

\section{Does the Community College Help or Hinder Student Success?}

A great deal of research presented here and elsewhere in the field shows that attending a community college can be detrimental to a student's educational goals (Dougherty \& Townsend, 2006; Kinnick \& Kempner, 1988; Pascarella \& Terenzini, 1991; Prager, 1993; Zamani, 2001). Though this study will return to identifying some issues that have a negative effect on student outcomes, it is important to discuss some of the reasons why community colleges are both appealing, and potentially helpful, to students. The lower cost of tuition, coupled with the convenience of a local campus (O'Banion, 2010), make the two-year college ideal for students who have family commitments, need to live at home, and/or need to work while attending school part time 
(Melguizo et al., 2008; Townsend, 2007). Due to the open access policies at most of these institutions, community colleges cater to students with lower grades and those for whom developmental coursework will be a requirement (Hawley \& Harris, 2006; Hoyt, 1999; Townsend, 2007).

Often times, these underperforming students are the ones who feel unsure about college and their academic future. The smaller campus, smaller class size, and a faculty that is more focused on teaching than research can certainly be a draw (Townsend, 2007). In line with the conceptual framework for this study, Townsend (2007) describes the community college as a "bridging experience" (p. 130) for students who need more attention, further noting that the two-year college "serves as a bridge from the local high school to a 4-year institution that is just too intimidating to attend initially; this underscores the importance of the transfer function for the community college and its students" (p. 130). According to Pascarella and Terenzini (2005), studies show that when the institution is functioning as it should, the community college environment can help improve students' "critical thinking, analytic competencies, and general intellectual development" (p. 600) and that successful campuses are ones that stress frequent facultystudent interaction and faculty concern for students' growth. If students form close relationships with their professors and have a positive academic experience, it may help them to be successfully retained at the community college (Melguizo et al., 2008; Tinto, 1975). Tinto (1975) suggests that "where expectations have been enhanced as a result of one's experience in college, upward transfer may be the outcome" (p. 97). Faculty interaction has been shown to increase both the social and academic integration of 
students (Tinto, 1975). If this is the case, then why are community college students still failing to succeed?

Some critics claim that faculty at the community college level have fallen short of these expectations of connection and stronger emphases on student learning and are watering down the curriculum. According to Lee and Frank (1990), "with a considerable proportion of the curriculum devoted to either remedial or vocational training, the typical community college does not deliver a highly demanding academic program for the majority of its students" (p. 179). It is certainly difficult for professors to accommodate such a diverse student body, and students suffer as a consequence (Bueschel, 2009). Professors have also been accused of coddling students, with some reports showing that faculty were as much as a letter grade more lenient in some subjects than faculty at fouryear institutions (Carlan \& Byxbe, 2000). This potential grade inflation, coupled with the student population and less rigorous demands, can be a hindrance to adequate learning and can affect transfer students later in their career at the senior institution (Laanan, 1996).

Rouse (1995) discusses the act of community colleges attracting students who might otherwise have been prepared for and attended a four-year institution as the diversion effect. Of the roughly 7.7 million students at two-year institutions (Aud et al., 2012), it is estimated that between $30 \%$ and $40 \%$ expect to earn their bachelor's degree (Dougherty, 1987). Research has shown that students who start at the community college with such degree aspirations are $15 \%$ less likely to do so than students who begin at a four-year school, even when matched on common variables (such as SES, high school ability, academic aptitude, race/ethnicity, gender, educational aspirations, etc.) (Cuseo, 
2001; Ishitani, 2008; Townsend \& Wilson, 2006). For students intending to earn a baccalaureate degree, this diversion to the community college, while saving them money, may cost them their future. To even have a chance at achieving this goal, students will have to transfer to a four-year institution, and it is up to both institutions to help get them there.

The transfer function. Aside from CTE, transfer is one of community colleges' most important functions (Johnson, 2005; Laanan, 2007). Senior institutions depend on transfer students to round out their enrollment each year. In fact, according to Glass and Harrington (2002), "Wilson (1983) stated that at the outset, the primary function of the junior college, now community college, was to provide two years of course work suitable for transfer to four-year institutions" (p. 415). As discussed, students who know they intend to transfer to a four-year institution typically enroll in the liberal arts (academic) track, leading to either an associate of arts or science degree, though some studies indicate that students in CTE tracks are just as likely to transfer (Cuseo, 2001). The multifunctional nature of two-year institutions makes it difficult to serve the needs of such diverse populations. Anderson, Alfonso, and Sun (2006) note that "according to Dougherty, the contradictory character of community colleges is grounded in the following reality: Two-year institutions are both reproducers of inequity and the promoters of social mobility" (p. 423). Given the difficulties already discussed, students who do make the jump from the community college to the four-year college or university still face a few more hurdles.

Transfer problem \#1: Timing. Students transfer with varying levels of college coursework and with varying degrees of success (Palmer, Ludwig, \& Stapleton, 1994). 
Research by Palmer et al. (1994) indicates that approximately $1.8 \%$ of students transfer after earning between 1 and 12 credit hours, $4.4 \%$ between 13 and 24 credit hours ( 24 would be the equivalent of two full-time semesters), $18.3 \%$ after the completion of their general education requirements (Gen Eds), and 32.7\% after they complete their associate's degree (AA or AS), which is typically 60 credit hours or more. Transferring with anything fewer than 60 credit hours or an associate's degree is considered lower division. Transferring with 60 plus credits or an associate's degree is considered upper division since the student will be able to move directly into major coursework. The Kentucky Transfer Feedback Report for KCTCS students in 2007-08 indicated that students transferring to a four-year public school typically transferred in 60 or more credit hours (51.5\%). However, while 60 or more credit hours could equal an associate's degree, only $25.6 \%$ transferred in with that credential (KY CPE, 2010, "Transfer"). It could be that students take a variety of courses (making up the 60 hours) but without a central focus, leading to an accumulation of credits, but no degree. Transfer research shows that students transferring into the upper division are more successful than those who transfer into the lower (Best \& Gehring, 1993; Townsend \& Wilson, 2006). The Kentucky Transfer Feedback Report included graduation rates four years after transfer, indicating that $61.9 \%$ of students who had transferred with an associate's degree had graduated, as compared to $52.7 \%$ of students with 60 or more credit hours but no degree, and $30.4 \%$ of students with fewer than 60 credit hours and no degree (KY CPE, 2010, "Transfer"). Completing the transfer is one important step in the process, and the number of credits students are able to bring with them is another. 
Transfer problem \#2: Credits. One issue that many transfer students face is the loss of credits when making the transition to the four-year institution (Davies \& Dickmann, 1998; Dervarics, 2007). Dougherty (1992) compiled evidence that at least $58 \%$ of students around the country reported losing credits when transferring, $29 \%$ of those losing 10 or more hours. Moreover, approximately $25 \%$ of students indicated that even when they received credit for courses, some of those credits were not counted toward their major requirements. For community college students who are already struggling, this loss of credits means spending more time in school then they had planned for, either academically or financially. Two- and four-year colleges share the blame for the issues in transferring credits. The community college needs to do a better job ensuring that the classes they offer are transferable, and the four-year institution should do a better job at communicating the course requirements. Senior institutions could also be more reasonable with the credits they accept, including awarding credits for the same grades (a "D" for example) that they award native students.

Transfer problem \#3: Transfer shock. Apart from when a student transfers, there are some pitfalls they will face once they enter their new academic home (Laanan, 2007). Unfortunately, these obstacles translate into failure to earn a degree for over half of the students who make the decision to transfer (Best \& Gehring, 1993). The sudden drop in academic performance that transfer students typically experience within their first semester at a senior institution was termed "transfer shock" by Hills (1965, p. 202). Since then, the term has been used in myriad studies (Carlan \& Byxbe, 2000; Cejda, 1994; Flaga, 2006; Glass \& Harrington, 2002; Laanan, 2004) to represent the decline in grade point average (GPA) within the first year (two semesters) of transfer. In some studies, an 
estimated $76.7 \%$ of transfer students (Glass \& Harrington, 2002) experience a grade decline of 0.5 points (Hills, 1965; Kintzer \& Wattenbarger, 1985). If students make it through this rough patch, the majority of them will rebound within that first year (Diaz, 1992; Ishitani, 2008; Laanan, 2004; Townsend \&Wilson, 2006) and will closely resemble native students' GPAs (Carlan \& Byxbe, 2000; Glass \& Harrington, 2002). Unfortunately, the 'shock' alone could be enough for the student to drop out of school and never complete his or her degree (Dougherty, 1987; Glass \& Harrington, 2002). While transfer shock is measured by GPA, Laanan (2004) argues that its cause is not only academic, but social and psychological as well. It seems reasonable that transfer shock is, in part, caused by students having to acclimate to new surroundings, larger classes, a different group of students, and new professors (Best \& Gehring, 1993; Laanan, 2004). It is, in effect, a form of "culture shock" (Pascarella \& Terenzini, 1991, p. 58). According to Laanan (2007), transfer students need to possess the coping mechanisms to deal with the stressful adjustments of their "cross-cultural" relocation (p. 41). The skills will likely not come naturally to most students; they need to be fostered from the very beginning of the community college experience. The theories expressed by both Kegan $(1982 ; 1994)$ and Astin $(1984 / 1999)$ indicate that active involvement on the part of the students in forming an understanding of their environment and their experiences will aid in their development. This active involvement in their own learning inevitably will be an asset to students as they try to cross the bridge to the four-year institution and adjust to their new college home both academically and socially (Tinto, 1975). Researchers have interviewed students and studied various programs to find some key elements that should exist to help ease this transition even further. 


\section{Building Relationships between Community Colleges and Universities}

According to Eggleston and Laanan (2001), transfer students indicated "a need for more course articulation, counseling and advising, faculty sensitivity, academic support services, transfer student-centered orientation programs, student activities, and knowledge of campus resources" (p. 95). Community colleges and universities have begun to partner to create these types of resources. As previously mentioned, there is great benefit to each institution to help students be successful at both the community college and at the four-year institution once they transfer (Cheslock, 2003).

Townsend and Wilson (2006) point out that in order to "increase institutional transfer rates, individual community colleges are working to develop programs and relationships with specific four-year colleges to improve the transferability of students and courses" (p. 36). Some institutions have taken the additional step to develop special partnerships with the local four-year institution (Hood \& Hunt, 2009; Kisker, 2007). The working relationships often involve joint programming initiatives, improvement of advising for transfer, and the creation of transfer centers that specialize in assisting students with the issues that have been discussed in this review (Anderson, Sun, \& Alfonso, 2006; Zamani, 2001). Dougherty (1992) suggests that transfer advising specifically "would be improved by clearly labeling transfer courses, establishing centers at community colleges to centralize and disseminate transfer information" (Dougherty, 1992, p. 205).

Laanan (1996) makes the intriguing point that there is a fine line between adequately supporting community college students before transfer and taking care of so much for them that they are unable to take care of themselves. In his review of the 
Transfer Alliance Program (TAP), Laanan (1996) observes that "perhaps TAP students are at a disadvantage when they transfer to UCLA because of the change from a nurturing environment to one where they often feel anonymous" (p. 80). Dougherty (1992) recommends that would-be transfer students be familiarized with the four-year college campus through visits and tours, perhaps aiding in the transition students must make to the physical environment. From the psychological preparation to the familiarity with the physical landscape, community college transfer students must be adequately prepared for their transition without being coddled so much that they are unable to make it on their own at the four-year institution. It is with these kinds of objectives in mind that UofL and JCTC created the ULtra Transfer Program, with a goal to help students transfer at the appropriate time, with courses that will be accepted, followed by successful integration at UofL.

\section{Summary}

The review of literature provided in this chapter indicates a clear need for successful transfer support programs for community college students making the transition to the four-year institution. From the establishment of the first community college in 1901 to the present, students and communities have struggled with creating a seamless process to bridge the two- and four-year college experience. No matter whose perspective on how community colleges should function is in fashion, the fact is that a significant portion of college students use this system as an entry point into higher education (Aud et al., 2012; Hudzik, 2010). These students have every intention of transferring and earning a bachelor's degree. Therefore, it is the responsibility of 
practitioners in the field of higher education to help ensure that these students are able to meet their goals.

The relevant information in chapters one and two regarding Kentucky's efforts to aid community college transfer students provides the necessary background on the path that public postsecondary institutions have taken to help improve the transfer function and increase students' success. The ULtra Transfer Program grew out of Pathways for Success and has become a highly utilized transfer center for JCTC students preparing to transition. Though the program appears to be successful, in the six years ULtra has been in its current form, it has never been strategically assessed to determine the effects it has on transfer students. This study supplies the necessary analysis to make such a determination. The methodological approach taken to conduct research on the ULtra Transfer Program is discussed in the following chapter. 


\section{CHAPTER III \\ METHODOLOGY}

\section{Introduction}

The following chapter outlines the methodological approach for this dissertation research study. The design is addressed and the research questions are reintroduced along with their corresponding variables and assessment methods. A brief overview of the setting and demographics of the sample follows. Next, the data sources and collection procedures are discussed. The chapter concludes with potential limitations.

\section{Research Design}

The current study was designed to evaluate the effects of an academically-based intervention, the ULtra Transfer Program, on transfer student academic success. Students self-selected to participate (and the extent to which they would participate) in the program and were therefore not randomly assigned to a condition. As such, this research was conducted using an ex post facto design. The data used for this study, such as background characteristics, GPAs, credit hours, ACT scores, and persistence, were gathered from existing student record information kept by the Office of Institutional Research and Planning (IRP) at UofL, JCTC, and Jefferson County Public Schools (JCPS). When using existing data (or data collected "after the fact"), and/or data not specifically gathered for the question(s) under consideration, it is important to be aware of two things: First, any possible "causes" are studied after they have potentially had their effect. Second, it is important to attempt to control for other variables that may have had 
an influence on the measured outcome (Vogt, 2005). Groups were defined after the students self-selected into one of the two (Non-ULtra or ULtra). Therefore, it was important to verify that the background characteristics of students were similar and to control for any variables necessary (see "Variables" section for more detail). Controlling for variables, while not a perfect substitute, is an attempt to approximate a randomized experimental design. Though the ULtra Transfer Program is the only case that is under review for this study, it will allow for an in-depth analysis and potentially can be used as an example for similar programs at other colleges and universities.

\section{Population and Sample}

The ULtra Transfer Program's main office is located on the JCTC downtown campus, with academic advisors visiting other JCTC locations throughout the semester. Of the 650 to 680 students who transfer from JCTC every year, approximately two-thirds transfer to UofL (T. Newberry, personal communication, January 5, 2011). The population for this research study was defined as students who transferred from JCTC to the University of Louisville between spring 2006 and spring 2011.

\section{Variables}

The variables used in this study were drawn from relevant research cited in chapter two. Background variables most commonly used to study student persistence and success are gender, race/ethnicity, and socioeconomic status (SES) (Wang, 2009) and as such, they were utilized in this study. Pell Grant eligibility based on a student's estimated family contribution (EFC) was used as the proxy for SES (Lips, 2011; Mahan, 2011). Age was also included as a demographic variable in this study to help further determine if the participants in the groups were similar. Age is also the most common indicator of 
student status as either "traditional" or "nontraditional", and research indicates that traditional students are more likely to transfer than nontraditional students (Dougherty \& Kienzl, 2006). Age has also been found to influence retention, with relatively younger and relatively older students more likely to persist and graduate when compared to middle-aged (35-44) students (Berger, 1992). Variables measuring pre-college academic performance (high school GPA and ACT score) were also included to help establish baseline achievement for both groups prior to exposure to the independent variable (ULtra) (Berger, 1999; Lee \& Frank, 1990; Tinto, 1975; Townsend, McNerny, \& Arnold, 1993). The decision to control for certain variables in the analysis of any research questions is based on finding significant difference between the groups (Schuh, et al., 2001), the conceptual importance of the variables, and/or, in the case of low power (due to small sample size), based on the effect size (Bordens \& Abbott, 2002).

The independent variable has two levels, depending on the student participation: (a) the non-ULtra group is comprised of students who did not participate in the ULtra program while enrolled at JCTC, while (b) the ULtra group is comprised of students who joined ULtra at some point after they enrolled at JCTC. This could mean that they began participating in ULtra right away, attending the ULtra Orientation, and/or that they received academic counseling and participated in ULtra services at some point in their college career at JCTC.

The dependent variables were selected because of their relation to student academic achievement cited in the research, as well as their relation to the goals of the ULtra program. ULtra is designed to help ensure that students are taking classes that are academically appropriate, which should translate to greater achievement. JCTC credits 
attempted compared to JCTC credits earned should provide a ratio of how successful ULtra students were compared to Non-ULtra students. Also, research shows that the more credit hours a student earns before transfer, the more likely he or she is to earn a bachelor's degree (Best \& Gehring, 1993; Townsend \& Wilson, 2006). The ULtra program encourages students to complete more of their coursework at JCTC before transferring to UofL. JCTC credits earned was the indicator used to see if ULtra students did complete more coursework than other transfer students. The JCTC GPA is also an important variable because early academic performance "has been proven to be the single strongest predictor for degree attainment" (Wang, 2009, p. 574). In this study, the community college GPA was used to represent early college academic performance.

Academic advisors in the program are charged with helping students create an academic program plan (APP) that will lead to successful transfer. The courses outlined in the program plan are mapped out in accordance with the state transfer and articulation policies mentioned in chapter two. ULtra students should have a higher number of their JCTC credits transferred to UofL and applied to their major than Non-ULtra students. The comparison between the JCTC GPA and the UofL first and second semester GPAs was used to determine the students' levels of transfer shock and recovery (Hills, 1965). UofL first to second semester persistence was ascertained to see if ULtra students were retained at a higher rate compared to Non-ULtra students. Lastly, overall persistence was used as a final measure of "transfer student success" as it was the final component of the operational definition for this study. For a complete list of the variables with levels of measurement and coding, see Table 1 . 
Table 1

Background, Independent, and Dependent Variables

\begin{tabular}{|c|c|c|c|}
\hline $\begin{array}{l}\text { Type of } \\
\text { Variable }\end{array}$ & Variable & $\begin{array}{l}\text { Level of } \\
\text { Measurement }\end{array}$ & Coding \\
\hline \multirow{6}{*}{$\begin{array}{l}\text { Independent } \\
\text { background } \\
\text { variables }\end{array}$} & Age & Ratio & $20-37$ \\
\hline & Gender & $\begin{array}{l}\text { Nominal, } 2 \\
\text { levels }\end{array}$ & Male $=0 ;$ Female $=1$ \\
\hline & Race/Ethnicity & $\begin{array}{l}\text { Nominal, } 2 \\
\text { levels }\end{array}$ & White $=0 ;$ Other $=1$ \\
\hline & SES $(E F C=$ Pell Eligible? $)$ & $\begin{array}{l}\text { Nominal, } 2 \\
\text { levels }\end{array}$ & No $=0 ;$ Yes $=1$ \\
\hline & High School GPA & Interval & $0.0-4.0$ \\
\hline & ACT Score & Ratio & $0-36$ \\
\hline $\begin{array}{l}\text { Independent } \\
\text { variable }\end{array}$ & $\begin{array}{l}\text { ULtra Transfer Program } \\
\text { participation status }\end{array}$ & $\begin{array}{l}\text { Nominal, } 2 \\
\text { levels }\end{array}$ & Non-ULtra $=0 ;$ ULtra $=1$ \\
\hline \multirow{8}{*}{$\begin{array}{l}\text { Dependent } \\
\text { variables }\end{array}$} & JCTC credits attempted & Ratio & $0-99$ \\
\hline & JCTC credits earned & Ratio & $0-99$ \\
\hline & JCTC GPA & Interval & $0.0-4.0$ \\
\hline & JCTC credits transferred & Ratio & $0-99$ \\
\hline & UofL $1^{\text {st }}$ semester GPA & Interval & $0.0-4.0$ \\
\hline & $\begin{array}{l}\text { UofL } 1^{\text {st }} \text { to } 2^{\text {nd }} \text { semester } \\
\text { persistence }\end{array}$ & $\begin{array}{l}\text { Nominal, } 2 \\
\text { levels }\end{array}$ & No $=0 ;$ Yes $=1$ \\
\hline & UofL $2^{\text {nd }}$ semester GPA & Interval & $0.0-4.0$ \\
\hline & Overall persistence & $\begin{array}{l}\text { Nominal, } 2 \\
\text { levels }\end{array}$ & No $=0 ;$ Yes $=1$ \\
\hline
\end{tabular}

\section{University of Louisville}

\section{Setting}

Categorized as a metropolitan research university, UofL enrolls approximately 22,000 students (15,000 undergraduates) annually (Snyder \& Dillow, 2010). Of these students, about 17,000 are enrolled full-time. The student population is roughly $51 \%$ 
female, $75 \%$ White, and 25\% minority, with African Americans representing about $41 \%$ of the minority population (UofL, 2012, "Just the Facts") and has an average undergraduate age of 23 (UofL, 2012, "Common Data Set 2011-2012"). The UofL student body represents 117 Kentucky counties (with only three unaccounted for), 53 U.S. states and territories, and 107 countries. UofL conferred roughly 2,600 baccalaureate degrees out of 4,700 total degrees for the 2010-11 school year,. The school has about a $51 \%$ six-year graduation rate for first-time, full-time, baccalaureate degree-seeking students and a 78\% retention rate for the same students in 2011. The average ACT score for these students is 24.7 . In-state tuition is $\$ 4,465$ and out-of-state tuition is $\$ 10,825$ per semester. The university subsists on a $\$ 1.2$ billion operating budget, which includes \$178.5 million from the Commonwealth of Kentucky (UofL, 2012, "Just the Facts").

\section{Jefferson Community and Technical College}

Based in Louisville, JCTC is the largest of the 16 colleges within the Kentucky Community and Technical College system (KCTCS). Spread out over six campuses, the two-year college is a "comprehensive, public postsecondary intuition providing students access to a wide variety of programs of study" (JCTC, n.d., "A Brief History", para. 1). In the 2008-09 academic year, the school awarded just over 900 associate's degrees, 200 diplomas, and 1,600 certificates. Fall 2009 enrollment for JCTC was approximately 15,000 (down 3\% from 2007) (Snyder \& Dillow, 2010) with 61\% attending part time. The student population is $54 \%$ female with approximately $49 \%$ of students between the ages of 18 and 24 (KCTCS, n.d., "Colleges \& Campuses") and about 30\% minority (JCTC, n.d., "Visitors and Community"). 


\section{Data Sources and Collection Procedures}

Though this study was designed to determine if students who participated in the ULtra Transfer Program were more successful than those who did not, no students were actually engaged in the research process. As noted in the research design, the study utilized secondary data garnered from the PeopleSoft $\bigcirc$ Human Resource and Student Administration System which is used to house and maintain all student academic data (demographic, admission, transcripts, grades, financial aid, etc.) at UofL and JCTC. Included in this data was a student group indicator (ULTR) that specified which transfer students from JCTC participated in the ULtra program. The high school data (GPA and ACT score) for each participant were pulled from the Jefferson County Public Schools (JCPS) database. With the assistance of the UofL Office of Institutional Research and Planning (IRP), a Statistical Analysis System (SAS) query was developed to obtain the relevant data on both groups of students (Non-ULtra and ULtra). To ascertain the number of transfer credit hours students were able to apply to their major at UofL, degree audits were run for all participants. Research volunteers with the correct level of clearance to view student records at UofL then hand-counted number of credit hours for each student. All college data were pulled from PeopleSoft $\mathbb{C}$ for this study and can be found in Table 1. In order to maintain appropriate participant anonymity, IRP used SAS to create random identification numbers for each student. All identifiable student data (name, Social Security number, UofL ID, and JCTC ID) were removed before the data were handed over to the researcher for analysis. All participant data were treated in accordance with the "Ethical principles of psychologists and code of conduct" (American Psychological Association, 2002, p. 1061). 


\section{Research Questions and Analyses}

This study addressed the five research questions and their corresponding directional hypotheses. The data were analyzed using the Statistical Package for the Social Sciences (SPSS) (version 20) for Windows. A variety of statistical techniques were employed to respond to the questions presented in this section. For clarity, the methods used and their corresponding assumptions will be discussed first.

Group equivalence on background variables (e.g., SES, ACT score) was assessed using chi-square tests (for categorical data) and $t$-tests for continuous variables. Both tests require that the data are independent (i.e., that the scores of participants are unrelated to the scores of other participants). The $t$-test also carries the assumption that the data are independent, and has the additional assumptions that the variables are normally distributed and that the population variances of the groups are equal.

A variety of statistical techniques were used to analyze the dependent variables. When examining one dependent variable at a time, analysis of covariance (ANCOVA) was used to determine mean differences between the groups on continuous dependent variables, while controlling for extraneous variables (the covariates). The assumptions when using ANCOVA are that a linear relationship exists between the dependent variable and the covariates, that there is homogeneity of the regression slopes, and that the covariate(s) is measured without error (Stevens, 2002).

Multivariate analysis of variance (MANOVA) was used to analyze multiple related dependent variables while controlling for the potential correlations between them (Vogt, 2005). Multivariate analysis of covariance (MANCOVA) was used to determine between-group differences for questions with multiple dependent variables, while 
controlling for covariates. When using either MANOVA or MANCOVA, it is assumed that the observations are independent of one another, that the observations follow a multivariate normal distribution, and that the population covariance matrices are equal (Stevens, 2002).

Finally, a logistic regression analysis was conducted when outcome variables were dichotomous and the predictor variables were categorical or continuous, and used to determine if the probability of a participant belonging to a particular group (e.g., whether a student persisted) could be predicted based on their ULtra participation (Field, 2005). The level of significance for all statistical analyses was set at an alpha level of .05.

\section{Background Characteristics}

1. Do students who utilize the ULtra Transfer Program differ in background characteristics (age, race/ethnicity, gender, SES, high school GPA, ACT score) from non-ULtra transfer students?

$\mathrm{H}_{1}$ : The background characteristics of transfer students who utilized the ULtra Transfer Program do not differ from the transfer students who did not participate in ULtra (Non-ULtra).

i. IV: ULtra Program participant status as indicated in PeopleSoftC: "Non-ULtra" or "ULtra".

ii. DV: Participant background characteristics as indicated in PeopleSoft $\mathbb{C}$ : Age, race/ethnicity, gender, SES (EFC/Pell Eligibility as a proxy), high school GPA, and ACT score.

Analysis: The background characteristics race/ethnicity, gender, and 
SES were placed into cross tabulation in SPSS examined through Chisquare tests to determine whether or not there were statistically significant differences between the groups. The variable age was analyzed using an independent samples $t$-test in order to determine if there were any statistically significant differences between the group means (Non-ULtra and ULtra). The students' high school GPA and ACT score were analyzed using a multivariate analysis of variance (MANOVA) to see if there was a statistically significant difference among groups. See Table 1 for coding specifications. Background characteristics that were found to be statistically significantly different (or in the case of low power, variables found to have a small effect size) were controlled for during the testing of remaining research questions.

\section{Prior to Transfer (JCTC)}

2. Do students who utilize the ULtra Transfer Program complete more, and more appropriate, preparatory work at JCTC prior to transfer?

a. Do students earn a higher number of credit hours?

b. Do students have a higher ratio of credit hours attempted to credit hours earned?

c. Do students have a higher number of credit hours accepted toward their major?

$\mathrm{H}_{2}$ : Students with the ULtra Transfer Program have more appropriate preparatory work (work that will be accepted toward their major by the receiving institution) successfully completed prior to transfer. 
i. IV: ULtra Program participant status as indicated in PeopleSoftC: "Non-ULtra", "ULtra".

ii. DV: a) JCTC credit hours earned before transfer, as collected from PeopleSoftC and measured from 0 to $99 ;$ b) JCTC credit hours attempted collected from PeopleSoft $\subset$ and measured from 0 to 99 , and JCTC credit hours earned collected from PeopleSoft $C$ measured from 0 to 99 . The ratio of these credit hours will be used for the analysis; c) JCTC credit hours accepted towards the major upon transfer to UofL, as collected from PeopleSoftC and measured from 0 to 99 .

Analysis: Multivariate analysis of covariance (MANCOVA) was used to determine if there was a statistically significant difference among groups in pre-transfer preparatory work at the community college. See Table 1 for coding specifications. Covariates were those variables found to be important predictors of program participation (age, ACT, and high school GPA).

3. Do students who utilize the ULtra Transfer Program have a higher GPA at the time of transfer?

$\mathrm{H}_{3}$ : Students with the ULtra Transfer Program have higher JCTC GPAs at the time of transfer when compared to Non-ULtra transfer students.

i. IV: ULtra Program participant status as indicated in PeopleSoftC: "Non-ULtra" or "ULtra". 
ii. DV: Measure of transfer JCTC GPA as collected in PeopleSoftC on a scale from 0.0 to 4.0 .

Analysis: The JCTC GPA at time of transfer was examined using a oneway analysis of covariance (ANCOVA) in order to determine if there were any statistically significant differences between the group means (NonULtra and ULtra). See Table 1 for coding specifications.

\section{Post Transfer (UofL)}

4. Do students who utilize the ULtra Transfer Program suffer less transfer shock in their first year at the four-year institution?

a. Do students experience a smaller decline in GPA in the first semester?

b. Do students experience a greater rebound in GPA in the second semester?

$\mathrm{H}_{4}$ : Students with the ULtra Transfer Program experience less transfer shock in their first year at UofL, relative to Non-ULtra transfer students. IV: ULtra Program participant status as indicated in PeopleSoftC: "NonULtra" or "ULtra".

i. DV: a) JCTC GPA and UofL first semester GPA as collected from PeopleSoft $\subset$ on a scale from 0.0 to $4.0 ; \mathrm{b}$ ) UofL first semester GPA and UofL second semester GPA as collected from PeopleSoft $\mathcal{C}$ on a scale from 0.0 to 4.0 . Analysis: Two $t$-tests for independent samples were run to determine if there is a statistically significant difference among groups with regard to 
JCTC GPA and UofL first semester GPA and UofL first semester and second semester GPA. Difference scores were computed for JCTC GPA/UofL first semester GPA, and UofL first semester GPA/UofL second semester GPA. Additionally, two one-way ANOVAs were run to look for statistically significant difference between the two groups for first semester GPA and second semester GPA. See Table 1 for coding specifications.

5. Do students who utilize the ULtra Transfer Program have a higher persistence rate?

a. Do students have a higher first to second semester persistence rate?

b. Do students have a higher second to third semester persistence rate?

c. Do students have a higher overall persistence rate?

$\mathrm{H}_{5}$ : Students in the ULtra Transfer Program have higher persistence rates, relative to Non-ULtra transfer students.

IV: ULtra Program participant status as indicated in PeopleSoft $\mathrm{C}$ : "NonULtra" or "ULtra".

i. DV: a) Measure of UofL first to second semester enrollment as collected from PeopleSoft $\mathrm{C}$ measured "yes" or "no"; b) measure of UofL second to third semester enrollment as collected from PeopleSoftC measured "yes" or "no".

Analysis: The first-to-second and second-to-third semester persistence rates were computed into one variable and examined using a logistic 
regression equation in order to determine if a significant difference existed between the two groups.

\section{Limitations}

There are some limitations to consider in this study when reviewing the results presented in chapter four. First, any research that relies solely on existing data is limited in the ability to accurately account for other variables. Since surveys or focus groups were not employed, factors such as student employment, dependents/family responsibilities, and other variables that research suggests can contribute to transfer student success (Duggan \& Pickering, 2008) are not included as a part of the analysis. Not having access to self-reported data does create limitations, but the use of institutional student record data to obtain student academic information (high school GPA, ACT scores, JCTC GPA, UofL GPA, credit hours, etc.) is far more accurate than relying on students to report this information (Grubb, 1991; Sappington, Kinsey, \& Munsayac, 2002).

Second, the ULtra Transfer Program is still in the process of creating a strong practice of data gathering for program evaluation purposes. Currently, there are not centralized data which indicate which students use ULtra services on a consistent basis, how often they see an academic advisor, or which workshops and programs they attend. This data would help more clearly define true "ULtra" students from "Non-ULtra" students, and more specifically could even have allowed for a better analysis of "High Impact" ULtra students (those who use services consistently and have attended the specialized orientation) and "Low Impact" ULtra students (those who use ULtra services sporadically). While "Low Impact" students certainly should benefit from their 
participation in ULtra, the possibility that they made a few missteps before getting on the right track to transfer is higher than for the "High Impact" students. Students who began their college career as ULtra participants would have the advantage of receiving the very first possible intervention (Orientation), which was designed to immediately set them on the right path for transfer (meeting with an academic advisor to sign up for the right classes the very first semester, learning about the services ULtra has to offer, etc.). It would strengthen the findings for this study if these students could be analyzed separately.

Third, given that the ULtra Transfer Program is not mandatory, students selfselect to participate (and how much they participate). Background characteristics show that the groups appear to be from the same population (no significant difference between groups based on race/ethnicity, gender, or SES), though they do vary by age. What could not be ascertained was how student motivation played a role in their self-selection into the ULtra Transfer Program (Wang, 2009). It would stand to reason that students who are highly motivated to achieve and are focused on transferring to a four-year university would participate in programming that can help ensure they are successful. Students who are less motivated (and therefore potentially less likely to succeed) may not seek out ULtra services and be less successful in their transition. Again, without direct student contact through a survey or focus group, this study is unable to account for student motivation as a variable. Given this reality, prior academic achievement was used as somewhat of a proxy for motivation; analyses did not show that students who participate in ULtra have significantly higher pre-college academic characteristics (high school GPA or ACT scores) than non-participants. 
Fourth, ULtra is advertised to JCTC students as a program designed to aid in their transition to UofL. For students who know they want to transfer (presumably those in an academic/transfer track), this program would hold some appeal. However, current research suggests that transfer students do not always follow the "traditional" transfer path they once did. As discussed in chapter two, many students (some studies indicating up to $50 \%$ ) start in a technical or vocational track and yet still choose to transfer to a fouryear institution (Fredrickson, 1998). For these CTE students, ULtra may never have been on their radar, and therefore they did not benefit from the services. So, if we assume that students in the ULtra program are mainly those within an academic/transfer track, and that those students not involved in ULtra are either uninterested in the support or are in a vocational or technical track, a question would be how these students differ from one another. One example from research is that these groups of students differ in age, with students in the traditional transfer program significantly younger than those in an occupational track (Eggleston \& Laanan, 2001). Another potential difference reported by Fredrickson (1998) is that transfer students in a technical track had higher first and second semester GPAs after transfer, while students in the transfer track had higher second and third semester persistence rates after transfer.

Fifth, this research serves as an inter-institutional case study of one particular transfer program, ULtra. The specific design of the ULtra program should be considered when thinking about the results in terms of transfer program success in a more general context. Though there is no reason to believe that the transfer students in this study differ significantly from those nationally on any meaningful variables or characteristics, they 
will have to be compared to the larger body of research before findings can be generalized.

Finally, the ULtra transfer program has been in existence in its current iteration only since the 2005-06 school year. The goal was to be able to break the students up into three groups, "Non-ULtra", "Low Impact ULtra", and "High Impact ULtra". There was not a large enough sample to look at intensity data, so "Low Impact ULtra" and "High Impact ULtra" were collapsed into a single group. Even with this larger group of students, the time frame is relatively small in terms of student transfer. Grubb (1991) suggests that a period of at least seven years is necessary to begin to see transfer and, more specifically, graduation of transfer students. Fredrickson (1998) points out that community college students who transfer tend to "pause before, during, and after attending community colleges" (p. 53). Since the final measure of the operational definition of transfer student success in this study will be persistence to the second year at the university-level (and not graduation), this should not be as concerning, but still worth noting. 


\section{CHAPTER IV \\ RESULTS OF THE STUDY}

\section{Introduction}

As stated in chapter one, the current study examined the relationship between key variables, both demographic and academic, as they relate to transfer student success. Five research questions and their corresponding directional hypotheses were introduced, and the details about the methodology employed to test these hypotheses were discussed in chapter three. This chapter contains the sample demographics followed by the results based on the analyses for each research question described.

\section{Sample Demographics}

The overall sample for this study consisted of 227 students who transferred from Jefferson Community and Technical College (JCTC) to the University of Louisville (UofL) between spring 2006 and spring 2011. The sample was comprised of 114 men $(50 \%)$ and 113 women (50\%), which approximate UofL's general population (49\% and $51 \%$ respectively) but is slightly skewed from the overall JCTC population ( $44 \%$ and $56 \%$ respectively). With regard to race/ethnicity, the sample was primarily White $(75 \%)$, with $15 \%$ identifying as Black, $4 \%$ as Hispanic, and $6 \%$ as "Other". Because the sample size was small, the minority groups were combined, and $25 \%$ were identified as minority. The minority percentage matches UofL's student minority population (25\%) and is just under JCTC's minority population of $30 \%$. Students in the sample were between the ages of 20 and 37 with a mean age of 23.7. Looking at the individual groups, 94 students 
participated in the ULtra transfer program, and 133 students were part of the Non-ULtra group for comparison. See Table 2 for general group characteristics. Analyzing precollege achievement for the group revealed that the average high school GPA for participants was 2.95 and the average ACT score was 18.96 (Table 3 provides descriptive statistics for high school GPA and ACT scores).

Table 2

Descriptive Statistics for the Sample: Age, Gender, Race/Ethnicity, and SES

\begin{tabular}{|c|c|c|}
\hline Variable & $n$ & $\%$ of the sample \\
\hline \multicolumn{3}{|c|}{ Program Participation Status } \\
\hline Non-ULtra & 133 & $58.6 \%$ \\
\hline ULtra & 94 & $41.1 \%$ \\
\hline \multicolumn{3}{|l|}{ Age } \\
\hline 20 & 1 & $0.4 \%$ \\
\hline 21 & 13 & $5.7 \%$ \\
\hline 22 & 35 & $15.4 \%$ \\
\hline 23 & 50 & $22 \%$ \\
\hline 24 & 52 & $22.9 \%$ \\
\hline 25 & 67 & $29.5 \%$ \\
\hline 26 & 8 & $3.5 \%$ \\
\hline $30+$ & 1 & $0.4 \%$ \\
\hline \multicolumn{3}{|l|}{ Gender } \\
\hline Male & 114 & $50.2 \%$ \\
\hline Female & 113 & $49.8 \%$ \\
\hline \multicolumn{3}{|l|}{ Race/Ethnicity } \\
\hline White & 170 & $74.9 \%$ \\
\hline Other & 57 & $25.1 \%$ \\
\hline \multicolumn{3}{|l|}{ SES (Pell Eligible?) } \\
\hline NO & 92 & $40.5 \%$ \\
\hline YES & 135 & $59.5 \%$ \\
\hline
\end{tabular}


Table 3

Descriptive Statistics for Pre-college Achievement (High School GPA and ACT Score)

\begin{tabular}{ccc}
\hline Variable & $n$ & $\%$ of the sample \\
\hline High School GPA & 25 & $11 \%$ \\
$1.00-2.00$ & 35 & $15.4 \%$ \\
$2.01-2.50$ & 57 & $25.1 \%$ \\
$2.51-3.00$ & 65 & $28.6 \%$ \\
$3.01-3.50$ & 45 & $19.8 \%$ \\
$3.51-4.00$ & & \\
$10-12$ & 2 & $0.9 \%$ \\
$13-15$ & 24 & $10.6 \%$ \\
$16-18$ & 84 & $37 \%$ \\
$19-21$ & 77 & $33.9 \%$ \\
$22-24$ & 24 & $10.6 \%$ \\
$25-27$ & 13 & $5.7 \%$ \\
$28-30$ & 2 & $0.9 \%$ \\
$31-33$ & 1 & $0.9 \%$ \\
$34-36$ & 0 & $0 \%$ \\
\hline
\end{tabular}

\section{Background Characteristics}

\section{Results}

Research Question 1. Do students who utilize the ULtra Transfer Program differ in background characteristics (age, race/ethnicity, gender, SES, high school GPA, and ACT score) from non-ULtra transfer students?

The background characteristics race/ethnicity, gender, and SES were examined through a series of cross-tabulations and through Chi-square tests. Analyses show that there were not statistically significant differences between the Non-ULtra and ULtra groups for race/ethnicity, $\chi^{2}(1 d f)=1.11, p=.35$; gender, $\chi^{2}(1 d f)=.05, p=.89$; or SES, $\chi^{2}(1 d f)=.27, p=.68$ (Table 4). An independent samples $t$-test determined that there was a statistically significant difference between the group means for age $t(225)=2.42, p=$ .02 with Non-ULtra student $(M=23.92, S D=1.79)$ significantly older than ULtra students $(M=23.40, S D=1.2)$, though this difference is small in magnitude (less than six months; see Table 5). A test for normality was conducted on age, and it was found not to 
be normally distributed between the groups. If the sample size was larger this would not be an issue, but given a smaller sample, outliers can exert undue influence on the analyses. A stem and leaf plot was created, and outliers ( 1 in the Non-ULtra group and 6 in the ULtra group) were found and temporarily removed to see if they influenced the results. Age was still found to be a significant covariate, and all other tests were rerun and the direction of their significance remained unchanged. Therefore, it was decided to leave the seven participants in the study.

Table 4

Cross-tabulations for Non-ULtra and ULtra: Gender, Race/Ethnicity, and SES

\begin{tabular}{|c|c|c|c|c|}
\hline \multirow[b]{2}{*}{ Variable } & \multicolumn{2}{|c|}{ Non-Ultra } & \multicolumn{2}{|c|}{ ULtra } \\
\hline & $n$ & $\%$ & $N$ & $\%$ \\
\hline \multicolumn{5}{|l|}{ Gender } \\
\hline Male & 66 & $49.6 \%$ & 48 & $51.1 \%$ \\
\hline Female & 67 & $50.4 \%$ & 46 & $48.9 \%$ \\
\hline \multicolumn{5}{|l|}{ Race/Ethnicity } \\
\hline White & 103 & $77.4 \%$ & 67 & $71.3 \%$ \\
\hline Other & 30 & $22.6 \%$ & 27 & $28.7 \%$ \\
\hline \multicolumn{5}{|c|}{ SES (Pell Eligible?) } \\
\hline NO & 52 & $39.1 \%$ & 40 & $42.6 \%$ \\
\hline YES & 81 & $60.9 \%$ & 54 & $57.4 \%$ \\
\hline Group Totals & 133 & $58.6 \%$ & 94 & $41.4 \%$ \\
\hline
\end{tabular}

Table 5

Cross-tabulations for Non-ULtra and ULtra: Age

\begin{tabular}{|c|c|c|c|c|}
\hline \multirow[b]{2}{*}{ Variable } & \multicolumn{2}{|c|}{ Non-Ultra } & \multicolumn{2}{|c|}{ ULtra } \\
\hline & $n$ & $\%$ & $N$ & $\%$ \\
\hline Age & & & & \\
\hline 20 & 0 & $0 \%$ & 1 & $1.1 \%$ \\
\hline 21 & 10 & $7.5 \%$ & 3 & $3.2 \%$ \\
\hline 22 & 18 & $13.5 \%$ & 17 & $18.1 \%$ \\
\hline 23 & 20 & $15 \%$ & 30 & $31.9 \%$ \\
\hline 24 & 27 & $20.3 \%$ & 25 & $26.6 \%$ \\
\hline 25 & 52 & $39.1 \%$ & 15 & $16 \%$ \\
\hline 26 & 5 & $3.8 \%$ & 3 & $3.2 \%$ \\
\hline $30+$ & 1 & $0.8 \%$ & 0 & $0 \%$ \\
\hline
\end{tabular}


The students' high school academic achievement, as measured by GPA and ACT scores, was analyzed using a multivariate analysis of variance (MANOVA). No significant differences were found between the groups, $F(2,224)=1.09, p=.34$; Wilk's $\lambda=.99, \eta^{2}=.01$ (see Table 6 for high school GPA and Table 7 for ACT score). It is noteworthy that non-ULtra students actually performed slightly (though not statistically significantly) better in high school, as measured by their GPAs $(d=-0.15 ; M=2.98, S D$ $=.68$ vs. $M=2.89, S D=.62)$ and their ACT scores $(d=-0.13 ; M=19.2, S D=3.3$ vs. $M$ $=18.7, S D=3.2$.

Given that a statistically significant difference was found between the Non-ULtra and ULtra students for age, that variable was used as a covariate for other tests in the study. Though high school GPA and ACT score were not found to be statistically significant between the two groups, they were still employed as covariates based on general research findings about their importance in determining academic achievement (Wolniak \& Engberg, 2010).

Table 6

Cross-tabulations for Pre-college Achievement: High School GPA

\begin{tabular}{cccccc} 
& \multicolumn{2}{c}{ Non-ULtra } & & \multicolumn{2}{c}{ ULtra } \\
\cline { 2 - 3 } \cline { 5 - 6 } Variable & $n$ & $\%$ & & $n$ & $\%$ \\
\hline High School GPA & 15 & $11.3 \%$ & & 10 & $10.6 \%$ \\
$1.00-2.00$ & 17 & $12.8 \%$ & & 18 & $19.1 \%$ \\
$2.01-2.50$ & 30 & $22.6 \%$ & & 27 & $28.7 \%$ \\
$2.51-3.00$ & 41 & $30.8 \%$ & & 24 & $25.5 \%$ \\
$3.01-3.50$ & 30 & $22.6 \%$ & & 15 & $16 \%$ \\
$3.51-4.00$ & & & &
\end{tabular}


Table 7

Cross-tabulations for Pre-college Achievement: ACT Score

\begin{tabular}{cccccc} 
& \multicolumn{2}{c}{ Non-ULtra } & & \multicolumn{2}{c}{ ULtra } \\
\cline { 2 - 3 } \cline { 5 - 6 } Variable & $n$ & $\%$ & & & \\
\hline ACT Score & 2 & $1.5 \%$ & & 0 & $0 \%$ \\
$10-12$ & 12 & $9 \%$ & & 12 & $12.8 \%$ \\
$13-15$ & 43 & $32.3 \%$ & & 41 & $43.6 \%$ \\
$16-18$ & 53 & $39.8 \%$ & & 24 & $25.5 \%$ \\
$19-21$ & 11 & $8.3 \%$ & & 13 & $13.8 \%$ \\
$22-24$ & 10 & $7.5 \%$ & & 3 & $3.2 \%$ \\
$25-27$ & 1 & $0.8 \%$ & 1 & $1.1 \%$ \\
$31-33$ & 1 & $0.8 \%$ & 0 & $0 \%$ \\
$34-36$ & 0 & $0 \%$ & 0 & $0 \%$ \\
\hline
\end{tabular}

\section{Prior to Transfer (JCTC)}

Research Question 2. Do students who utilize the ULtra Transfer Program complete more, and more appropriate, preparatory work at JCTC prior to transfer?

Multivariate analysis of covariance (MANCOVA) was used to determine if there was a statistically significant difference among groups in pre-transfer preparatory work at the community college. Covariates were age, high school GPA, and ACT score. The multivariate analysis showed that there was a statistically significant difference between the groups, $F(3,220)=4.47, p=.005 ;$ Wilk's $\lambda=.94, \eta^{2}=.06$.

For the multivariate analysis, Box's Test of Equality of Covariance Matrices (Box's $M$ test) was significant, Box's $M=60.31, F(18,4805.08)=2.88, p<.001$. Finding significance with this test indicates that we have failed to meet the assumption 
that the variance-covariance matrices within the individual cells of the design have been sampled from the same population in order to create a single estimate of error (Tabachnick \& Fidell, 1989). If the sample sizes between the groups were equal, we would be able to disregard the results of this test completely. However, because we have unequal group sizes, it is important to note the sample sizes and the variances and covariances for the individual cells. Given that the larger sample (Non-ULtra, $n=133$ ) has the larger variances and covariances for all three dependent variables, we can assume that the alpha level is conservative and that the null hypothesis may be rejected with confidence. In other words, if the sample sizes had been equal, it is likely that the findings would have been even more significant (Tabachnick \& Fidell, 1989).

The tests of between-subjects effects show that, compared to Non-ULtra students, ULtra participants earned a statistically significantly higher number of credit hours at JCTC, $F(1,222)=9.99, p=.002$. When comparing the estimated marginal means, this difference equates to earning approximately 9 more credit hours (typically 3 courses) at JCTC before transfer. ULtra students also had a significantly higher ratio of credit hours attempted to credit hours earned at $\mathrm{JCTC}, F(1,222)=7.58, p=.01$. The credit ratio was calculated by dividing each student's credit hours earned by the number of credit hours they attempted to earn at JCTC. The ratio indicates that ULtra students earn credit for approximately $91 \%$ of the courses they attempt, compared to Non-ULtra students who earn credit for approximately $86 \%$ of the courses they attempt. Finally, ULtra students had a higher number of their JCTC transfer credits accepted toward their major requirements at UofL, $F(1,222)=7.56, p=.006$. For descriptive information on the analysis of question two, see Table 8 . Review the corresponding Tables for a breakdown 
of JCTC credits attempted (Table 9), JCTC credits earned (Table 10), and JCTC credits accepted toward a major (Table 11).

Table 8

MANCOVA Estimates: JCTC Credits Earned, Credit Ratio, and Credits toward Major

\begin{tabular}{|c|c|c|c|c|c|c|}
\hline \multirow{2}{*}{ Variable } & \multicolumn{2}{|c|}{ Non-Ultra } & \multicolumn{3}{|c|}{ ULtra } & \multirow{2}{*}{ Sig. } \\
\hline & $M$ & $S D$ & & $M$ & $S D$ & \\
\hline Credits Earned & $46.65^{\mathrm{a}}$ & 21.05 & & $55.72^{\mathrm{a}}$ & 21.12 & $.002^{*}$ \\
\hline Credit Ratio & $0.86^{\mathrm{a}}$ & 0.15 & & $.92^{\mathrm{a}}$ & 0.16 & $.011^{*}$ \\
\hline Credits toward Major & $28.20^{\mathrm{a}}$ & 17.52 & & $34.76^{\mathrm{a}}$ & 17.58 & $.006^{*}$ \\
\hline \multicolumn{7}{|c|}{$\begin{array}{l}\text { Note. Samples size was } 133 \text { for Non-ULtra and } 94 \text { for ULtra. } \\
\text { a Covariates appearing in the model are evaluated at the following values: } \mathrm{HS} \mathrm{GPA}=2.95, \mathrm{ACT}=18.96, \mathrm{Age}=23.7\end{array}$} \\
\hline \multicolumn{7}{|l|}{ Table 9} \\
\hline \multicolumn{7}{|c|}{ Cross-tabulations for the Groups: JCTC Credits Attempted } \\
\hline & \multirow{2}{*}{\multicolumn{2}{|c|}{$\begin{array}{r}\text { Non-Ultra } \\
n \quad \% \\
\end{array}$}} & \multicolumn{2}{|c|}{ ULtra } & \multicolumn{2}{|c|}{ Total } \\
\hline Variable & & & $n$ & $\%$ & $n$ & $\%$ \\
\hline \multicolumn{7}{|l|}{ Credits Attempted } \\
\hline $0-9$ & 3 & $2.3 \%$ & 0 & $0 \%$ & 3 & $1.3 \%$ \\
\hline $10-19$ & 10 & $7.5 \%$ & 3 & $3.2 \%$ & 13 & $5.7 \%$ \\
\hline $20-29$ & 20 & $15 \%$ & 7 & $7.4 \%$ & 27 & $11.9 \%$ \\
\hline $30-39$ & 6 & $4.5 \%$ & 10 & $10.6 \%$ & 16 & $7 \%$ \\
\hline $40-49$ & 13 & $9.8 \%$ & 6 & $6.4 \%$ & 19 & $8.4 \%$ \\
\hline $50-59$ & 16 & $12 \%$ & 12 & $12.8 \%$ & 28 & $12.3 \%$ \\
\hline $60-69$ & 20 & $15 \%$ & 22 & $23.4 \%$ & 42 & $18.5 \%$ \\
\hline $70-79$ & 25 & $18.8 \%$ & 18 & $19.1 \%$ & 43 & $18.9 \%$ \\
\hline $80-89$ & 9 & $6.8 \%$ & 10 & $10.6 \%$ & 19 & $8.4 \%$ \\
\hline $90-99$ & 11 & $8.3 \%$ & 6 & $6.4 \%$ & 17 & $7.5 \%$ \\
\hline
\end{tabular}


Table 10

Cross-tabulations for the Groups: JCTC Credits Earned

\begin{tabular}{|c|c|c|c|c|c|c|}
\hline \multirow[b]{2}{*}{ Variable } & \multicolumn{2}{|c|}{ Non-Ultra } & \multicolumn{2}{|c|}{ ULtra } & \multicolumn{2}{|c|}{ Total } \\
\hline & $n$ & $\%$ & $n$ & $\%$ & $n$ & $\%$ \\
\hline Credits Earned & & & & & & \\
\hline $0-9$ & 8 & $6 \%$ & 1 & $1.1 \%$ & 9 & $4 \%$ \\
\hline $10-19$ & 10 & $7.5 \%$ & 2 & $2.1 \%$ & 12 & $5.3 \%$ \\
\hline $20-29$ & 19 & $14.3 \%$ & 9 & $9.6 \%$ & 28 & $12.3 \%$ \\
\hline $30-39$ & 15 & $11.3 \%$ & 11 & $11.7 \%$ & 26 & $11.5 \%$ \\
\hline $40-49$ & 15 & $11.3 \%$ & 9 & $9.6 \%$ & 24 & $10.6 \%$ \\
\hline $50-59$ & 10 & $7.5 \%$ & 14 & $14.9 \%$ & 24 & $10.6 \%$ \\
\hline $60-69$ & 34 & $25.6 \%$ & 30 & $31.9 \%$ & 64 & $28.2 \%$ \\
\hline $70-79$ & 13 & $9.8 \%$ & 11 & $11.7 \%$ & 24 & $10.6 \%$ \\
\hline $80-89$ & 5 & $3.8 \%$ & 7 & $7.4 \%$ & 12 & $5.3 \%$ \\
\hline $90-99$ & 4 & $3 \%$ & 0 & $0 \%$ & 4 & $1.8 \%$ \\
\hline
\end{tabular}


Table 11

Cross-tabulations for the Groups: JCTC Credits Accepted toward Major

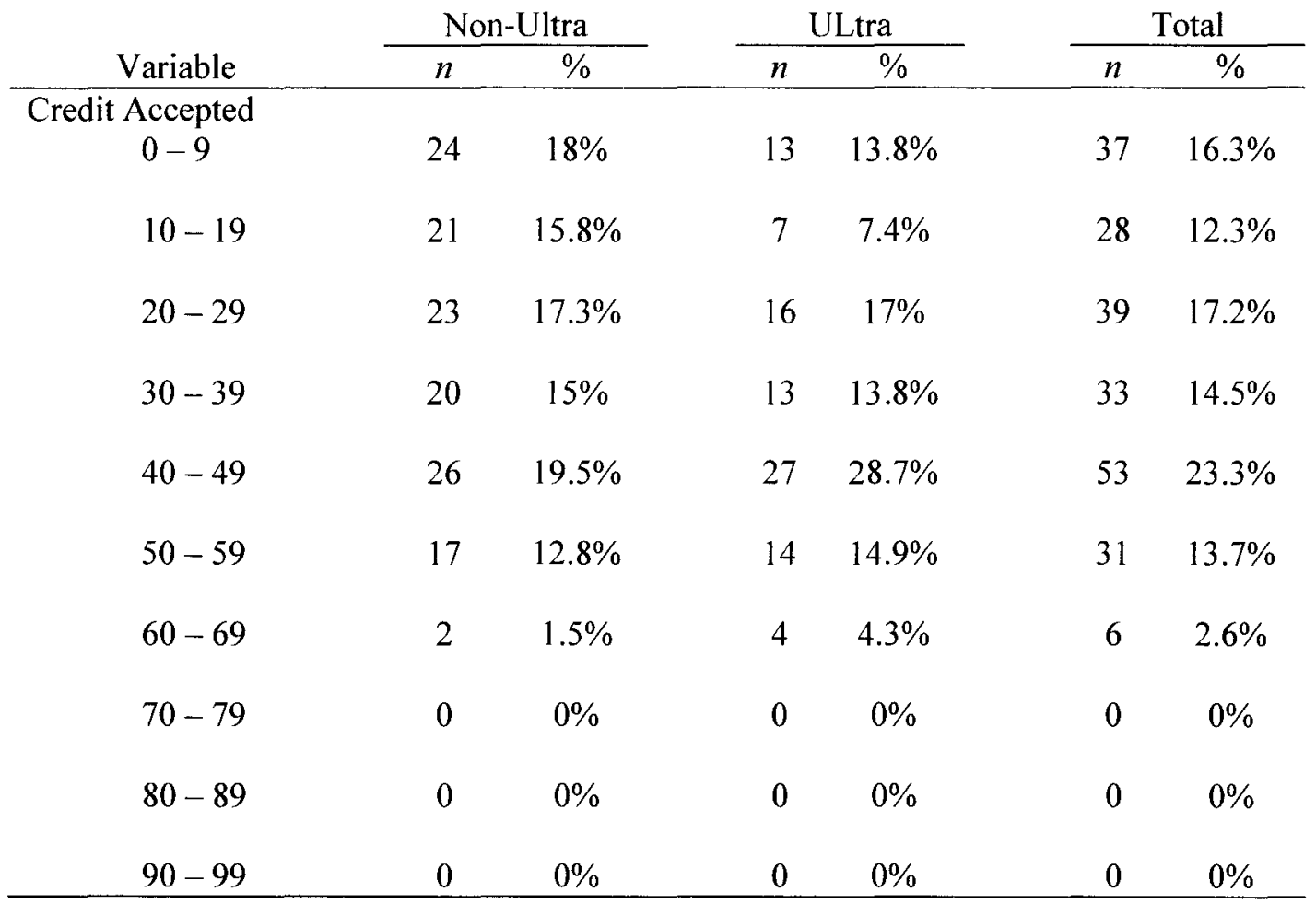

Research Question 3. Do students who utilize the ULtra Transfer Program have a higher GPA at the time of transfer?

The JCTC GPA at the time of transfer was examined using a one-way analysis of covariance (ANCOVA) in order to determine if there were any statistically significant differences between the groups. Covariates were age $(M=23.70)$, high school GPA $(M=$ 2.95), and ACT score $(M=18.96)$. ULtra students had a slightly higher JCTC GPA at the time of transfer $(M=2.96, S D=.579)$ as compared to the Non-ULtra students $(M=2.88$, $S D=.644), d=.12$, but the differences were not statistically significant, $F(1,225)=2.02$, $p=.16$. 


\section{Post Transfer (UofL)}

Research Question 4. Do students who utilize the ULtra Transfer Program suffer less transfer shock in their first year at the four-year institution?

Transfer shock was analyzed for both groups. Given that some studies estimate that over two-thirds of transfer students (Glass \& Harrington, 2002) experience a grade decline of 0.5 points (Hills, 1965; Kintzer \& Wattenbarger, 1985), the groups were compared on descriptive statistics first to see if they met this definitional threshold. The Non-ULtra student group came closest to the 0.5 GPA drop $(M=-.42, S D=1.03)$; ULtra student group $(M=-.38, S D=.78)$.

Two $t$-tests for independent samples were run to determine if there was a statistically significant difference among groups with regard to JCTC GPA and UofL first semester GPA and UofL first semester and second semester GPA. Difference scores were computed for JCTC GPA/UofL first semester GPA, and no significant difference was found between the Non-ULtra $(M=-.42, S D=1.03)$ and ULtra $(M=-38, S D=.78)$ student groups; $t(225)=-.34, p=.73$, suggesting that the two groups of students saw GPA declines of similar magnitudes. Difference scores were then computed for the UofL first semester GPA/UofL second semester GPA. Non-ULtra students $(M=-.08, S D=$ 1.01) saw a slight decline in their first-to-second semester GPA, while ULtra students experienced a rebound $(M=.18, S D=.84)$. This difference was nearly statistically significant, $t(204)=-1.87, p=.06$.

To examine these data in a slightly different way, two one-way ANOVAs were run. There was no statistically significant difference between the Non-ULtra $(M=2.46$, $S D=.96)$ and ULtra $(M=2.58, S D=.86)$ groups for the UofL first semester GPA $(d=$ 
$.13), F(1,225)=.93, p=.34$. However, ULtra students $(M=2.82, S D=.81)$ had a significantly higher second semester GPA compared to Non-ULtra students $(M=2.47$, $S D=.96) ; F(1,204)=8.10, p=.005, d=.40($ Table 12$)$.

Table 12

Descriptive Statistics for the Groups: JCTC GPA, UofL $1^{\text {st }}$ and $2^{\text {nd }}$ Semester GPAs

JCTC GPA UofL $1^{\text {st }}$ Semester GPA UofL $2^{\text {nd }}$ Semester GPA

\begin{tabular}{lcccccc} 
Group Status & $M$ & $S D$ & $M$ & $S D$ & $M$ & $S D$ \\
\hline Non-ULtra & 2.92 & .65 & 2.55 & .90 & $2.47^{*}$ & .93 \\
\hline ULtra & 2.97 & .58 & 2.65 & .81 & $2.82^{*}$ & .81 \\
\hline The mean difference is significant at the 05 level & & & &
\end{tabular}

*The mean difference is significant at the .05 level

A graphical representation (Figure 4) of the groups' mean GPAs across the three time measures shows that both groups suffer transfer shock in the first semester as expected. Figure 4 also shows that the ULtra group rebounded in the second semester, while the Non-ULtra students continued to decline.

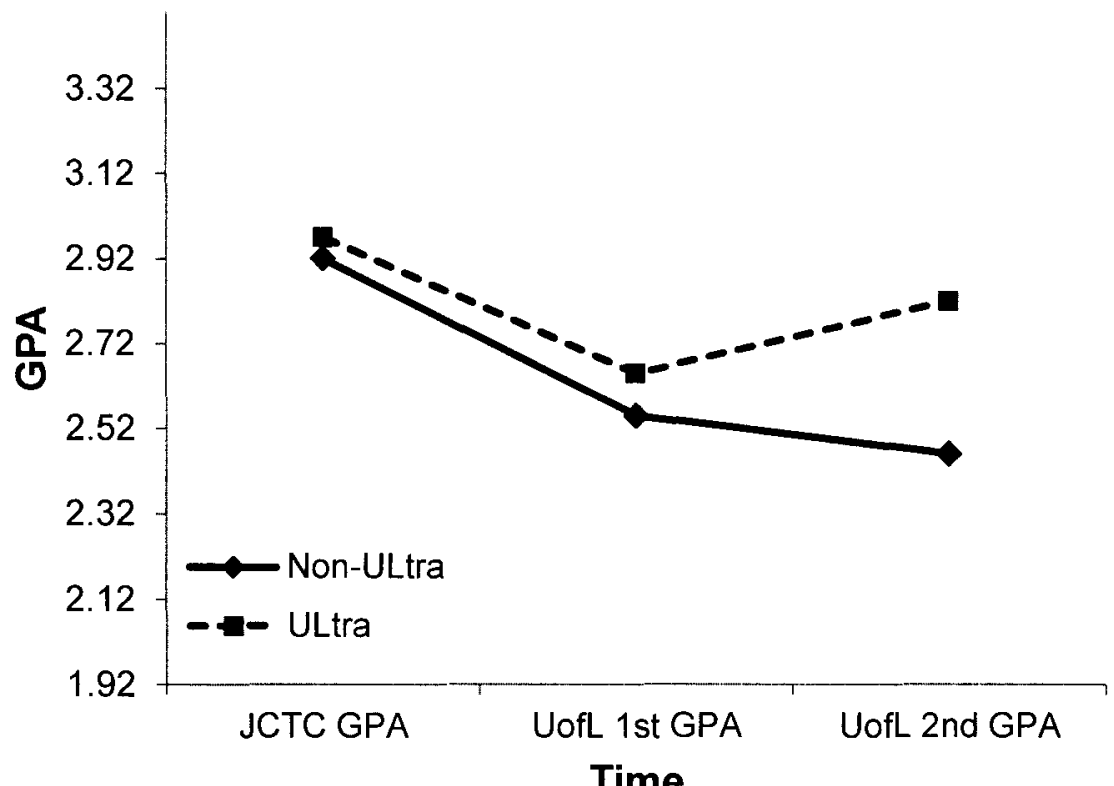

Figure 4. Estimated Marginal Means of GPA between Non-ULtra and ULtra students. 
Research Question 5. Do students who utilize the ULtra Transfer Program have a higher persistence rate?

Persistence is presented as a dichotomous variable $(\mathrm{No}=0, \mathrm{Yes}=1)$. Therefore, a logistic regression analysis was conducted to predict the odds of persisting from the firstto-second semester at UofL based on participation in the ULtra Transfer Program. The covariates were age, high school GPA, and ACT score (see Table 13 for the crosstabulations for Non-ULtra and ULtra student persistence). For first-to-second semester persistence, there was no significant finding for program participation. (See Table 14 for the summary of results).

Table 13

Cross-tabulation: First to Second Semester Persistence Rates

\begin{tabular}{|c|c|c|c|c|}
\hline \multirow[b]{3}{*}{ Group } & \multicolumn{4}{|c|}{ Persistence } \\
\hline & \multicolumn{2}{|c|}{$\mathrm{NO}$} & \multicolumn{2}{|c|}{ YES } \\
\hline & $n$ & $\%$ & $n$ & $\%$ \\
\hline Non-ULtra & 20 & $15 \%$ & 113 & $85 \%$ \\
\hline ULtra & 11 & $11.7 \%$ & 83 & $88.3 \%$ \\
\hline
\end{tabular}

Table 14

Logistic Regression Results: First to Second Semester Persistence Rates

\begin{tabular}{lcccccc}
\multicolumn{1}{c}{ Variables } & $B$ & S.E. & Wald & df & Sig. & Exp $(B)$ \\
\hline Age & .113 & .139 & .666 & 1 & .414 & 1.120 \\
H.S. GPA &. .035 & .297 & .014 & 1 & .906 & .965 \\
ACT Score & .041 & .063 & .425 & 1 & .514 & 1.042 \\
Program Participation & .355 & .410 & .748 & 1 & .387 & 1.426 \\
Constant & -1.636 & 3.848 & .181 & 1 & .671 & .195 \\
\hline
\end{tabular}


Logistic regression was also run for overall persistence, students who persisted from first-to-second semester and then through second-to-third semester. The covariates age, high school GPA, and ACT score were used (see Table 15 for the cross-tabulations for Non-ULtra and ULtra student persistence). For overall persistence, there was a significant finding for program participation $(\mathrm{OR}=1.91, p=.04)$, suggesting that ULtra students are about $20 \%$ more likely to persist beyond the second semester than NonULtra students (see Table 16 for the summary of results).

Table 15

Cross-tabulation: Overall Persistence Rates

\begin{tabular}{|c|c|c|c|c|}
\hline \multirow[b]{3}{*}{ Group } & \multicolumn{4}{|c|}{ Persistence } \\
\hline & \multicolumn{2}{|c|}{ NO } & \multicolumn{2}{|c|}{ YES } \\
\hline & $n$ & $\%$ & $n$ & $\%$ \\
\hline Non-ULtra & 41 & $30.8 \%$ & 92 & $69.2 \%$ \\
\hline ULtra & 19 & $20.2 \%$ & 75 & $79.8 \%$ \\
\hline
\end{tabular}

Table 16

Logistic Regression Results: Overall Persistence Rates

\begin{tabular}{|c|c|c|c|c|c|c|}
\hline Variables & $B$ & S.E. & Wald & $d f$ & Sig. & $\operatorname{Exp}(B)$ \\
\hline Age & .173 & .112 & 2.394 & 1 & .122 & 1.189 \\
\hline H.S. GPA & -.027 & .232 & .013 & 1 & .908 & .973 \\
\hline ACT Score & .009 & .048 & .033 & 1 & .855 & 1.009 \\
\hline Program Participation & .649 & .326 & 3.963 & 1 & .047 & 1.914 \\
\hline Constant & -3.401 & 3.077 & 1.221 & 1 & .269 & .033 \\
\hline
\end{tabular}

Preparing the persistence data for analysis entailed coding students who persisted from their first semester to their second semester as a "Yes" and those who did not persist in consecutive semesters as a "No". The same is true for the overall persistence. However, there were noticeable patterns in students' enrollment that are not accounted 
for by this standard definition of persistence. For instance, some students were enrolled for several fall semesters in a row but never in a spring semester. With the standard definition of persistence, these students would be counted as non-persisters in this study because they did not persist in consecutive semesters, even though they enrolled in courses on a consistent basis. Given what we know about transfer students and their habit of "pause[ing] before, during, and after attending community colleges" (Fredrickson, 1998, p. 53), an expanded definition of persistence was included. Another logistic regression was run which included students who enrolled in courses in a later semester after stopping out for one. Cross-tabulations were run for expanded first-to-second semester persistence (Table 17) and expanded overall persistence (Table 18).

For the expanded definition of persistence, the covariates age, high school GPA, and ACT score were used. Though the results were in the same direction as the previous analyses, indicating that ULtra students were more likely to persist using this expanded definition, the difference was not statistically significant for either the first-to-second semester $(\mathrm{OR}=1.66, p=.29)$ or overall expanded persistence (equal to persisting through from the second-to-third semester $),(\mathrm{OR}=1.83, p=.11)$.

Table 17

Cross-tabulation: Expanded First to Second Semester Persistence Rates

\begin{tabular}{|c|c|c|c|c|}
\hline \multirow[b]{3}{*}{ Group } & \multicolumn{4}{|c|}{ Persistence } \\
\hline & \multicolumn{2}{|c|}{$\mathrm{NO}$} & \multicolumn{2}{|c|}{ YES } \\
\hline & $n$ & $\%$ & $n$ & $\%$ \\
\hline Non-ULtra & 15 & $11.3 \%$ & 118 & $88.7 \%$ \\
\hline ULtra & 7 & $7.4 \%$ & 87 & $92.6 \%$ \\
\hline
\end{tabular}


Table 18

Cross-tabulation: Expanded Overall Semester Persistence Rates

\begin{tabular}{|c|c|c|c|c|}
\hline \multirow[b]{3}{*}{ Group } & \multicolumn{4}{|c|}{ Persistence } \\
\hline & \multicolumn{2}{|c|}{$\mathrm{NO}$} & \multicolumn{2}{|c|}{ YES } \\
\hline & $n$ & $\%$ & $n$ & $\%$ \\
\hline Non-ULtra & 28 & $21.1 \%$ & 105 & $78.9 \%$ \\
\hline ULtra & 13 & $13.8 \%$ & 81 & $86.2 \%$ \\
\hline
\end{tabular}

\section{Summary}

Chapter four began with an introduction of the sample demographics. The sample consisted of 227 students who transferred from JCTC to UofL between spring 2006 and spring 2011. Ninety-four students participated in the ULtra transfer program, and 133 students were part of the Non-ULtra group. The sample consisted of 114 men $(50 \%)$ and 113 women (50\%). The sample was primarily White $(75 \%)$, with $15 \%$ identifying as Black, $4 \%$ as Hispanic, and $6 \%$ as "Other". Students in the sample were between the ages of 20 and 37 . The average high school GPA for participants was 2.95 and the average ACT score was 18.96.

Next, the research questions which were designed to examine the relationship between key variables, both demographic and academic, as they relate to transfer student success were reintroduced. The five research questions and their corresponding directional hypotheses were addressed, and the details about the methodology employed to test these hypotheses were discussed and the data analyzed using SPSS 20.0. Results for each question were provided, and significance was set at an alpha level of .05. Table 19 provides a summary of the results. 
Table 19

Overview of Results

\begin{tabular}{|c|c|c|}
\hline Research Question & Statistical Procedures & Results \\
\hline $\begin{array}{l}\text { 1. Do transfer students who utilize } \\
\text { the ULtra Transfer Program differ } \\
\text { in background characteristics (age, } \\
\text { race/ethnicity, gender, SES, high } \\
\text { school GPA, and ACT score) from } \\
\text { non-ULtra transfer students? }\end{array}$ & $\begin{array}{l}\text { Chi-Square; } t \text {-test for } \\
\text { independent samples; } \\
\text { MANOVA }\end{array}$ & $\begin{array}{l}\text { ULtra students were } \\
\text { significantly younger. No } \\
\text { significant difference was } \\
\text { found for race/ethnicity, } \\
\text { gender, SES, high school } \\
\text { GPA, or ACT score. }\end{array}$ \\
\hline $\begin{array}{l}\text { 2. Do students who utilize } \\
\text { the ULtra Transfer Program } \\
\text { complete more, and more } \\
\text { appropriate, preparatory work at } \\
\text { JCTC prior to transfer? }\end{array}$ & MANCOVA & $\begin{array}{l}\text { ULtra students earned } \\
\text { significantly more credit } \\
\text { hours, had a higher ratio of } \\
\text { credit hours attempted and } \\
\text { earned, and a higher number } \\
\text { of credit hours accepted } \\
\text { toward their major. }\end{array}$ \\
\hline $\begin{array}{l}\text { 3. Do transfer students who utilize } \\
\text { the ULtra Transfer Program have a } \\
\text { higher GPA at the time of transfer? }\end{array}$ & ANCOVA & $\begin{array}{l}\text { No significant difference } \\
\text { was found between groups } \\
\text { on JCTC GPA. }\end{array}$ \\
\hline $\begin{array}{l}\text { 4. Do transfer students } \\
\text { who utilize the ULtra Transfer } \\
\text { Program suffer less transfer shock } \\
\text { in their first year at the four-year } \\
\text { institution? }\end{array}$ & $\begin{array}{l}t \text {-test for independent } \\
\text { samples; ANOVA }\end{array}$ & $\begin{array}{l}\text { No difference was found } \\
\text { between groups for first } \\
\text { semester difference score or } \\
\text { GPA. A nearly significant } \\
\text { difference was found for } \\
\text { second semester difference } \\
\text { score, and a significant } \\
\text { difference was found for } \\
\text { second semester GPA with } \\
\text { ULtra student scoring } \\
\text { higher. }\end{array}$ \\
\hline $\begin{array}{l}\text { 5. Do transfer students who } \\
\text { utilize the ULtra Transfer Program } \\
\text { have a higher persistence rate? }\end{array}$ & Logistic Regression & $\begin{array}{l}\text { ULtra students had a } \\
\text { significantly higher overall } \\
\text { persistence rate. }\end{array}$ \\
\hline
\end{tabular}




\section{CHAPTER V}

\section{SUMMARY AND CONCLUSIONS}

This dissertation sought to determine if the ULtra Transfer Program, designed as a bridge between Jefferson Community and Technical College and the University of Louisville, aids in transfer student success. Success for this study was defined as transfer students a) having more credit hours earned and accepted toward their major, b) suffering less transfer shock after the transition to UofL and earning a higher first and second semester GPA, and c) having a higher persistence rate at UofL. Data obtained from the University of Louisville, Jefferson Community and Technical College, and the Jefferson County Public School System were analyzed for the five research questions in the study, and the results were presented in chapter four. This final chapter will discuss the results in more detail, tying them back to research in the field. This chapter will also address recommendations for practice and future research.

Chapters one and two presented past research indicating that more students are beginning their postsecondary education at the two-year college level with the intention of transferring to earn a bachelor's degree, making the transfer function more important (Dougherty \& Kienzl, 2006). For students to transfer successfully, they must be retained at the community college and be prepared for the transition to the four-year institution (Dougherty, 1992). Research has shown that students who start at the community college are at a disadvantage when compared to their four-year counterparts (Alfonso, 2006) and that only about $50 \%$ who intend to transfer actually make it (Bradburn \& Hurst, 2001). 
For the community college students who $d o$ successfully transfer to the four-year institution, the question is whether or not they are adequately prepared to excel in their new environment. Institutions must work to find ways to help ease the transition for transfer students (Prager, 1993). As Wang (2009) noted, the clear drawbacks associated with beginning at a community college necessitate an obligation for researchers to identify the factors that affect transfer student achievement.

From the establishment of the community college system to the present, students and communities have struggled with creating a smooth process to bridge the two- and four-year college experience. When students have the intention of transferring and earning a bachelor's degree, it is the responsibility of practitioners in the field of higher education to help ensure that they are able to meet their goals. This shows that there is a clear need for successful transfer support programming for community college students making the transition to the four-year institution.

Information in chapters one and two discussed Kentucky's efforts to aid community college transfer students and provided background on the path that public postsecondary institutions have taken to help better the transfer function and increase students' success. The focus of this dissertation was the ULtra Transfer Program, which has become a highly utilized transfer center for JCTC students preparing to transition. Though the program appears to be successful, in the six years ULtra has been in its current form, it had never been strategically assessed to determine the effects it is having on transfer students. This study attempted to make such a determination. 


\section{Discussion}

Results from research question one indicate that the students in the Non-ULtra and ULtra student groups most likely came from the same population. With the exception of age, no significant differences were found for background characteristics (race/ethnicity, gender, SES, high school GPA, ACT score). This allowed for the assumption that comparable groups were being tested on the independent variable, program participation. There are, however, a few interesting findings to discuss. Duggan and Pickering (2008) noted that lower income students are more likely to start their college career at the junior level. In the current study sample, a majority of students in the sample were Pell Grant eligible (59.5\%), indicating that these students were more likely from a lower income bracket. This finding connects to the research on the general transfer student population, but it does not follow the common findings that community college transfer students are typically members of a higher social class than their community college peers (Lee \& Frank, 1990; Melguizo et al., 2008). Chapter two cited research on the differences between CTE and academic track students, and the argument was made in chapter three that ULtra students were more likely to fall into the academic track given their self-selection into a program that was geared toward transfer. Though the finding was not statistically significant, ULtra students were less likely to be Pell Grant eligible (57.4\% vs. $60.9 \%$ ), which aligns with research findings that academic track students are less likely to receive financial aid (Levesque et al., 2008).

Findings from the current student sample are consistent with the findings presented from the Kentucky Transfer Feedback Report for KCTCS (KY CPE, 2012, "Transfer") with regard to transfer students tending to be White (87.4\%) and traditionally 
aged (24 and younger) (57.7\%). While ULtra students were younger $(M=23.4)$ than Non-ULtra student $(M=23.9)$, both groups fell into the traditional college-aged category $(M=23.7)$. The majority of students in the ULtra and Non-ULtra groups were White (71.3\% and $77.4 \%$ respectively). It is interesting to note that ULtra students were more likely to be minority $(28.7 \%)$ than Non-ULtra students $(22.6 \%)$, though not significantly so.

Lee and Frank (1990) found that transfer students were more academically oriented in high school (compared to other community college students) and closely resembled their four-year counterparts. At the University of Louisville, the average high school GPA for a degree-seeking first-time freshman was 3.46 (UofL, 2012, "Common Data Set 2011-2012") with an average ACT score of 24.7 (UofL, 2012, “Just the Facts"). For the transfer student sample in this study, the average high school GPA was 2.95 with an average ACT score of 18.96 , both notably below their UofL native peers. The students in this sample do not seem to align with the research in the field, though data on community college students who did not transfer would need to be analyzed to make a strong case for this point. As mentioned in chapter four, Non-ULtra students actually performed slightly (though not significantly) better in high school as measured by their GPAs (2.98 vs. 2.89$)$ and ACT scores (19.14 vs. 18.72). It is curious that the Non-ULtra students outperformed ULtra students in high school yet lagged behind once they got to college.

Research question two indicated that ULtra students significantly outperformed Non-ULtra students on all pre-transfer measures. Comparing the estimated marginal means, students in the ULtra program on average earned about 56 credit hours at JCTC, 
which is approximately 9 more credit hours than the Non-ULtra students $(M=47)$. Chapter two addressed the problem of timing, noting that students transfer with varying levels of college-level coursework behind them and with varying degrees of success (Palmer, Ludwig, \& Stapleton, 1994). Though this study was unable to determine whether or not students transferred over as general education certified, the number of credit hours that both Non-ULtra and ULtra students earned prior to transfer would suggest that they fell into the $18.3 \%$ group that past research suggests transfer after completing their Gen Eds (Palmer et al., 1994). With 56 transfer credit hours, the average ULtra student comes very close to the 60 credit hour threshold that could place them immediately into upper division coursework.

ULtra students earned a slightly higher ratio of credit hours to those attempted at JCTC. ULtra students earn credit for approximately $91 \%$ of the courses they attempt, compared to Non-ULtra students who earn credit for approximately $86 \%$ of the courses they attempt. This supports the idea that ULtra students received proper advising that ensured they took classes appropriate to their academic ability, creating a better chance for successful completion of courses.

Students who participated in the ULtra program also had a significantly higher number of their transfer credits accepted towards their intended major at UofL. When comparing the estimated marginal means, ULtra students transferred approximately 35 credits over that were applied to their major, as compared to 28 credits for Non-ULtra students. Chapter two discussed the transfer problem of credits, citing past research indicating that at least $58 \%$ of students report losing credits when transferring, $29 \%$ of those losing 10 or more hours (Dougherty, 1992). Research also noted that approximately 
$25 \%$ of students indicated that even when they received credit for courses, some were not counted toward their major hours. Both ULtra and Non-ULtra students earned approximately 20 credit hours at JCTC that were not directly accepted toward their major, most often counting instead as general elective credits. Though both groups of students lost about the same number of credit hours, as stated previously, ULtra students still had a significantly higher number applied to their major coursework. This finding lends credence to the ULtra program's success with the Academic Program Plans (APPs) that are designed to help JCTC students take the right courses at the community college that will transfer over as a direct equivalency for their intended major at UofL. Students who participate in the ULtra program and meet with an advisor have the advantage of making sure they are setting themselves up for success upon transfer, thus saving themselves time and money.

In the limitations presented in chapter three, it was noted that ULtra students are difficult to operationally define. In the future, if student participation is better tracked, it should be expected that "high impact" ULtra students (those who most frequently utilize ULtra resources) will have an even higher average number of credits accepted toward their majors at UofL. All of the findings on pre-transfer measures were significant, even after controlling for the covariates age, high school GPA, and ACT score. These findings point to the possibility that participation in the ULtra program helps students better prepare for the transfer process and pave a clearer path for success.

Though research question three reported that ULtra students had a slightly higher JCTC GPA at the time of transfer $(M=2.96, S D=.58)$ as compared to the Non-ULtra students $(M=2.88, S D=.64)$, this difference was not statistically significant. This could 
give some credence to the assumption that the students in these two groups are in fact similar in academic ability (as indicated by the non-significant difference between group high school GPAs and ACT scores). It does not however support the assumption that ULtra students were more likely to be in the academic track (Levesque et al., 2008) or that they were significantly more likely to take the right level of course work for their ability level, allowing them to achieve at higher rates compared to Non-ULtra students. That being said, Non-ULtra students had access to JCTC academic advisors who are arguably just as well trained (if not more so) at JCTC course selection as ULtra advisors. It would be reasonable to assume (and is supported by this finding) that both groups of students were placed in the appropriate level of coursework for their academic ability based on their COMPASS test scores and other information available to their advisors.

Transfer shock was addressed with research question four. It was evident that both Non-ULtra and ULtra students experienced the traditional decline in GPA in the first semester after they transferred to UofL, as was expected (Hills, 1965). ULtra students did appear to suffer less shock than Non-ULtra students (though not significantly so) in the first semester at UofL. The real measure of ULtra's success with regard to this measure comes in the comparison of the second semester GPAs between the groups. ULtra students nearly completely rebounded to their original GPA prior to transfer, while Non-ULtra students continued to decline slightly. ULtra students were able to rebound within the first year, as predicted by research (Diaz, 1992; Ishitani, 2008; Laanan, 2004; Townsend \& Wilson, 2006), while Non-ULtra students failed to bounce back.

Laanan (2007) noted that students need to possess the coping mechanisms required to deal with the stressful adjustments of their transfer and that these skills should 
be fostered from the very beginning of the community college experience. The theoretical frameworks of Kegan $(1982 ; 1994)$ and Astin (1984/1999) discussed in chapter two indicated that students should be actively involved in forming an understanding of their environment and their experiences. This active involvement will be an asset to students as they try to adjust to their new college environment both academically and socially (Tinto, 1975). The significant finding for research question four may indicate that ULtra students are indeed more prepared for transfer and higher level coursework than their Non-ULtra counterparts. It is also likely that with more credit hours accepted toward their major, ULtra students are taking higher level courses than Non-ULtra students; this usually translates to smaller class sizes and more dedicated student-teacher interaction. If this is the case, ULtra students are still at an advantage based on the ability of the ULtra program to help them get the most transferable value out of their community college academic experience.

Finally, research question five showed no significant difference between NonULtra (85\%) and ULtra (88.3\%) students for first-to-second semester persistence, with the vast majority of students persisting in both groups. The significant finding was that ULtra students do have an overall higher persistence rate (persist on from the second-tothird semester) $(79.8 \%)$ than Non-ULtra students $(69.2 \%)$. Coupled with the transfer shock findings from the previous question, it is not surprising that perhaps the ULtra students who do better academically and see a rebound in their GPA decide to persist at the institution, while Non-ULtra students who continue to suffer with a low GPA are more likely to depart. However, as noted in the analyses for question five, the expanded definition of persistence (which allows us to look beyond consecutive semesters) does not 
show this significant difference, with the majority of students persisting in both the NonULtra (78.9\%) and ULtra (86.2\%) groups.

Eggleston and Laanan (2001) recommended "a need for more course articulation, counseling and advising, faculty sensitivity, academic support services, transfer studentcentered orientation programs, student activities, and knowledge of campus recourses" (p.95). Based on the findings from this study, it seems evident that the ULtra Transfer Program, designed to provide these types of experiences for transfer students, has been successful in its mission.

\section{Recommendations for Policy and Practice}

Results from this study provided evidence that, even when accounting for significant background characteristics, participants in the ULtra Transfer Program a) have more credit hours earned (and accepted) toward their major, b) suffer less transfer shock after the transition to UofL and earn a slightly higher first and significantly higher second semester GPA, and c) have a higher persistence rate at UofL. These findings support the role of ULtra (and transfer programming more generally) in bridging the gap between the community college and four year institution and the demonstrate the value added for students who choose to take advantage of the services.

In 1997, the Kentucky General Assembly enacted House Bill 1 to establish goals and objectives for the Kentucky CPE, charged with improving the system of higher education in the state (KY CPE, 2011), creating an integrated system of higher education. To do that, colleges and universities had to work together to create new partnerships that helped facilitate transitions between schools. Given the overall success of this partnership between JCTC and UofL, it would be advantageous for the KY CPE to view the ULtra 
program as a viable model that could be modified to work at other institutions across the state. Until this study, the ULtra program had never been formally assessed. The findings presented here provide a foundation from which UofL and JCTC could create a comprehensive report documenting the value of this program. It is recommended that the faculty, staff, and administrators who work closely with the program form a work group to further document the ULtra Program, its components, the students it reaches, and a more thorough analysis of participation and student success. This report could then be shared out across the KCTCS system and more broadly in the field.

For the University of Louisville, it would be valuable to work with the larger KCTC system to see if expanding the ULtra program model to other campuses would be beneficial. Community college transfer students are a vital resource for four-year institutions such as UofL. With the increased pressure to keep enrollment and graduation numbers up and tuition dollars coming in, it is important for universities to help facilitate the successful transfer to and retention of students at their schools (Wang, 2009). Likewise, this partnership could give UofL the opportunity to increase their diversity, given that JCTC has a higher population of minority students. It could be beneficial for UofL if ULtra conducted some targeted outreach to these student populations. As noted in chapter two and demonstrated by the results in chapter four, transfer students tend to bring with them enough credit hours to start at the four-year institution as sophomores or higher (Cheslock, 2003). This helps balance out the attrition of first and second year students.

With the knowledge that ULtra is positively impacting transfer students and assisting in their retention at the university, more efforts should be made to ensure that 
incoming JCTC students are aware of the program and the value of the services. Currently, students who are denied acceptance to UofL receive a letter recommending that they start at JCTC and participate in the ULtra program, with the goal of transferring when they are ready. More can be done to promote the ULtra program to general incoming JCTC students who may never have applied to UofL. The Office of Communications and Marketing (OCM) at UofL could work to create a more intentional marketing plan for the ULtra program. Traditional marketing methods may not be impactful enough; outreach to students should be made through more popular media venues. This could come in the form of email and Facebook campaigns, a redesigned website replete with helpful information about getting started in the program, as well as an updated print campaign, as other universities have found success with an updated approach (Arguijo, 2010).

Getting more students to participate in the ULtra program is essential to help it continue to grow and to help support transfer for as many students as possible. Continued assessment of ULtra and subsequent transfer student success is just as critical. Through the course of data collection for this study, it was evident that the system by which agencies at the local and state levels gather and share student data is complicated to navigate. In order to obtain the data needed for the students in this sample, five separate agencies were contacted: the University of Louisville, Jefferson Community and Technical College, the Jefferson County Public School System, the Kentucky Council on Postsecondary Education, and the Kentucky Department of Education. Each agency presented a challenge for acquiring the necessary data. In the end, the three agencies reported in chapter three (UofL, JCTC, and JCPS) were able to supply enough data to 
proceed. In order for useful research on student transfer to be conducted, agencies must do a better job working together to house and share essential data on this important population.

In 2009, the Higher Education Work Group (HEWG) strongly recommended that Kentucky's public universities "implement, promote, and sustain an electronic system to help KCTCS and four-year institutions connect their existing infrastructure to offer a unified course articulation and transfer information system to meet the needs of students, transfer advisers, registrars, faculty, and other stakeholders" (HEWG, 2009, p. 6). It seems that work still needs to be done in this area to create a system that allows for easy access to data that will help facilitate important decisions for this student population. It is strongly recommended that the various government entities within the state create a more integrated system of data collection and sharing.

More specifically for the ULtra program, a limitation noted in chapter three was that ULtra is still in the process of creating a strong practice of data collection for evaluative purposes. Without integrated data which identify the students who use ULtra services on a consistent basis, how frequently they meet with an academic advisor, or which workshops and programs they attend, it is difficult to measure fully the value of the program's service. The collection of this level of detailed data would help better operationally define "ULtra" students and allow for specific analysis as to which features of the program are most beneficial to students (orientation, advising, APPs, workshops, etc.). It is recommended that ULtra create a systematic process for collecting relevant data on student participation in the program. 
With the need for more attention to be paid to data collection and analysis, and the potential for ULtra to see an influx of participants if they market their services more widely, it may quickly become necessary to hire more staff to meet the growing demands on the program. Currently at JCTC, the ULtra staff consists of two full time advisors, a project coordinator, a graduate assistant, and a director who splits time between the JCTC and UofL campuses. The staffing needs should be evaluated to see the amount and quality of time advisors are able to spend with their students, how many programs, workshops, etc. are able to be offered, and the participation rates for each. If it is determined that students would benefit from increased interaction with the program, efforts should be made to decrease the advisor to student ratio and increase staffing to meet the demands. This program is proving to aid the university in its goals for persistence and retention of transfer students, and it should be provided with the resources necessary to continue to grow in its outreach. A benchmarking study of comparison schools could be conducted to determine what resources are made available to meet the needs of similar programs. Information from such a study would help ULtra create a strong proposal to request additional support to meet the growing needs of the program.

The results from the current study provide evidence that ULtra is effective. Through participation in the program, students become actively engaged in their own learning; Astin (1984/1999) identified this as an important component of student success. As ULtra grows, it will be important for the staff to continually recommit to the mission of the program, ensuring that they stay the course. Kegan's $(1982 ; 1994)$ work was cited as a theoretical framework for this dissertation as a means to contextualize where the 
transfer students are in their growth and development, as well as the work that ULtra does and the goals that the program strives to reach. Pascarella and Terenzini (1991) referred to the transition between schools as a form of "culture shock" (p. 58), and Laanan (2007) suggested that transfer students will need to develop the skills necessary to deal with their "cross-cultural" relocation (p. 41). The ULtra staff seem to meet the students where they are (literally and figuratively) and help them to develop the skills and academic competencies required to be successful college students. Given that these skills may not come naturally, the ULtra program can play a key role in their successful transition, fostering these coping mechanisms from the beginning of their experience at the community college.

Students should be actively engaged in their learning and have a solid understanding of what it will take to be successful and earn their degree. ULtra can help prepare transfer students through well-structured academic advising and programs. Through initiatives like the class visit program and campus tours, for example, ULtra students get a feel for the campus and their new environment, bridging the gap between their school experiences. Kegan's bridge metaphor could be a useful philosophy for ULtra to more formally adopt to guide their work and future efforts. As ULtra designs new components of the program or refreshes old ones, the staff should be mindful of the students' ways of knowing and making meaning, and learning should be situated in their current understanding whenever possible. Working within a framework such as Kegan's could help students be maximally successful.

The overall recommendation based on the findings from this study would be to continue to monitor and grow the ULtra transfer program, possibly expanding to other 
schools in the KCTC system and providing the resources students need to help them transfer successfully to the University of Louisville. Attracting and retaining transfer students is essential to the life of the institution and as such, the students should be regarded as an important population that deserves resources and services that will help them do well at the community college, transfer successfully, and graduate from the university.

\section{Recommendations for Future Research}

As with any study, limitations and other constraints did not allow for as thorough a study as possible, leaving plenty of room for continued research in this area. Once ULtra has begun to track student involvement in the program more specifically, it would be important to conduct a study similar to this one, using intensity data (how involved a student was in the program) to help determine the overall value of ULtra and the specific services that the program offers. This information could help ULtra parse out its resources more effectively and provide stronger evidence for needed funding and staffing.

Chapter two addressed the issue of timing, indicating that when students transferred (the number of credit hours they had earned, the number that came over, etc.) was an important variable in determining their success at the four-year institution. It would be useful for a future study to look more closely at the coursework students completed at the community colleges, including the amount of developmental courses a student was required to complete. In this study, developmental coursework was not used as a covariate, given that it would be highly correlated with high school GPA and would therefore not add significantly to the analysis. The number of developmental courses 
taken would, however, most likely be negatively correlated with the number of courses transferred to the four-year institution (since these courses are not accepted for credit of any kind). This would be useful information in a study that looked at students who intended to transfer in order to determine if they are less likely to make it to the senior institution. Likewise, while the current study looked at number of credit hours and credit accepted toward the major, it would also be valuable to differentiate students by the number of credit hours they brought in and whether that placed them into upper division courses, which could be more challenging, but also often have smaller class sizes, or lower division courses, which may be easier but provide less support and higher studentto-teacher ratios.

It would be interesting to note if ULtra students are more likely to come in as "Gen Ed Certified". This distinction is placed on a student's transcript if they complete all of their general education coursework at the community college and also ask the Registrar to verify their completion and include the notation. ULtra students are typically encouraged to take care of this process so that all of their general education courses will be accepted at UofL under the General Education Transfer Policy in Kentucky. Continuing this line of inquiry further, a future study could also look at whether or not ULtra students are more likely to have completed an associate's degree before transfer. Earning a higher number of credit hours at the community college before transfer would also indicate that the students are staying there longer. Given that research presented in chapter two shows that transferring later in one's academic career has a positive impact on academic success (Best \& Gehring, 1993; Townsend \& Wilson, 2006), it would be 
important to discern whether ULtra is the driving force for students choosing to wait to transfer, as opposed to financial, personal, or other factors.

In chapter two, the differences between transfer track and career and technical education (CTE) students were also discussed. It was noted that CTE students often begin in the technical track, but between $5 \%$ and $30 \%$ of them will eventually transfer to a baccalaureate program (Cohen \& Brawer, 2008). A limitation of the current study was the inability to distinguish between transfer track and CTE students. The possibility was presented that students who started out in the CTE track originally were not considering transferring and therefore were not taking the appropriate classes that would have a direct equivalent at UofL. If any CTE students ended up in this study, they most likely would have been part of the Non-ULtra group. A future study should attempt to tease these students out and run separate analyses on the CTE group to see how they are affecting the results.

The current study looked at students who only had transfer work from JCTC before they transitioned to UofL. This meant that a number of students who had varying levels of coursework from other institutions, and who may or may not have participated in ULtra, were eliminated from the study sample. Though this gives us the cleanest look at the effects the ULtra program can have on transfer students, it is not necessarily indicative of the normal transfer student experience. A study should be designed that can account and control for other transfer coursework in order to see the value of participation in ULtra for students who have previous transfer experience.

Finally, the study conducted here was purely quantitative in design, using secondhand data from the student records database. Though this type of research allows 
for a thorough analysis of grades, credits, background characteristics, and the like, it cannot account for other aspects of the student experience that could be obtained in a qualitative or mixed methods study. Focus groups, surveys, and other methods could be used to create a more complete picture of the ULtra student experience. How do they feel about the academic advising they receive? Do they enjoy and/or see value in participating in programs and workshops offered by ULtra? Understanding the program from the perspective of the student could help make improvements for future transfer cohorts. Likewise, understanding aspects such as self-selection and participation could help account for covariates like motivation, allowing for more accurate analyses.

\section{Conclusion}

Recognizing the importance of the transfer student population in higher education and the difficulty that these students have in making the transition from the community college to the four-year institution, this dissertation was designed to test the relationship that the ULtra Transfer Program has to transfer student success. Chapter one provided the foundation for the problem, stating that more and more students are beginning their college careers at the two-year level and are in need of support structures that will help them reach their goal of earning a bachelor's degree. The ULtra program was identified as a promising practice that was designed to help students through the transition, but it had never formally been evaluated for its effectiveness. Five research questions were introduced which were crafted to determine the extent to which ULtra students differed from Non-ULtra students on variables meaningful to the transfer process.

Chapter two provided a thorough review of higher education in Kentucky and the legislation which led to the creation of first the Pathways to Success program, which later 
became the ULtra Transfer Program as it stands today. The theoretical frameworks for the study were discussed, couching the transfer student issue in terms of Kegan's (1982; 1994) constructive-developmental theory and Astin's (1984/1999) Student Involvement Theory. Next, the literature review provided background research pertaining to higher education (a statistical overview); the community college system, foundations, and populations; the transfer function; and specific problems that students face when attempting to transfer. Finally, the burgeoning relationships between community colleges and universities were discussed.

The methodology for the study was laid out in chapter three, providing the details of the research design and introducing the population and sample for the study. The variables to be used were described in more detail, the setting was addressed, and the data source and collection procedures were discussed. Finally, the research questions were reintroduced with the intended analyses and associated variables, and the limitations of the study were shared.

Chapter four provided the results of the statistical analyses run for each of the five research questions in the study. Results indicated that, even when controlling for background characteristics (age, high school GPA, and ACT score), students who participated in the ULtra program had more credit hours earned and accepted toward their major, suffered less transfer shock after the transition to UofL and earned a slightly higher first and significantly higher second semester GPA, and had a higher persistence rate at UofL.

Chapter five provided a summary of the study and offered possible explanations for the findings from chapter four. Recommendations for policy and practice were 
offered, and suggestions for future research were discussed. The current study was able to limit the effects of background characteristics on variables under review and to determine that participation in the ULtra Transfer Program was a statistically significant predictor in transfer student success from Jefferson Community and Technical College to the University of Louisville. 


\section{REFERENCES}

Alfonso, M. (2006). The impact of community college attendance on baccalaureate attainment. Research in Higher Education, 47, 873-903. doi: 10.1007/s11162006-9019-2

American Association of Community Colleges (2006). Community colleges past to present. Retrieved November 16, 2009 from http://www.aacc.nche.edu/AboutCC/history/Pages/ pasttopresent.aspx American Association of Community Colleges (2009). Fast facts. Retrieved March 6, 2011 from http://www.aacc.nche.edu/AboutCC/Pages/fastfacts.aspx

National Center for Academic Achievement and Transfer (1991). Setting the national agenda: Academic achievement and transfer. Washington, DC: American Council on Education.

American Psychological Association (2002). Ethical principles of psychologists and code of conduct. American Psychologist, 57, 1060-1073.

Amey, M. J. (2010). Leading partnerships: Competencies for collaboration. New Directions for Community Colleges, 149, 13-23. doi: 10.1002/cc.391

Anderson, G. M., Alfonso, M., \& Sun, J. C. (2006). Rethinking cooling out at public community colleges: An examination of fiscal and demographic trends in higher education and the rise of statewide articulation agreements. Teaching College Record, $108,422-451$.

Anderson, G. M., Sun, J. C., \& Alfonso, M. (2006). Effectiveness of statewide 
articulation agreements on the probability of transfer: A preliminary policy analysis. The Review of Higher Education, 29, 261-291.

Arguijo, D., \& Howard, L. L. (May 2010). Last word: Freshening up transfer programs. Diverse Issues in Higher Education, 27, 7.

Astin, A. W. (1984/1999). Student involvement: A developmental theory for higher education. Journal of College Student Development, 40, 518-529.

Astin, A. W. (1991). Assessment for excellence: The philosophy and practice of assessment and evaluation in higher education. New York: Macmillan.

Astin, A. W. (1993). What matters in college: Four critical years revisited. San Francisco: Jossey-Bass.

Astin, A. W. (2005). Making sense out of degree completion rates. Journal of College Student Retention, 7(1-2), 5-17.

Aud, S., Hussar, W., Johnson, F., Kena, G., Roth, E., Manning, E., Wang, X., Zhang, J., Notter, L., Nachazel, T., \& Yohn, C. (2012). The condition of education 2012 (NCES 2012-045). Washington, DC: U.S. Department of Education, Institute of Education Sciences, National Center for Education Statistics. Retrieved November 18, 2012 from http://nces.ed.gov/pubs2012/2012045.pdf

Aud, S., Hussar, W., Planty, M., Snyder, T., Bianco, K., Fox, M., Frohlich, L., Kemp, J., \& Drake, L. (2010). The condition of education 2010 (NCES 2010-028). Washington, DC: U.S. Department of Education, Institute of Education Sciences, National Center for Education Statistics. Retrieved February 27, 2011 from http://nces.ed.gov/pubs2010/2010028.pdf

Baxter Magolda, M. B. (2002). Helping students make their way to adulthood: Good 
company for the journey. About Campus, 6, 2-9.

Becker, G. S. (1960). Underinvestment in college education. American Economic Review, $50,346-354$

Berger, R. (1992). Student retention: A critical phase in the academic careers of minority baccalaureate social workers. Journal of Social Work Education, 28, 85-97.

Berkner, L., \& Choy, S. (2008). Descriptive summary of 2003-04 beginning postsecondary students: Three years later (NCES 2008-174). Washington, DC: U.S. Department of Education, Institute of Education Sciences, National Center for Education Statistics. Retrieved April 17, 2011 from http://nces.ed.gov/pubs2008/2008174.pdf

Best, G. A., \& Gehring, D. D. (1993). The academic performance of community college transfer students at a major state university in Kentucky. Community College Review, 21, 32-41.

Blimling, G. S., Whitt, E. J., American College Personnel Association, \& National Association of Student Personnel Administrators. (1999). Good practice in student affairs: Principles to foster student learning. San Francisco: Jossey-Bass.

Borden, K. S., \& Abbott, B. B. (2002). Research design and methods: A process approach $\left(5^{\text {th }}\right.$ ed.). New York: McGraw-Hill.

Boring, E. G. (1930). A new ambiguous figure. The American Journal of Psychology, 42, $444-445$.

Bradburn, E. M., \& Hurst, D. G. (2001). Community college transfer rates to 4-year institutions using alternative definitions of transfer (NCES 2001-197). Washington, DC: U.S. Department of Education, Institute of Education Sciences, 
National Center for Education Statistics. Retrieved March 22, 2011 from

http://nces.ed.gov/pubs2001/2001197.pdf

Bragg, D. D., Kim, E., \& Barnett, E. A. (2006). Creating access and success: Academic pathways reaching underserved students. New Directions for Community Colleges, 135, 5-19.

Brand, J. E., \& Xie, Y. (2010). Who benefits most from college? Evidence for negative selection in heterogeneous economic returns to higher education. American Sociological Review, 75, 273-302. doi: 10.1177/0003122410363567

Bueschel, A. C. (2009). The landscape of policies and practices that support student preparation and success. New Directions for Community Colleges, 145, 1-10. doi: $10.1002 /$ cc. 351

Cameron, C. (2005). Experiences of transfer students in a collaborative baccalaureate nursing program. Community College Review, 33, 22-44.

Campbell, M. E. (2009). Multiracial groups and educational inequity: A rainbow or a divide? Social Problems, 56, 425-446. doi: 10.1525/sp.2009.56.3.425

Carlan, P. E., \& Byxbe, F. R. (2000). Community colleges under the microscope: An analysis of performance predictors for Native American transfer students. Community College Review, 28, 27-42.

Cejda, B. D. (1994). Reducing transfer shock through faculty collaboration: A case study. Community College Journal of Research and Practice, 18, 189-199.

Chen, E., Martin, A. D., \& Matthews, K. A. (2006). Understanding health disparities: The role of race and socioeconomic status in children's health. American Journal of Public Health, 96, 702-708. 
Chen, R., \& DesJardins, S. L. (2008). Exploring the effects of financial aid on the gap in student dropout risks by income level. Research in Higher Education, 49, 1-18.

Cheslock, J. J. (2003). Determining the costs of transfer students at American colleges and universities. New Directions for Institutional Research, 119, 55-66.

Choy, S. (2002). Nontraditional undergraduates 2002 (NCES 2002-012). Washington, DC: U.S. Department of Education, Institute of Education Sciences, National Center for Education Statistics. Retrieved March 2, 2011 from http://nces.ed.gov/pubs2002/2002012.pdf

Clark, B. R. (1960). The "cooling-out" function in higher education. The American Journal of Sociology, 65, 569-576.

Cohen, A. M., \& Brawer, F. B. (1987). The collegiate function of community colleges: fostering higher learning through curriculum and student transfer. San Francisco: Jossey-Bass.

Cohen, A. M., \& Brawer, F. B. (2003). The American community college ( $4^{\text {th }}$ ed.). San Francisco: Jossey-Bass.

Cohen, A. M., \& Brawer, F. B. (2008). The American community college (5 $5^{\text {th }}$ ed.). San Francisco: Jossey-Bass.

Crisp, G., \& Nora, A. (2010). Hispanic student success: Factors influencing the persistence and transfer decisions of Latino community college students enrolled in developmental education. Research in Higher Education, 51, 175-194. doi: $10.1007 / \mathrm{s} 11162-009-9151-\mathrm{x}$

Cuseo, J. (2001). The transfer transition: Student advancement from 2-year to 4-year institutions. Retrieved from ERIC database. (ED462130) 
Davies, T. G., \& Dickmann, E. M. (1998). Student voices in the transfer process: Do we hear them? Do we listen? Community College Journal of Research and Practice, $22,541-557$.

Dervarics, C. (2007, July). Education department, congress has sights trained on community college transfer of credit problem. Diverse Issues in Higher Education, 24(11), 9.

Dewey, J. (1916). Democracy and education: An introduction to the philosophy of education. New York: The Macmillan Company.

Diaz, P. E. (1992). Effects of transfer of academic performance of community college students at the four-year institution. Community/Junior College Quarterly, 16, $279-291$.

Doyle, W. R. (2009). Impact of increased academic intensity on transfer rates: An application of matching estimators to student-unit record data. Research in Higher Education, 50, 52-75. doi: 10.1007/s11162-008-9107-6

Dougherty, K. J. (1987). The effects of community colleges: Aid or hindrance to socioeconomic attainment? Sociology of Education, 60, 86-103.

Dougherty, K. J. (1992). Community colleges and baccalaureate attainment. Journal of Higher Education, 63, 188-214.

Dougherty, K. J., \& Kienzl, G. S. (2006). It's not enough to get through the open door: Inequalities by social background in transfer from community college to four-year colleges. Teachers College Record, 108, 452-487.

Dougherty, K. J., \& Townsend, B. K. (2006). Community college missions: A theoretical and historical perspective. New Directions for Community Colleges, 136, 5-13. 
Duggan, M. H., \& Pickering, J. W. (2008). Barriers to transfer student academic success and retention. Journal of College Student Retention, 9, 437-459.

Duncan, A. (2011). College completion tool kit. Washington, DC: U.S. Department of Education.

Eggleston, L. E., \& Laanan, F. S. (2001). Making the transition to the senior institution. New Directions for Community Colleges, 114, 87-97.

Fadiman, J., \& Frager, R. (2002). Personality \& personal growth $\left(5^{\text {th }}\right.$ ed.). Upper Saddle River, N. J.: Prentice Hall.

Field, A. (2005). Discovering statistics using SPSS ( $2^{\text {nd }}$ ed.). London: Sage Publications.

Flaga, C. T. (2006). The process of transition for community college transfer students. Community College Journal of Research and Practice, 30, 3-19.

Fredrickson, J. (1998). Today's transfer students: Who are they? Community College Review, 26, 43-54.

Gabb, S., Tinberg, H., \& Weisberger, R. (2011). Kegan's theory of development applied to community college students. In M. London (Ed.), The Oxford handbook of lifelong learning (pp. 102-116). New York: Oxford University Press.

Gladding, S. T. (2004). Counseling: A comprehensive profession $\left(5^{\text {th }}\right.$ ed.). Upper Saddle River, N.J.: Merrill.

Glass, J. C., \& Harrington, A. R. (2002). Academic performance of community college transfer students and "native" students at a large state university. Community College Journal of Research and Practice, 26, 415-430.

Goldrick-Rab, S., \& Pfeffer, F. (2009). Beyond access: Explaining socioeconomic differences in college transfer. Sociology of Education, 82, 101-125. 
Grubb, W. N. (1991). The decline of community college transfer rates: Evidence from national longitudinal surveys. Journal of Higher Education, 62, 194-222.

Hawley, T. H., \& Harris, T. A. (2006). Student characteristics related to persistence for first-year community college students. Journal of College Student Retention, 7, $117-142$.

Higher Education Work Group. (2009). The final report of the Higher Education Work Group. Retrieved from Kentucky Council on Postsecondary Education website: http://cpe.ky.gov/NR/rdonlyres/CFCC3CB9-29B6-4A4F-9EB6F32992CDF054/0/FINALHEWGNovemberReport.pdf

Hills, J. R. (1965). Transfer shock: The academic performance of the junior college transfer. The Journal of Experimental Education, 33, 201-215.

Hood, L., Hunt, E., \& Haeffele, L. (2009). Illinois post-secondary transfer students: Experiences in navigating the higher education transfer system. Planning and Changing, 40, 116-131.

Howarth, D. A. (2003). Pathways to success: A successful university/community college/public school partnership. Metropolitan Universities: An International Forum, 14, 78-89.

Hoyt, J. E. (1999). Remedial education and student attrition. Community College Review, $27,51-72$.

Hudzik, J. K. (2010). The economy, higher education, and campus internationalization. International Educator, 19, 96-102.

Ignash, J. M., \& Townsend, B. K. (2000). Evaluating state-level articulation agreements according to good practice. Community College Review, 28, 1-19. 
Ignelzi, M. (2000). Meaning-making in the learning and teaching process. New Directions for Teaching and Learning, 82, 5-14.

Integrated postsecondary education data system [IPEDS] glossary (n.d.). Retrieved April 28, 2011 from http://nces.ed.gov/ipeds/glossary/

Ishitani, T. T. (2008). How do transfers survive after "transfer shock"? A longitudinal study of transfer student departure at a four-year institution. Research in Higher Education, 49, 403-419.

Jefferson Community \& Technical College. (n.d.). A brief history. Retrieved March 19, 2011 from http://jefferson.kctcs.edu/About_Us/About_Jefferson

Jefferson Community \& Technical College. (n.d.). Academic program plans. Retrieved March 20, 2011 from http://jefferson.kctcs.edu/Academics/Academic_Program Plans/UofL-APPs

Jefferson Community \& Technical College. (n.d.). Visitors and community. Retrieved November 17, 2012 from http://www.jefferson.kctcs.edu/Visitors_and_Community

Johnson, M. D. (2005). Academic performance of transfer versus "native" students in natural resources \& sciences. College Student Journal, 39, 570-579.

Jurgens, J. C. (2010). The evolution of community colleges. College Student Affairs Journal, 28, 251-261.

Kegan, R. (1982). The evolving self: Problems and process in human development. Cambridge, MA: Harvard University Press.

Kegan, R. (1994). In over our heads: The mental demands of modern life. Cambridge, MA: Harvard University Press. 
Kentucky Community \& Technical College System. (n.d.). Colleges and campuses.

Retrieved March 19, 2011 from http://www.kctcs.edu/en/Colleges_and_ Campuses.aspx

Kentucky Council on Postsecondary Education (2011). About us. Retrieved March 19, 2011 from http://cpe.ky.gov/

Kentucky Council on Postsecondary Education (2010). Diversity \& demographics.

Retrieved April 23, 2011 from http://cpe.ky.gov/info/

Kentucky Council on Postsecondary Education (2009). Educational attainment.

Retrieved April 23, 2011 from http://cpe.ky.gov/info/

Kentucky Council on Postsecondary Education (n.d.). Enrollment. Retrieved April 23, 2011 from http://cpe.ky.gov/info/

Kentucky Council on Postsecondary Education (2011). Retention \& Graduation Rates.

Retrieved April 23, 2011 from http://cpe.ky.gov/info/

Kentucky Council on Postsecondary Education. (2004). The general education transfer policy and implementation guidelines. Retrieved March 20, 2011 from http://cpe.ky.gov/NR/rdonlyres/6D7A8159-16D8-4810-A0B63D8161157D73/0/GenEdTranserPolicy.pdf

Kentucky Council on Postsecondary Education. (2010). Transfer policies and initiatives. Retrieved March 20, 2011 from http://cpe.ky.gov/policies/academicinit/Transfer/ Kentucky Postsecondary Education Improvement Act of 1997, § 97. (1997).

Kierkegaard, S. (1959). The journals of Kierkegaard (A. Dru, Trans.) New York: Harper.

Kinnick, M. K., \& Kempner, K. (1988). Beyond "front door" access: Attaining the bachelor's degree. Research in Higher Education, 29, 299-318. 
Kintzer, F. C., \& Wattenbarger, J. L. (1985). The articulation/transfer phenomenon: Patterns and direction. Retrieved from ERIC database. (ED257539)

Kisker, C. B. (2007). Creating and sustaining community college-university transfer partnerships. Community College Review, 34, 282-301.

Kozeracki, C. A. (2001). Studying transfer students: Designs and methodological challenges. New Directions for Community Colleges, 114, 61-75.

Kuh, G. D., Kinzie, J., Schuh, J. H., Whitt, E. J. \& Associates. (2005). Student success in college: Creating conditions that matter. San Francisco: Jossey-Bass.

Laanan, F. S. (1996). Making the transition: Understanding the adjustment process of community college transfer students. Community College Review, 23, 69-84.

Laanan, F. S. (2001). Transfer student adjustment. New Directions for Community Colleges, 114, 5-13.

Laanan, F. S. (2004). Studying transfer students: Part I: Instrument design and implications. Community College Journal of Research and Practice. 28, 331-351.

Laanan, F. S. (2007). Studying transfer students: Part II: Dimensions of transfer students' adjustment. Community College Journal of Research \& Practice, 31, 37-59.

Lee, V. E., \& Frank, K. A. (1990). Students' characteristics that facilitate the transfer from two-year to four-year colleges. Sociology of Education, 63, 178-193.

Leigh, D. E., \& Gill, A. M. (2004). The effect of community colleges on changing students' educational aspirations. Economics of Education Review, 23, 95-102.

Levesque, K., Laird, J., Hensley, E., Choy, S. P., Cataldi, E. F., \& Hudson, L. (2008). Career and technical education in the United States: 1990 to 2005. Washington, 
DC: U.S. Department of Education, Institute of Education Sciences, National Center for Education Statistics. Retrieved May 7, 2011, from http://nces.ed.gov/pubs2008/2008035.pdf

Lewis, S. K., \& Oppenheimer, V. K. (2000). Educational assortative mating across marriage markets: Non-Hispanic whites in the United States. Demography, 37, $29-40$.

Lips, A. J. A. (2011). A typology of institutional loan replacement grant initiatives for low- and moderate-income students. The Review of Higher Education, 34, 611655.

LouisvilleKY.gov. (2003). Louisville facts \& firsts. Retrieved March 19, 2011 from http://www.louisvilleky.gov/Visitors/

Love, P. G., \& Guthrie, V. L. (1999). Kegan's orders of consciousness. New Directions for Student Services, 88, 65-76.

Mahan, S. M. (2011). Federal pell grant program of the higher education act: Background, recent changes, and current legislative issues (Report No. R41437). Washington, DC: Congressional Research Service

Mayhew, M. J., Vanderlinden, K., \& Kim, E. K. (2010). A multi-level assessment of the impact of orientation programs on student learning. Research in Higher Education, 51, 320-345.

Melguizo, T. A., \& Dowd, A. C. (2009). Baccalaureate success of transfers and rising 4year college juniors. Teachers College Record, 111, 55-89.

Melguizo, T., Hagedorn, L. S., \& Cypers, S. (2008). Remedial/developmental education and the cost of community college transfer: A Los Angeles county sample. The 
Review of Higher Education, 31, 401-431.

Mincer, J. (1997). The production of human capital and the life cycle of earnings:

Variations on a theme. Journal of Labor Economics, 15, S26-S47.

Munkittrick, M. B. (2009). Indicators of persistence and success of community college transfer students attending a large, urban university in Pennsylvania.

(Unpublished doctoral dissertation). Temple University, Pennsylvania.

Myers, D. G. (2001). Psychology (6 ${ }^{\text {th }}$ ed.). New York: Worth Publishers.

O'Banion, T. (2010). The completion agenda: To what end? Community College Journal, $81,44-47$.

OECD. (2012). Education at a glance 2012: OECD indicators. Retrieved October 27, 2012 from http://www.oecd.org/edu/EAG\%202012_e-book_EN_200912.pdf

Palmer, J. C., Ludwig, M., \& Stapleton, L. (1994). At what point do community college students transfer to baccalaureate-granting institutions? Evidence from a 13-state study. (ED373844). Washington, DC: National Council on Education.

Pascarella, E. T., \& Terenzini, P. T. (1991). How college affects students: Findings and insights from twenty years of research. San Francisco: Jossey-Bass.

Pascarella, E. T., \& Terenzini, P. T. (2005). How college affects students: A third decade of research $\left(2^{\text {nd }}\right.$ ed. $)$. San Francisco: Jossey-Bass.

Perrine, R. M., \& Spain, J. W. (2009). Impact of a pre-semester college orientation program: Hidden benefits? Journal of College Student Retention, 10, 155-169.

Perry, W. G., \& Whitlock, C. P. (1967). Harvard University reading course. Cambridge, MA: Harvard University Press.

Prager, C. (1993). Transfer and articulation within colleges and universities. Journal of 
Higher Education, 64, 539-554.

Provasnik, S., \& Planty, M. (2008). Community colleges: Special supplement to the condition of education 2008 (NCES 2008-033). Washington, DC: U.S.

Department of Education, Institute of Education Sciences, National Center for Education Statistics. Retrieved March 5, 2011 from http://nces.ed.gov/pubs2008/2008033.pdf

Rouse, C. E. (1995). Democratization or diversion? The effects of community colleges on educational attainment. Journal of Business \& Economic Statistics, 13, 217-224.

Sandy, J., Gonzalez, A., \& Hilmer, M. J. (2006). Alternative paths to college completion: Effect of attending a 2-year school on the probability of completing a 4-year degree. Economics of Education Review, 25, 463-471. doi:

10.1016/j.econedurev.2005.05.003

Sanford, N. (1966). Self \& society: Social change and individual development. New York: Atherton Press.

Sappington, J., Kinsey, K., \& Munsayac, K. (2002). Two studies of reading compliance among college students. Teaching of Psychology, 29, 272-274.

Schuh, J. H., Upcraft, M, L., et al. (2001). Assessment practice in student affairs: An applications manual. San Francisco: Jossey-Bass.

Shavelson, R. J. (1996). Statistical reasoning for the behavioral sciences $\left(3^{\mathrm{rd}} \mathrm{ed}\right.$.). Boston, MA: Allyn \& Bacon.

Snyder, T. D., \& Dillow, S. A. (2010). Digest of education statistics 2009 (NCES 2010013). Washington, DC: U.S. Department of Education, Institute of Education Sciences, National Center for Education Statistics. Retrieved March 2, 2011 from 
http://nces.ed.gov/pubs2010/2010013.pdf

Snyder, T. D., \& Dillow, S. A. (2011). Digest of education statistics 2010 (NCES 2011015). Washington, DC: U.S. Department of Education, Institute of Education Sciences, National Center for Education Statistics. Retrieved July 17, 2011 from http://nces.ed.gov/pubs2011/2011015_0.pdf

Snyder, T. D., Dillow, S. A., \& Hoffman, C. M. (2009). Digest of education statistics 2008 (NCES 2009-020). Washington, DC: U.S. Department of Education, Institute of Education Sciences, National Center for Education Statistics. Retrieved March 2, 2011 from http://nces.ed.gov/pubs2009/2009020.pdf

Stevens, J. P. (2002). Applied multivariate statistics for the social sciences $\left(4^{\text {th }} \mathrm{ed}.\right)$. Mahwah, NJ: Lawrence Erlbaum Associates, Inc.

Tabachnick, B. G., \& Fidell, L. S. (1989). Using multivariate statistics $\left(2^{\text {nd }} \mathrm{ed}.\right)$. New York: Harper Collins.

Tinberg, H., \& Weisberger, R. (1998). In over our heads: Applying Kegan's theory of development to community college students. Community College Review, 26, 4356.

Tinto, V. (1975). Dropout from higher education: A theoretical synthesis of recent research. Review of Educational Research, 45, 89-125.

Townsend, B. K., \& Wilson, K. B. (2006). The transfer mission: Tried and true, but troubled? New Directions for Community Colleges, 136, 33-41. doi: $10.1002 / \mathrm{cc} .257$

Townsend, B. K. (2007). Interpreting the influence of community college attendance upon baccalaureate attainment. Community College Review, 35, 128-136. 
Townsend, B. K. (2008). "Feeling like a freshman again": The transfer student transition. New Directions for Higher Education, 144, 69-77. doi: 10.1002/he.327

Townsend, B. K., McNerny, N., \& Arnold, A. (1993). Will this community college transfer student succeed? Factors affecting transfer student performance. Community College Journal of Research and Practice, 17, 433-442.

U.S. Department of Education. (2006). A test of leadership: Charting the future of U.S. higher education. Retrieved May 14, 2011 from http://www2.ed.gov/about/bdscomm/list/hiedfuture/reports/pre-pub-report.pdf University of Louisville. (2000). A brief history of UofL. Retrieved March 19, 2011 from http://louisville.edu/about/history.html

University of Louisville. (2012). Common data set 2011-2012. Retrieved October 28, 2012 from http://louisville.edu/institutionalresearch/institutional-researchplanning/completed\%20CDS\%202011-12.pdf

University of Louisville. (2012). Just the facts. Retrieved October 27, 2012 from http://louisville.edu/institutionalresearch/institutional-research-planning/just-thefacts.html

University of Louisville Transfer Services. (2011). Retrieved March 19, 2011 from http://louisville.edu/ultra

University of Louisville Transfer Services. (2011). L.E.A.D. Retrieved March 19, 2011 from http://louisville.edu/ultra/l-e-a-d.html

Vogt, W. P. (2005). Dictionary of statistics \& methodology: A nontechnical guide for the social sciences $\left(3^{\text {rd }}\right.$ ed.). Thousand Oaks, CA: Sage Publications, Inc. Wang, X. (2009). Baccalaureate attainment and college persistence of community college 
transfer students at four-year institutions. Research in Higher Education, 50, 570588.

Whorton, S. (2009). Academic self-efficacy, academic integration, social integration, and persistence among first-semester community college transfer students at a fouryear institution (Unpublished doctoral dissertation). Clemson University, South Carolina.

Wilmer, E. (2009). The influence of learning communities on the interaction levels of developmental English students. Inquiry, 14, 55-67.

Wolniak, G. C., \& Engberg, M. E. (2010). Academic achievement in the first year of college: Evidence of the pervasive effects of the high school context. Research in Higher Education, 51, 451-467.

Zamani, E. M. (2001). Institutional responses to barriers to the transfer process. New Directions for Community Colleges, 114, 15-24. 


\section{CURRICULUM VITAE}

NAME: $\quad$ Kathren T. Partin

ADDRESS: 4220 Bay Pointe Drive

Louisville, KY 40241

EDUCATION

\& TRAINING: $\quad$ B.S., Psychology

Christopher Newport University

2000-04

M.Ed., Counseling \& Personnel Services

Concentration in College Student Personnel

University of Louisville

2004-06

Ph.D., Counseling \& Personnel Services, Concentration in College Student Personnel

University of Louisville

2007-12

PROFESSIONAL

EXPERIENCE: Coordinator, Office of First Year Initiatives

University of Louisville

Louisville, KY

2008-Present

Doctoral Intern - Assessment, Student Affairs

University of Louisville

Louisville, KY

2008-09

Graduate Student Assistant, ULtra Transfer Program

University of Louisville

Louisville, KY

2007-08 
Interim Coordinator of Student Activities, Office of Campus Life Indiana University Southeast

New Albany, IN

2006-07

Graduate Peer Counselor, Student Financial Aid Office

University of Louisville

Louisville, KY

2006; 2007

Graduate Intern - Student Program Council, Office of Campus

Life

Indiana University Southeast

New Albany, IN

2006

Graduate Intern - Leadership, Office of Campus Life

Indiana University Southeast

New Albany, IN

2006

Program Assistant, Office of Campus Life

Indiana University Southeast

New Albany, IN

2005-06

\section{PUBLICATIONS:}

Gibbons, J. A., Velkey, A. J., \& Partin, K. T. (2008). Influence of recall procedures on the modality effect with numbers and enumerated stimuli. The Journal of General Psychology, 135(1), 84-104.

Gibbons, J. A., Velkey, A. J., \& Partin, K. T. (2008). Enumeration produces poor primacy for tactile presentation relative to visual and auditory presentation as the only modality effect. Perceptual and Motor Skills, 106, 795-810.

\section{NATIONAL MEETING PRESENTATIONS:}

Partin, K. T., Metzger, C., \& Blake, B. (2012, March). Online peer mentoring: Staying connected from orientation to welcome week. Presentation at the meeting of the American College Personnel Association. Louisville, KY.

Partin, K. T., Clark, B., Reid, S., \& Bays, K. (2012, March). Student learning outcomes: Devising an assessment for student employees. Presentation at the meeting of the American College Personnel Association. Louisville, KY. 
Partin, K. T., Metzger, C., \& Gupta, N. (2012, March). Common reads and the classroom: Meeting faculty where they are. Presentation at the meeting of the American College Personnel Association. Louisville, KY.

Partin, K. T., Clark, B., \& Bays, C. (2010, March). Student learning outcomes: Devising a division-wide assessment for student employees. Presentation at the meeting of the College Personnel Association of Kentucky. Louisville, KY.

Partin, K. T., Wade, M., Metzger, C., \& Osborne, S. (2010, February). Online peer mentoring: Keeping students connected from orientation through the first semester. Presentation at the $29^{\text {th }}$ Annual Conference on The First-Year Experience. Denver, CO.

Gilchrist, C., Mandlehr, K., \& Partin, K. T. (2008, November). Boomerang students: Using research to find ways to return reverse transfer students to the four-year institution. Presentation at the $15^{\text {th }}$ National Conference on Students in Transition. Columbia, SC.

Partin, K. T. (2006). LEAP leadership program. Poster presentation at the meeting of the College Personnel Association of Kentucky. Louisville, KY.

Partin, K. T. (2004, April). Don't count on the classic modality effect. Presentation at the meeting of the Eastern Psychological Association. Washington, D.C.

Partin, K. T., Dunn, A., \& Clark, N. (2004). Effects of modality on immediate recall. Poster Presentation at the Annual Poster Contest, Christopher Newport University. Newport News, VA.

Partin, K. T. (2003). Assessing the effects of non-symbolic auditory and visual stimuli on immediate recall. Presentation at the meeting of the Eastern Psychological Association.

Partin, K. T. (2003). The modality effect, is it a classic? Annual Poster Session of the Tidewater Chapter of Sigma Xi. Newport News, VA.

INVITED PRESENTATIONS:

Partin, K. T. (2012, October). Student learning outcomes. Invited guest lecture for graduate assessment class in the School of Education and Human Development at the University of Louisville. Louisville, KY.

Partin, K. T., Metzger, C., \& Blake, B. (2012, May). Brainstorming Moore with UofL common reading integration workshop. Invited presentation at Northern Kentucky University. Highland Heights, KY. 
Chickuni, T., Partin, K. T., Partin, W. B., \& Taylor, A. B. (2011, November). Panel: Overview of the field. Invited panelist at the College Personnel Association of Kentucky Careers is Student Affairs Conference. Louisville, KY.

Partin, K. T., Metzger, C., \& Gupta, N. (2011, August). Finding common ground with your first year students through a common read. Invited presentation for the Delphi Center's Dine \& Discover Series at the University of Louisville. Louisville, KY.

Metzger, C. \& Partin, K. T. (2010, May). Designing student programs to emphasize critical thinking. Presentation at the $2010 \mathrm{i} 2 \mathrm{a}$ Institute. Louisville, KY.

Metzger, C., \& Partin, K. T. (2010, March). Book-in-Common: The devil's highway. Invited presentation for advisors at the University of Louisville. Louisville, KY.

Metzger, C. \& Partin, K. T. (2010, February). Fighting first-year fallout: Best practices for engaging with students. Presentation at the 2010 Celebration for Teaching \& Learning: Engaging Teaching, Engaging Learning. Louisville, KY.

\section{PROFESSIONAL SOCIETIES:}

American College Personnel Association (ACPA)

Member June 2011 to present

College Personnel Association of Kentucky (CPAK)

Member March 2006 to present

Eastern Psychological Association (EPA)

Student member April 2004 to present

National Association for Campus Activities (NACA)

Member spring 2006 to 2007

National Association for Student Personnel Administrators (NASPA)

Member spring 2010 to 2011

Omicron Delta Kappa (The National Leadership Honor Society)

Member spring 2004 to present

Psi Chi (The National Honor Society in Psychology)

Member fall 2003 to present 